\title{
Effect of transition metal substitution on the flexibility and thermal properties of MOF-based solid-solid phase change materials
}

Kieran Griffiths, ${ }^{1}$ Nathan R. Halcovitch ${ }^{1}$ and John M. Griffin ${ }^{* 1,2}$

1. Department of Chemistry, Lancaster University, Lancaster, LA1 4YB, UK

2. Materials Science Institute, Lancaster University, Lancaster, LA1 4YB, UK

*Corresponding author. Email j.griffin@lancaster.ac.uk

Table S1. Synthetic conditions for M-1つAB

Figure S1. Calibration curve for the relationship between mass of trans-AB and the energy of the melting endotherm.

Table S2. Calculation of excess trans-AB in M-1 $\supset A^{\text {vac- } 0 \mathrm{~h}}$ samples and correction of the energy density.

Figure S2. XRPD patterns of all composites of (a) Zn-1, (b) Co-1, (c) Ni-1 and (d) Cu-1....7

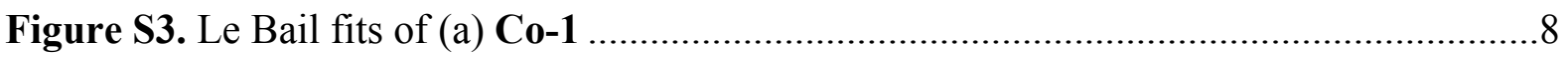

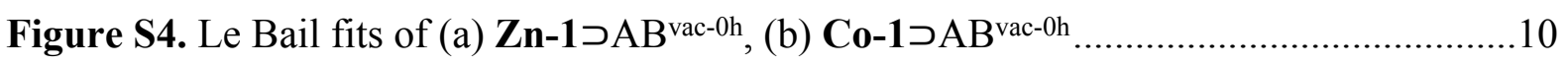

Table S3. Percentage contraction of reduced unit cell parameters for the $l p$ to $n p$ form ........10

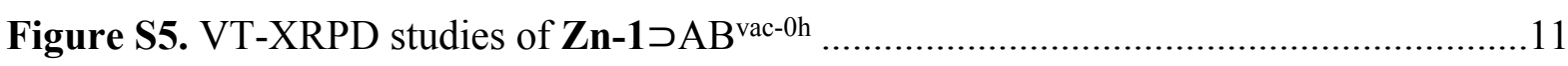

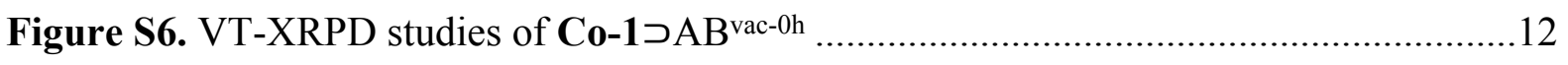

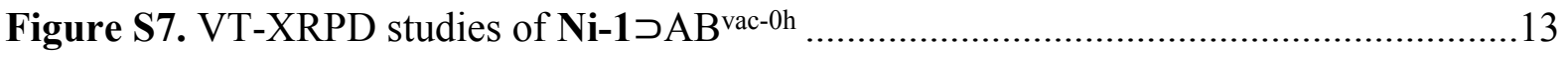

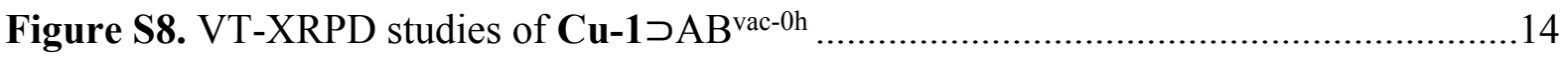

Figure S9. Le Bail fits of (a) Zn-1つAB ${ }^{\text {vac-0h }}$, (b) Co-1つAB $\mathbf{B}^{\text {vac-0h }}$, (c) Ni-1つAB $\mathbf{B}^{\text {vac-0h }}$ and (d)

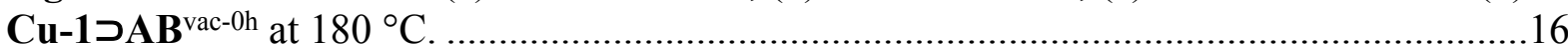

Table S4. Crystallographic information for VT-XRPD of $o p$ phases of M1つAB ${ }^{\mathrm{vac}-0 \mathrm{~h}}$..........16

Table S5. Percentage expansion of reduced unit cell parameters of $\mathbf{M - 1} \supset \mathbf{A B}_{\mathrm{vac}-0 \mathrm{~h}}$ from the $n p$

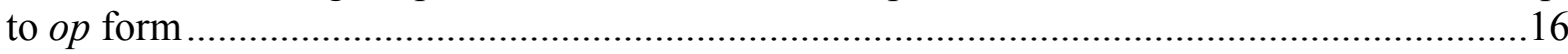

Figure S10. DSC traces of the $\mathbf{Z n - 1} \supset \mathrm{AB}^{\text {vac-xh }}$ with different durations of vacuum treatment at $120{ }^{\circ} \mathrm{C}$. 
Table S6. The effect of vacuum treatment length on the ratio of occluded trans-AB within Zn-1 and $n p \rightarrow o p$ phase transition enthalpy.....

Table S7. Calculation of the ratio of $\mathbf{Z n - 1} \supset \mathrm{AB}^{\text {vac-xh }}$ at different vacuum treatment times....19

Figure S11. Relationship between moles of $A B$ in $\mathbf{Z n - 1} \supset A B_{x}$ to enthalpy of the reversible phase change.

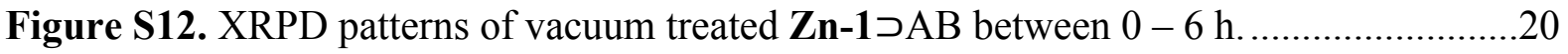

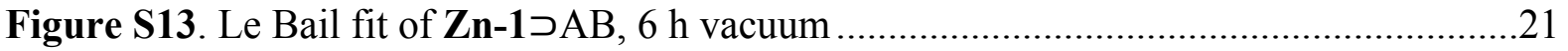

Figure S14. ${ }^{13} \mathrm{C}$ CPMAS NMR spectra of $\mathbf{Z n - 1} \supset \mathrm{AB}$ with different durations of vacuum treatment at $120{ }^{\circ} \mathrm{C}$.

Table S8. Calculation for estimated pore-filling efficiency.

Figure S15. TGA of M-1 $\supset \mathrm{AB}_{1.0}$. The final masses are consistent with the percentage loading of trans-AB in each composite and expected degradation product.

Figure S16. UV/Vis calibration curve for known concentrations of trans-AB in $\mathrm{MeOH}$.....24

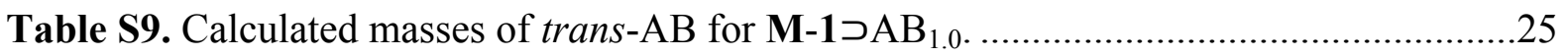

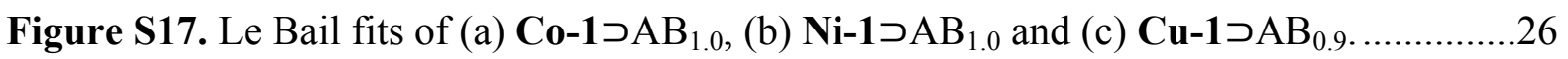

Figure S18. (a) DSC trace of the first heating branch, and (b) XRPD pattern and (c) Le Bail fit of $\mathbf{C u}-1 \supset \mathrm{AB}^{\text {vac-0h }}$ after 3 hours of vacuum treated at $120^{\circ} \mathrm{C}$

Figure S19. (a) DSC data for $\mathbf{C u}-1 \supset \mathrm{AB}_{\mathrm{x}}$ between $0-150{ }^{\circ} \mathrm{C}$ at a scan rate of $20 \mathrm{~K} \mathrm{~min}^{-1}$. (b) Plot of the endothermic transition enthalpy for $\mathbf{C u}-1 \supset \mathrm{AB}_{\mathrm{x}}$ as a function of mole fraction of trans- $\mathrm{AB}$ in the structure.

Figure S20. ${ }^{1} \mathrm{H}$ NMR spectra of a) trans-AB, b) extract from $\mathbf{Z n - 1} \supset \mathrm{AB}_{1.0}$ showing characteristic trans- $\mathrm{AB}$ resonances, c) extract from irradiated $\mathbf{Z n - 1} \supset \mathrm{AB}_{1.0}$ showing both trans- $\mathrm{AB}$ and cis- $\mathrm{AB}$ resonances. Measured in $\mathrm{MeOH}-d_{4}$.

Table S10. Relationship between unit cell contraction from $\mathbf{M}-\mathbf{1}$ to $\mathbf{M}-\mathbf{1} \supset \mathrm{AB}_{1.0}$ and the PSS.

Figure S21. Relationship between unit cell volume of $\mathbf{M}-1 \supset \mathrm{AB}_{1.0}$ and the photostationary state (PSS) of AB when irradiated with $365 \mathrm{~nm}$ light.

Figure S22. Relationship between percentage contraction of $\mathbf{M}-1 \supset \mathrm{AB}_{1.0}$ from $\mathbf{M}-\mathbf{1}$ and the photostationary state (PSS) of AB when irradiated with $365 \mathrm{~nm}$ light.

Figure S23. Le Bail fits of irradiated samples of (a) Co-1 $\supset A B_{1.0}$, (b) Ni-1 $\supset A B_{1.0}$ and (c) Cu-1つAB $\mathrm{AB}_{0.9}$. For (a), the crystal system was found to be tetragonal. For (b) and (c) two phases were observed:

Table S11. Crystallographic information for irradiated $M-1 \supset A_{1.0}$.

Table S12. Percentage expansion of reduced unit cell parameters of $\mathbf{M}-1 \supset \mathrm{AB}_{1.0}$ to the irradiated form.

Figure S24. UV-vis percentage reflectance spectra for M-1. ..........................................33

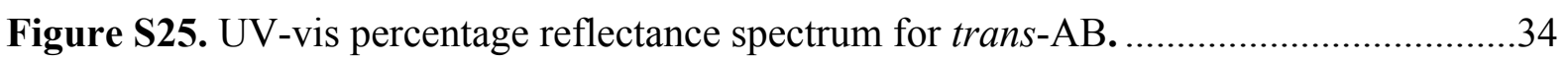

Table S13. Data for the first heating branch for irradiated Co-1 $\supset \mathrm{AB}_{1.0} .0-200{ }^{\circ} \mathrm{C}$ at $20{ }^{\circ} \mathrm{C}$ $\min ^{-1}$.

Table S14. Data for the first cooling branch for irradiated Co-1 $\supset \mathrm{AB}_{1.0} .0-200{ }^{\circ} \mathrm{C}$ at $20{ }^{\circ} \mathrm{C}$ $\min ^{-1}$. 
Table S15. Data for the first heating branch for irradiated Ni-1 $\supset \mathrm{AB}_{1.0 .} 0-200{ }^{\circ} \mathrm{C}$ at $20{ }^{\circ} \mathrm{C}$ $\min ^{-1}$

Table S16. Data for the first cooling branch for irradiated Ni-1 $\supset \mathrm{AB}_{1.0} .0-200{ }^{\circ} \mathrm{C}$ at $20{ }^{\circ} \mathrm{C}$ $\min ^{-1}$.

Table S17. Data for the first heating branch for irradiated $\mathbf{C u}-1 \supset \mathrm{AB}_{0.9} \cdot 0-200{ }^{\circ} \mathrm{C}$ at $20{ }^{\circ} \mathrm{C}$ $\min ^{-1}$.

Figure S26. DSC cycles of Co-1 $\supset \mathrm{AB}_{1.0}$ at different irradiation times between $100-200{ }^{\circ} \mathrm{C}$ at a rate of $20{ }^{\circ} \mathrm{C} \mathrm{min}-1$.

Figure S27. DSC cycles of Ni-1 $\supset \mathrm{AB}_{1.0}$ at different irradiation times between $100-200{ }^{\circ} \mathrm{C}$ at a rate of $20{ }^{\circ} \mathrm{C} \mathrm{min}-1$.

Figure S28 (previous page). Plotted data to compare the first heating branches for irradiation of $\mathbf{M}-1 \supset \mathrm{AB}_{1.0}(\mathrm{M}=\mathrm{Ni}, \mathrm{Co}$ and $\mathrm{Zn})$ for different lengths. a) endotherm magnitude, $\left.b\right)$ endotherm onset temperature, c) cis-trans exotherm energy, and d) cis-trans exotherm onset temperature.....

Figure S29 (previous page). Plotted data to compare the first heating branches for irradiation of $\mathbf{C u}-1 \supset \mathrm{AB}_{0.9}$ for different lengths. a) endotherm energy, b) endotherm onset temperature,

c) cis-trans exotherm energy, and d) cis-trans exotherm onset temperature....

Table S18. Calculated energy difference between trans-AB and cis-AB.

Table S19. Difference between observed energy difference on the first heating branch for UV irradiated Co-1 $\supset \mathrm{AB}_{1.0}$ and calculated cis-trans $\mathrm{AB}$ thermal relaxation energies.

Table S20. Difference between observed energy difference on the first heating branch for UV irradiated Ni-1 $\supset \mathrm{AB}_{1.0}$ and calculated cis-trans $\mathrm{AB}$ thermal relaxation energies.

Table S21. Difference between observed cis-AB exotherm for UV irradiated Cu-1دAB 0.9

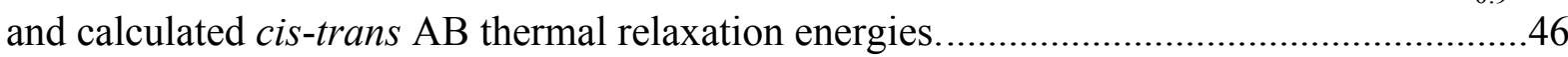

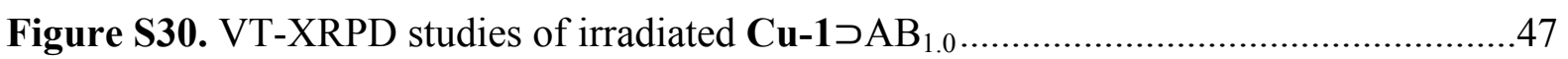

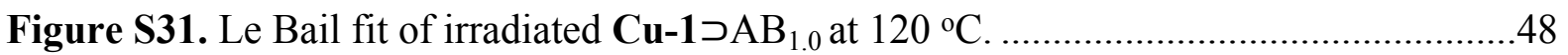

Figure S32. The relationship between energy density and irradiation time for $\mathbf{M}-1 \supset \mathrm{AB}_{1.0}$

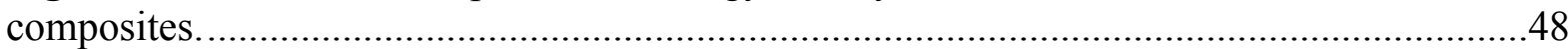

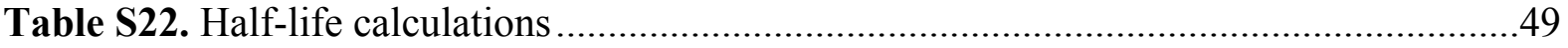

Table S23. Decay constants and half-lives for $\mathbf{M - 1} \supset \mathrm{AB}_{1.0}$ composites. ...............................50

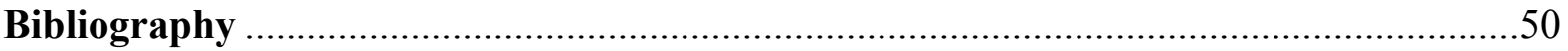


Table S1. Synthetic conditions for M-1つAB .

\begin{tabular}{cccccc}
\hline Entry & Compound & General Formula ${ }^{(a)}$ & $\begin{array}{c}\text { Mass of } \\
\mathbf{1} / \mathrm{g}\end{array}$ & $\begin{array}{c}\text { Mass } \\
\text { of } \\
\text { trans- } \\
\mathrm{AB} / \mathrm{g}\end{array}$ & $\begin{array}{c}\text { Excess } \\
\text { trans-AB } \\
\text { removal } \\
(\mathrm{b}) / \mathrm{h}\end{array}$ \\
& & & & & \\
\hline 1 & $\mathbf{Z n - 1} \supset \mathrm{AB}^{\text {vac-0h }}$ & {$\left[\mathrm{Zn}_{2}(\mathrm{BDC})_{2}(\mathrm{DABCO})(\mathrm{AB})_{1.3}\right]$} & 0.3 & 0.3 & 0 \\
2 & $\mathbf{C o - 1} \supset \mathrm{AB}^{\text {vac-0h }}$ & {$\left[\mathrm{Co}_{2}(\mathrm{BDC})_{2}(\mathrm{DABCO})(\mathrm{AB})_{1.3}\right]$} & 0.3 & 0.3 & 0 \\
3 & $\mathbf{N i - 1} \supset \mathrm{AB}^{\text {vac-0h }}$ & {$\left[\mathrm{Ni}_{2}(\mathrm{BDC})_{2}(\mathrm{DABCO})(\mathrm{AB})_{1.3}\right]$} & 0.3 & 0.3 & 0 \\
4 & $\mathbf{C u}-1 \supset \mathrm{AB}^{\text {vac-0h }}$ & {$\left[\mathrm{Cu}_{2}(\mathrm{BDC})_{2}(\mathrm{DABCO})(\mathrm{AB})_{1.3}\right]$} & 0.3 & 0.3 & 0 \\
5 & $\mathbf{C o - 1} \supset \mathrm{AB}_{1.0}$ & {$\left[\mathrm{Co}_{2}(\mathrm{BDC})_{2}(\mathrm{DABCO})(\mathrm{AB})_{1.0}\right]$} & 0.3 & 0.3 & 3 \\
6 & $\mathbf{N i}-1 \supset \mathrm{AB}_{1.0}$ & {$\left[\mathrm{Ni}_{2}(\mathrm{BDC})_{2}(\mathrm{DABCO})(\mathrm{AB})_{1.0}\right]$} & 0.3 & 0.3 & 3 \\
& $\mathbf{C u}-1 \supset \mathrm{AB}_{0.9}$ & {$\left[\mathrm{Ni}_{2}(\mathrm{BDC})_{2}(\mathrm{DABCO})(\mathrm{AB})_{0.9}\right]$} & 0.3 & 0.15 & 0 \\
\hline
\end{tabular}

(a) heated at $120{ }^{\circ} \mathrm{C}$ for $3 \mathrm{~h}$ in a stoppered vial. ${ }^{(b)}$ heated at $120{ }^{\circ} \mathrm{C}$ in an open vial under reduced pressure.

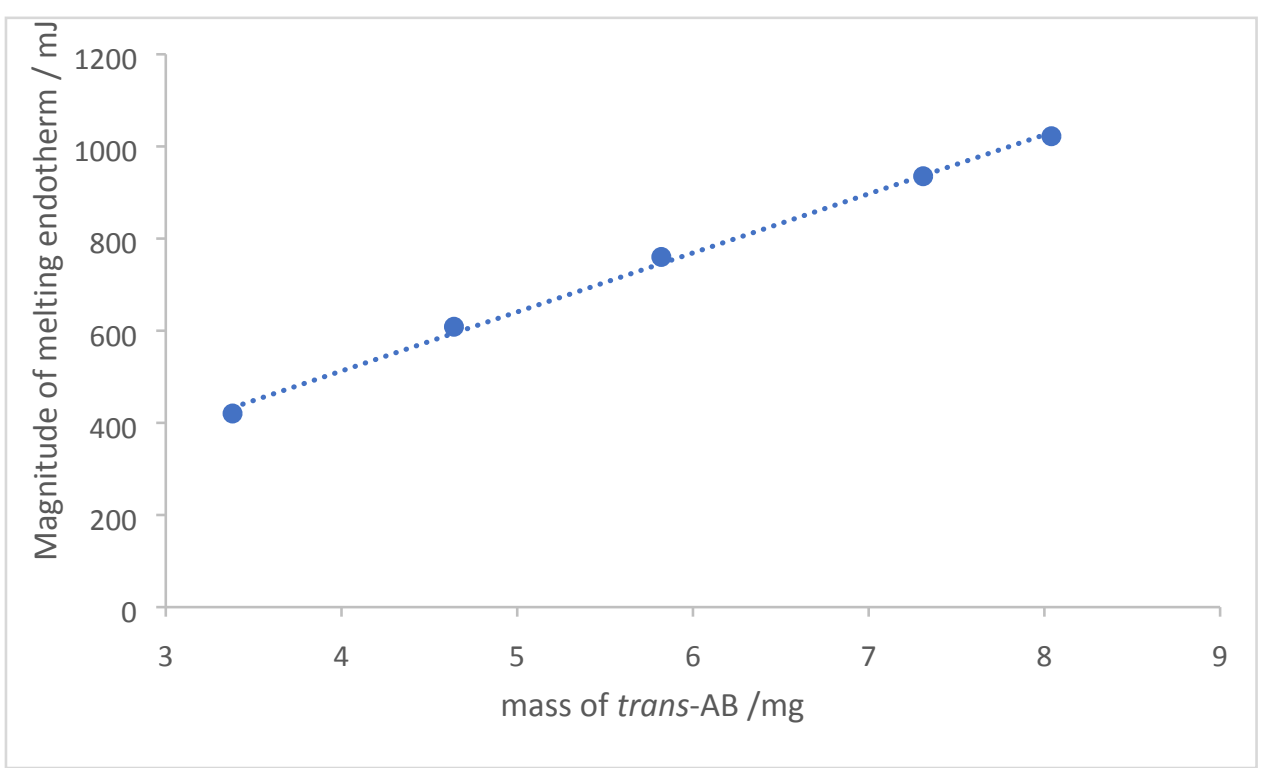

Figure S1. Calibration curve for the relationship between mass of trans-AB and the energy of the melting endotherm. 
Table S2. Calculation of excess trans-AB in M-1 つAB $\mathrm{AB}^{\mathrm{vac}-\mathrm{h}}$ samples and correction of the energy density.

\begin{tabular}{|c|c|c|c|c|c|c|c|}
\hline & $\begin{array}{l}\text { trans-AB } \\
\text { melting } \\
\text { endotherm } \\
/ \mathrm{mJ}\end{array}$ & $\begin{array}{l}\text { Equivalent mass } \\
\text { of trans- } \mathrm{AB} / \mathrm{mg}\end{array}$ & $\begin{array}{l}\text { Overall mass of } \\
\text { sample/ mg }\end{array}$ & $\begin{array}{c}\text { Phase } \\
\text { change } \\
\text { endotherm / } \\
\text { mJ }\end{array}$ & $\begin{array}{c}\text { (Sample mass- AB mass) / } \\
\text { mg }\end{array}$ & $\begin{array}{c}\text { Corrected } \\
\text { phase } \\
\text { change } \\
\text { endotherm / } \\
\text { Jg-1 }\end{array}$ & $\begin{array}{r}\% \text { mass of } \\
\text { sample AB }\end{array}$ \\
\hline Zn-1つAB vac-0h & 200.96 & 1.57 & 7.99 & 219.64 & 6.42 & 34.19 & 19.6 \\
\hline Co-1つAB vac-0h & 200.78 & 1.56 & 7.98 & 219.63 & 6.42 & 34.24 & 19.6 \\
\hline Ni-1つAB vac-0h & 90.01 & 0.70 & 4.80 & 141.38 & 4.10 & 34.50 & 14.6 \\
\hline Cu-1つAB vac-0h & 240.59 & 1.88 & 9.15 & 133.28 & 7.27 & 18.32 & 20.5 \\
\hline $\mathbf{C u}-1 \supset \mathrm{AB}_{0.0}$ & 31.31 & 0.24 & 6.11 & $\mathrm{n} / \mathrm{a}$ & 5.87 & $\mathrm{n} / \mathrm{a}$ & 4.0 \\
\hline
\end{tabular}


a)

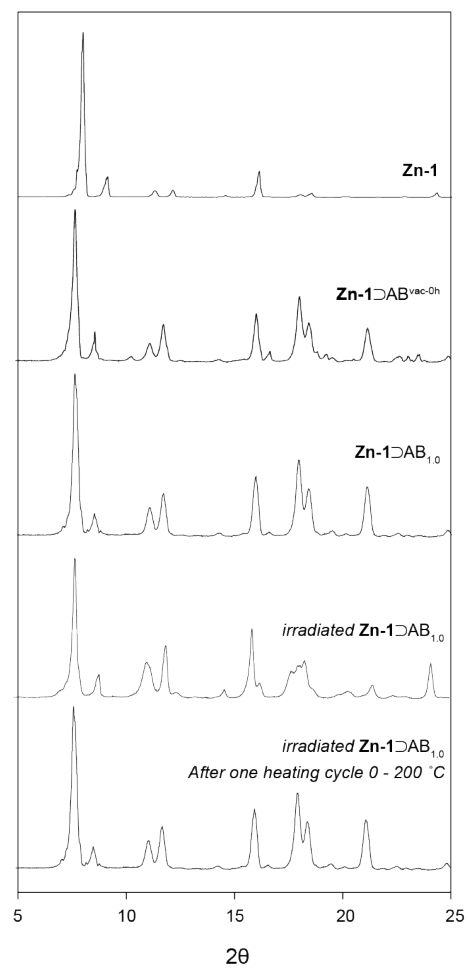

b)

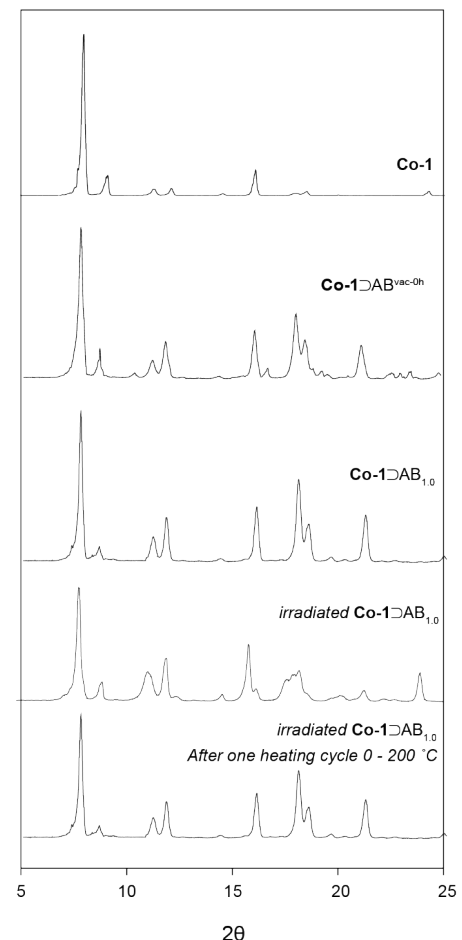


c)

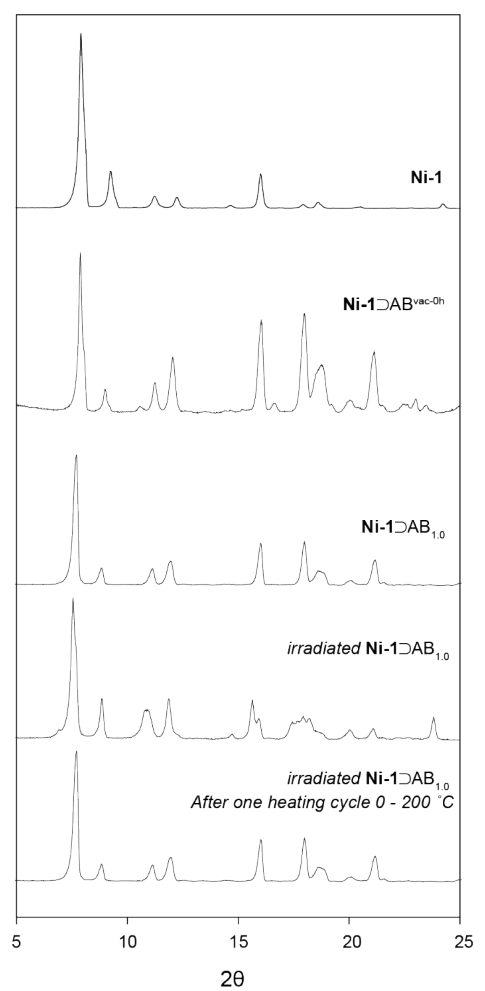

d)

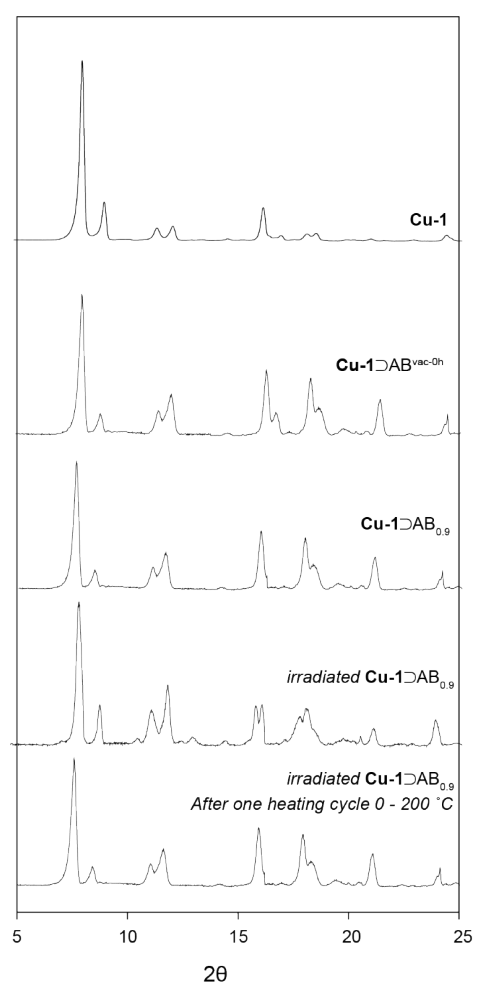

Figure S2. XRPD patterns of all composites of (a) Zn-1, (b) Co-1, (c) Ni-1 and (d) Cu-1. 
a)

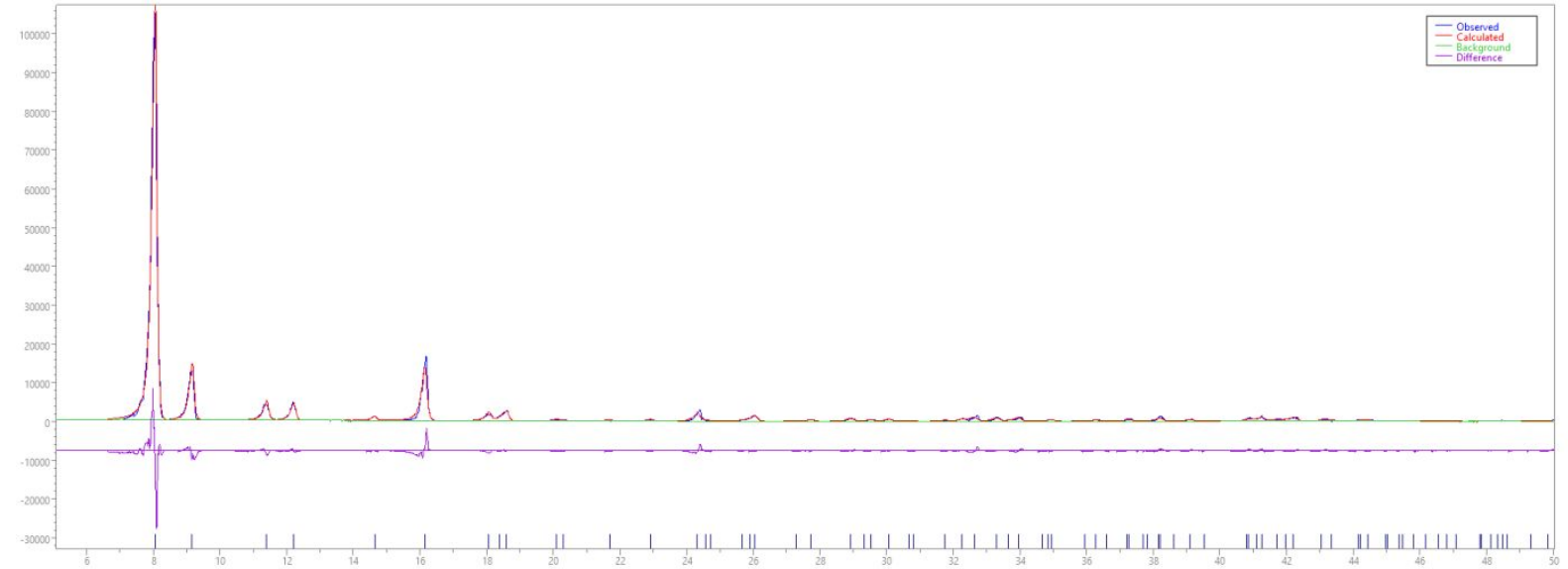

b)

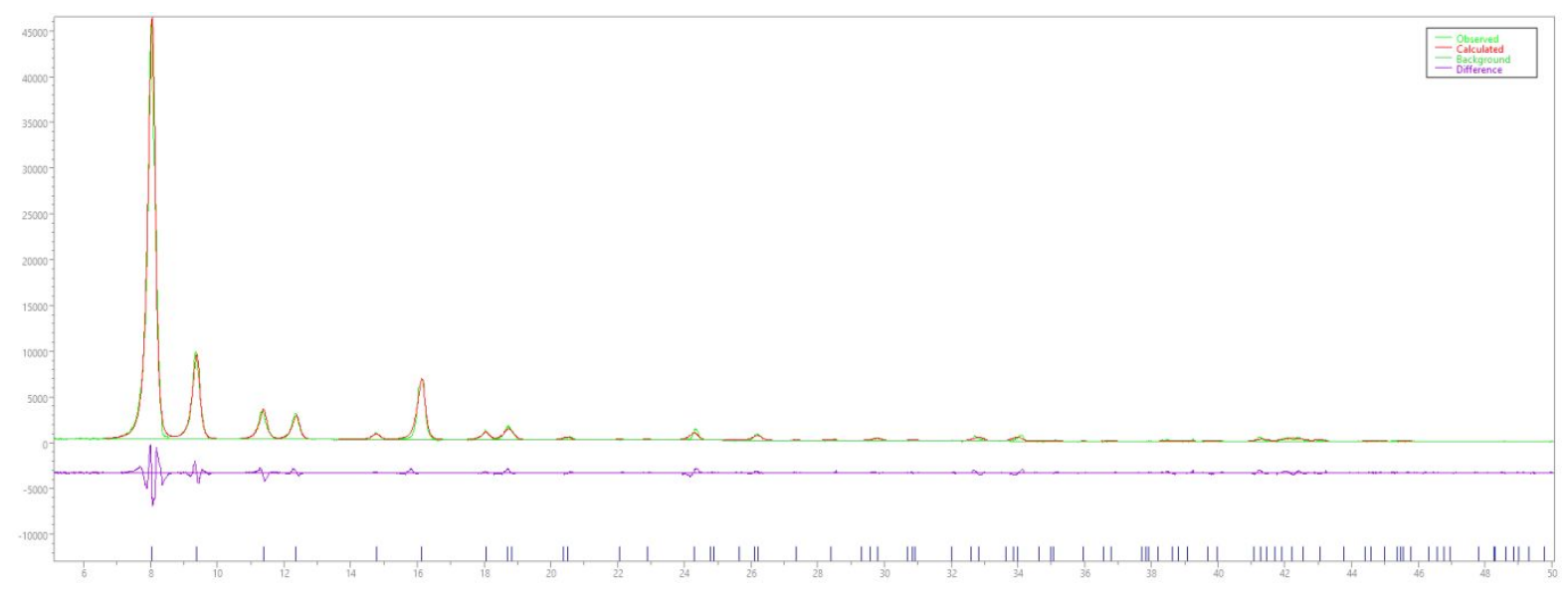

c)

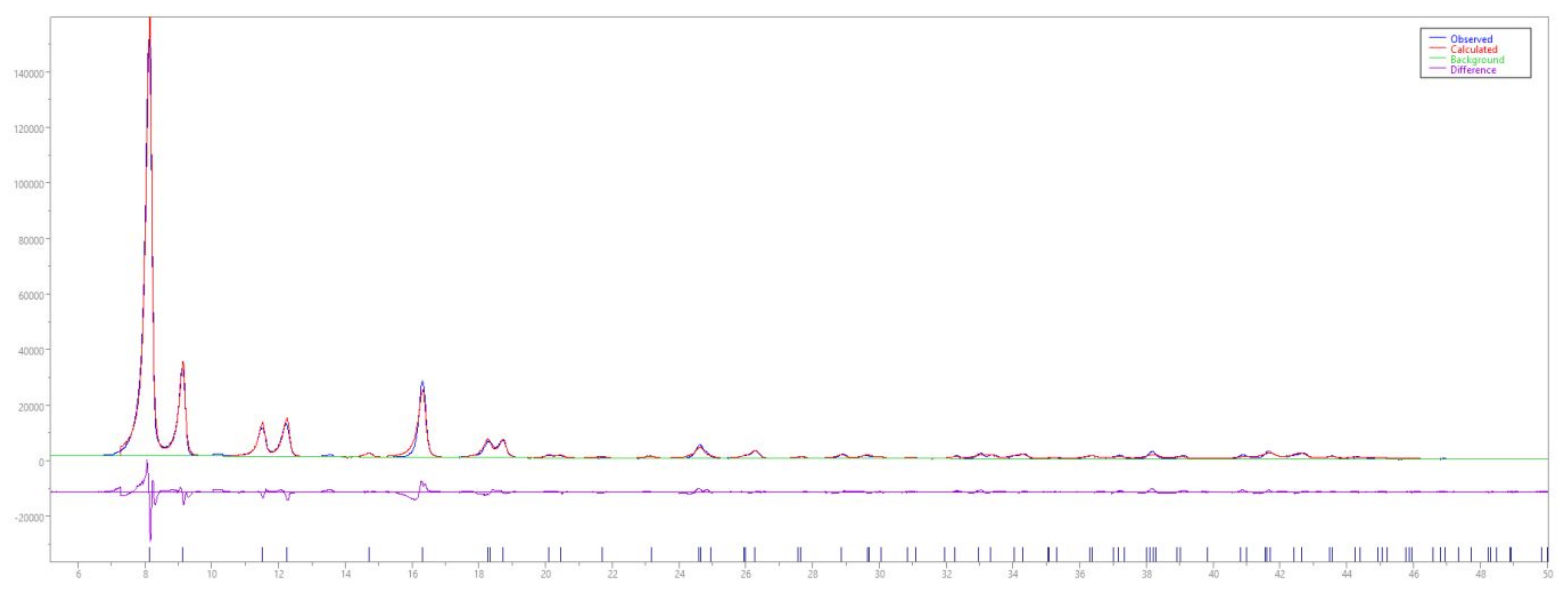

Figure S3. Le Bail fits of (a) Co-1, (b) Ni-1 and (c) Cu-1. The crystal system for each phase was found to be tetragonal in the $P 4 / \mathrm{mmm}$ spacegroup. The lattice parameters were refined to be (a) $a=$ $b=10.982(2) \AA, c=9.650(3) \AA, \alpha=\beta=\gamma=90^{\circ}, \mathrm{V}=1164.1(5) \AA^{3}$; (b) $a=b=10.981(3) \AA, c=$ 9.49(1) $\AA, \alpha=\beta=\gamma=90^{\circ}, \mathrm{V}=1143.9(6) \AA^{3}$; (c) $a=b=10.910(2) \AA, c=9.692(3) \AA, \alpha=\beta=\gamma=90^{\circ}$, $\mathrm{V}=1152.9(9) \AA^{3}$. The reliability (R) factors based on the powder profile $R p$ were (a) $8.91 \%$, (b) $6.77 \%$ and (c) $8.91 \%$ 
a)

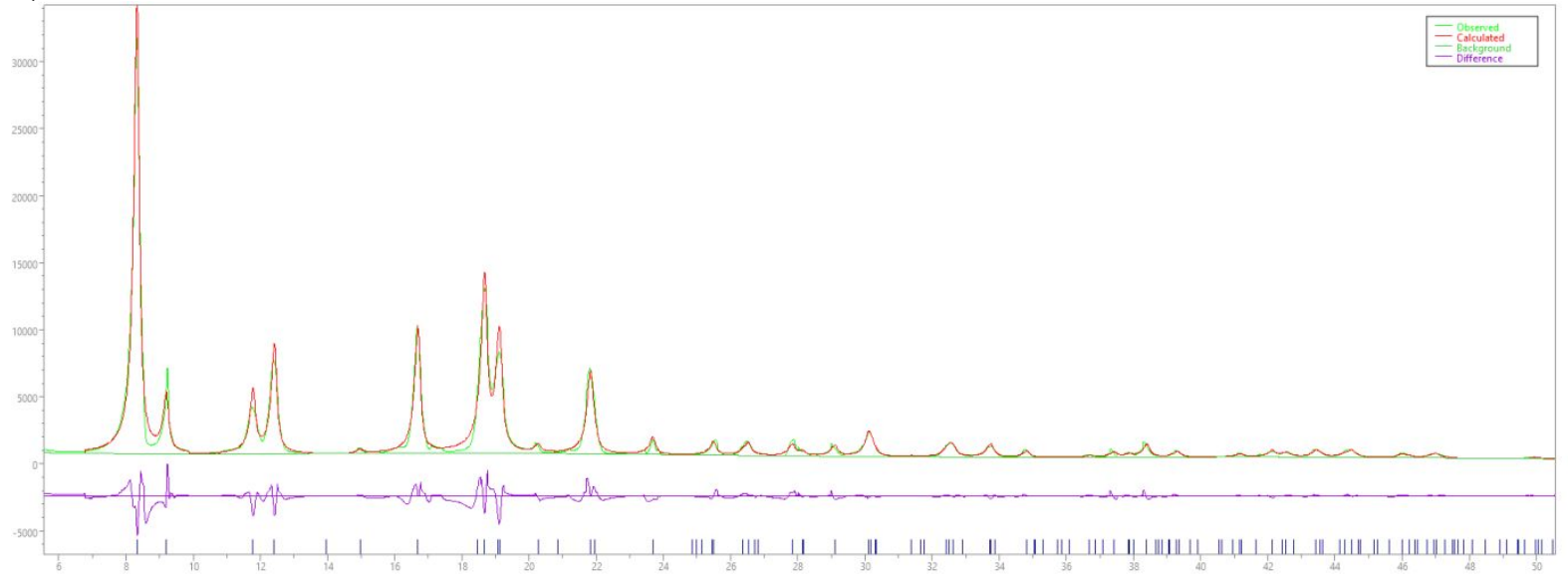

b)

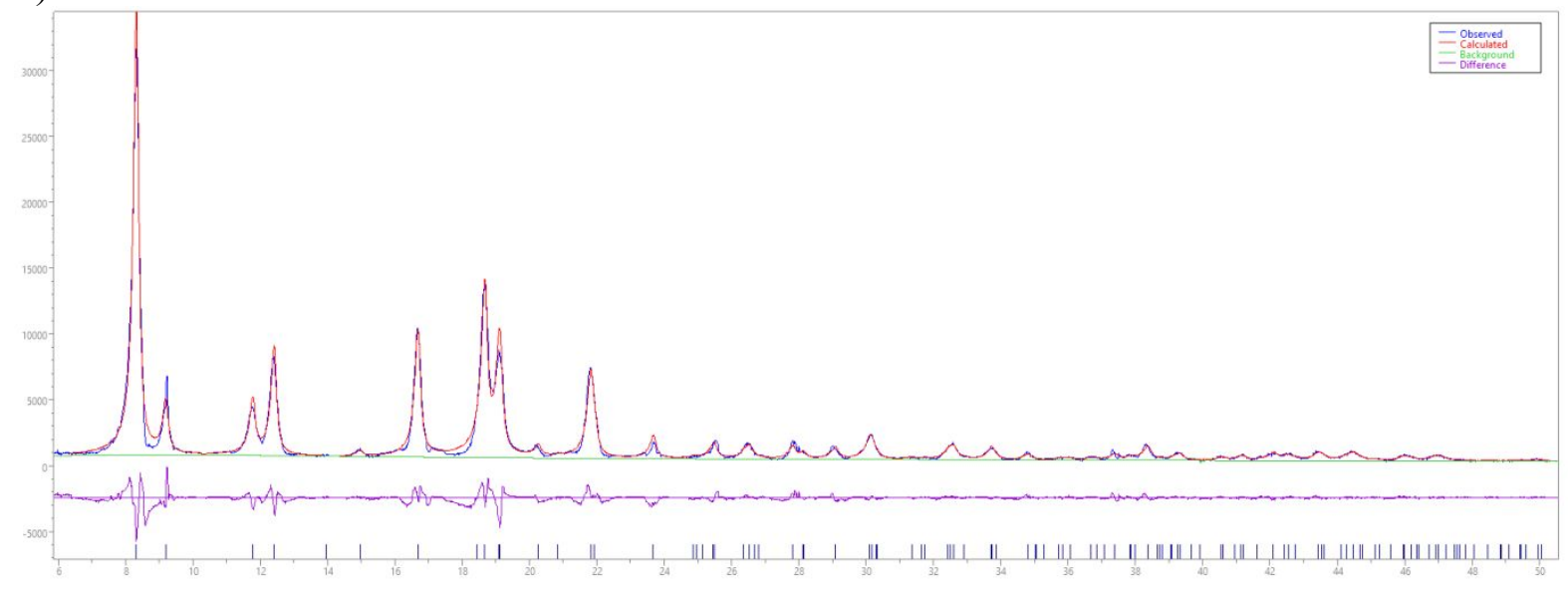

c)

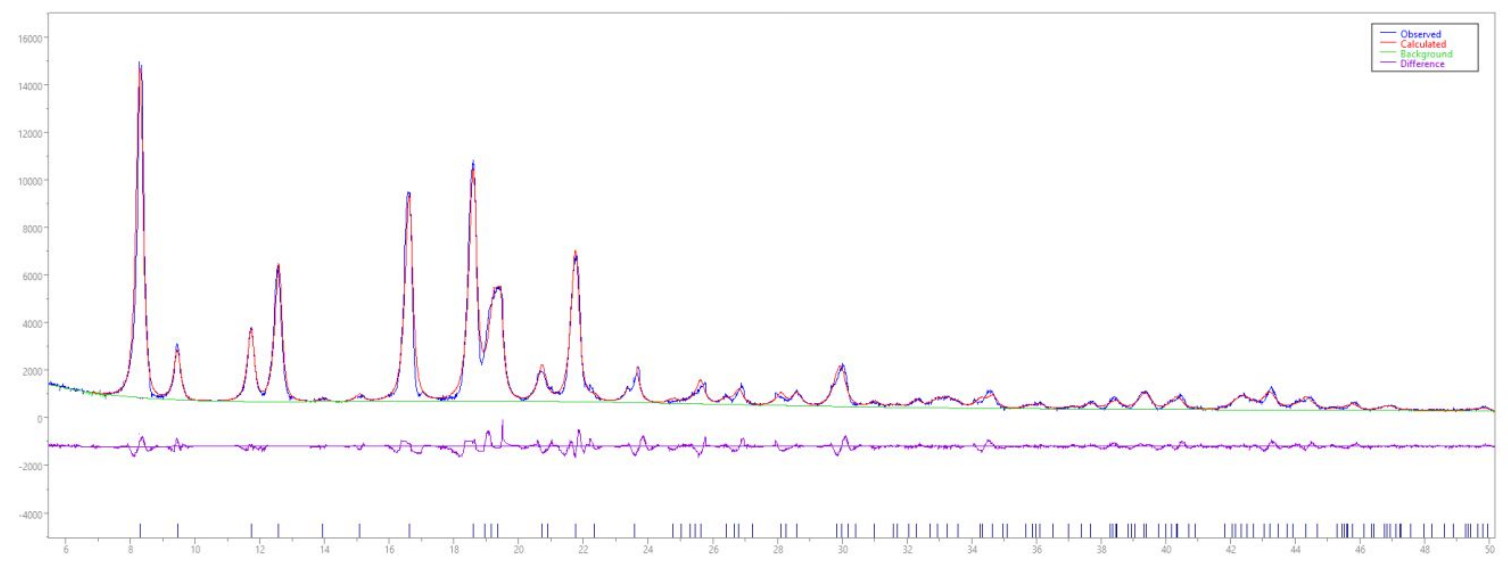


d)

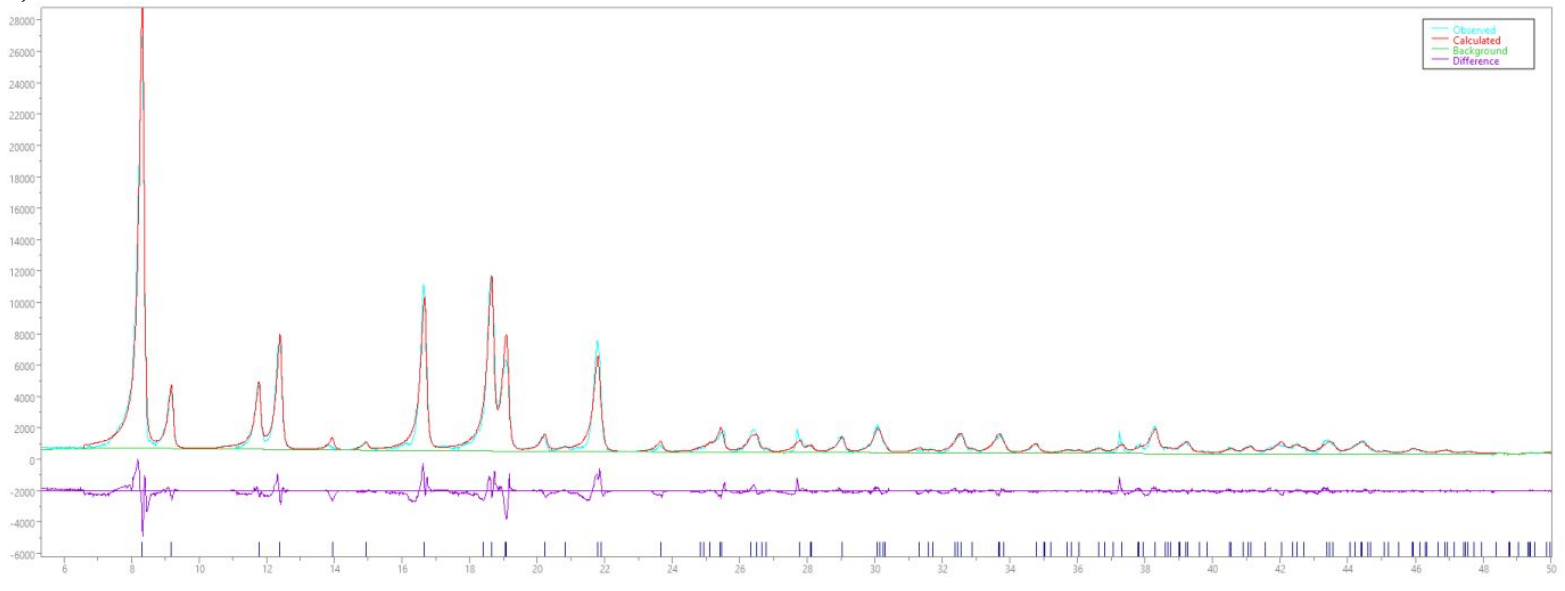

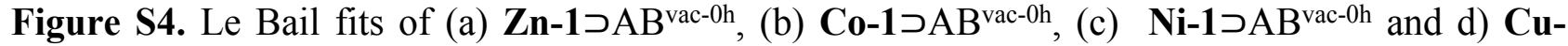
$1 \supset \mathrm{AB}^{\text {vac-oh }}$. The crystal system in each composite was found to be tetragonal in the spacegroup $I 4 / \mathrm{mcm}$. The lattice parameters were refined to be (a) $a=b=15.031$ (4) $\AA, c=19.285$ (4) $\AA$, $\alpha=\beta=\gamma=90^{\circ}, \mathrm{V}=4355.6(9) \AA^{3}$; (b) $a=b=15.054(5) \AA, c=19.289$ (2) $\AA, \alpha=\beta=\gamma=90^{\circ}, \mathrm{V}=$ 4366.1(7) $\AA^{3}$ (c) $a=b=15.231$ (4) $\AA, c=18.903(4) \AA, \alpha=\beta=\gamma=90^{\circ}, \mathrm{V}=4386.5(9) \AA^{3}$; (d) $a=b$ $=15.312(5) \AA, c=19.35(3) \AA, \alpha=\beta=\gamma=90^{\circ}, \mathrm{V}=4535.6(8) \AA^{3}$. The reliability (R) factors based on the powder profile $R p$ were (a) $11.21 \%$, (b) $15.21 \%$, (c) $10.33 \%$ and (d) $8.64 \%$.

Table S3. Percentage contraction of reduced unit cell parameters for the $l p$ to $n p$ form

\begin{tabular}{cccc}
\hline $\begin{array}{c}\text { M-1 }(l p) \text { contraction to } \mathbf{M}-1 \supset \mathrm{AB}^{\text {vac- }} \\
\text { oh }(n p)(\mathrm{M}=)\end{array}$ & $\begin{array}{c}\text { Contraction of reduced } \\
a=b \text { cell length } / \%\end{array}$ & $\begin{array}{c}\text { Contraction of } \\
\text { reduced } c \text { cell } \\
\text { length } \%\end{array}$ & $\begin{array}{c}\text { Contraction of } \\
\text { reduced unit } \\
\text { cell volume / } \\
\%\end{array}$ \\
\hline $\mathbf{Z n - 1}$ & 3.19 & 0.12 & 6.40 \\
$\mathbf{C o - 1}$ & 3.08 & 0.12 & 6.18 \\
$\mathbf{N i - 1}$ & 1.89 & 0.42 & 4.15 \\
$\mathbf{C u}-1$ & 0.77 & 0.15 & 1.69 \\
\hline
\end{tabular}




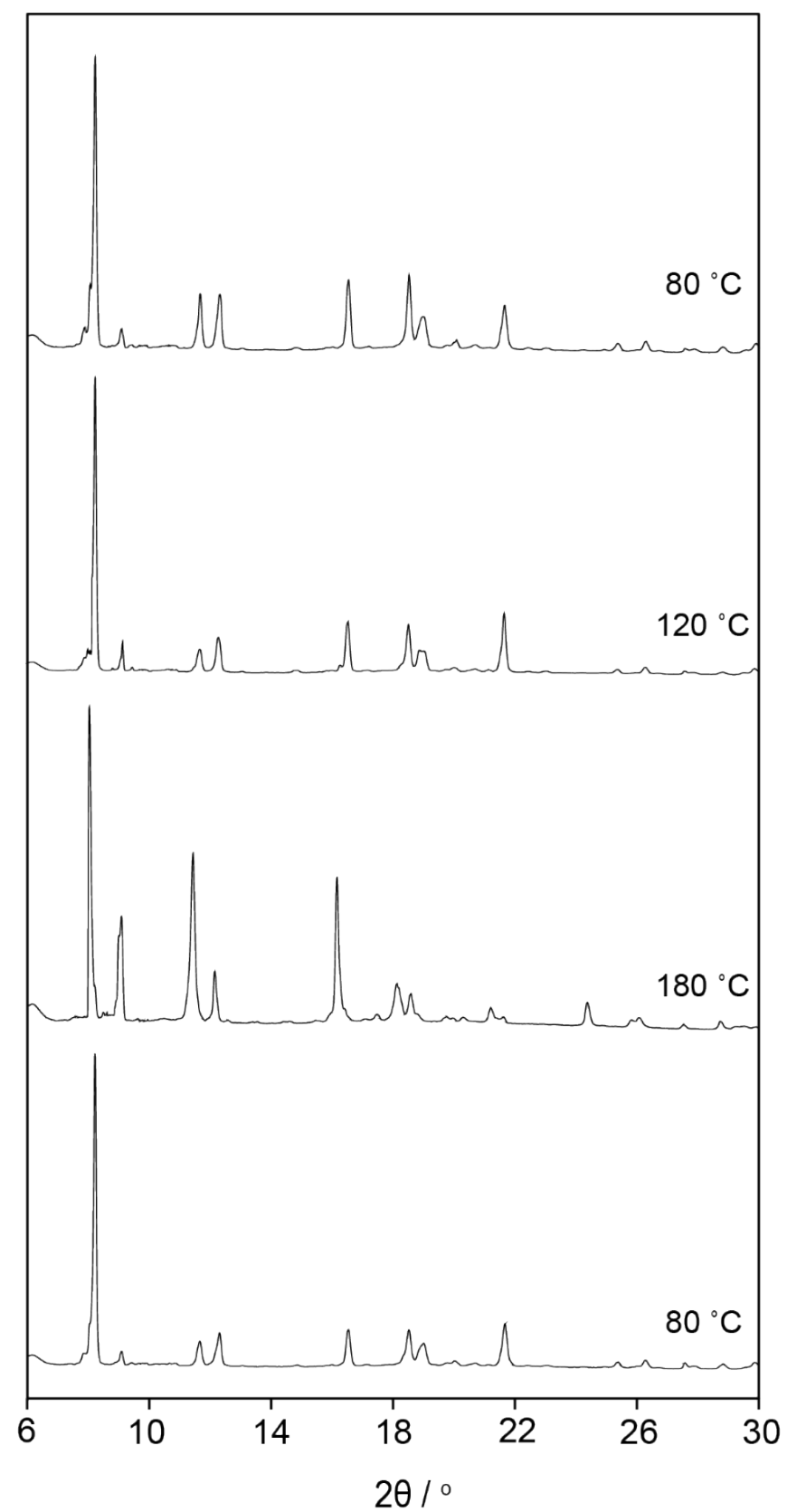

Figure S5. VT-XRPD studies of $\mathbf{Z n - 1} \supset \mathrm{AB}^{\text {vac-0h }}$ between ambient temperature to $180{ }^{\circ} \mathrm{C}$ to show the reversibility of the $n p$ phase to the $o p$ phase. 


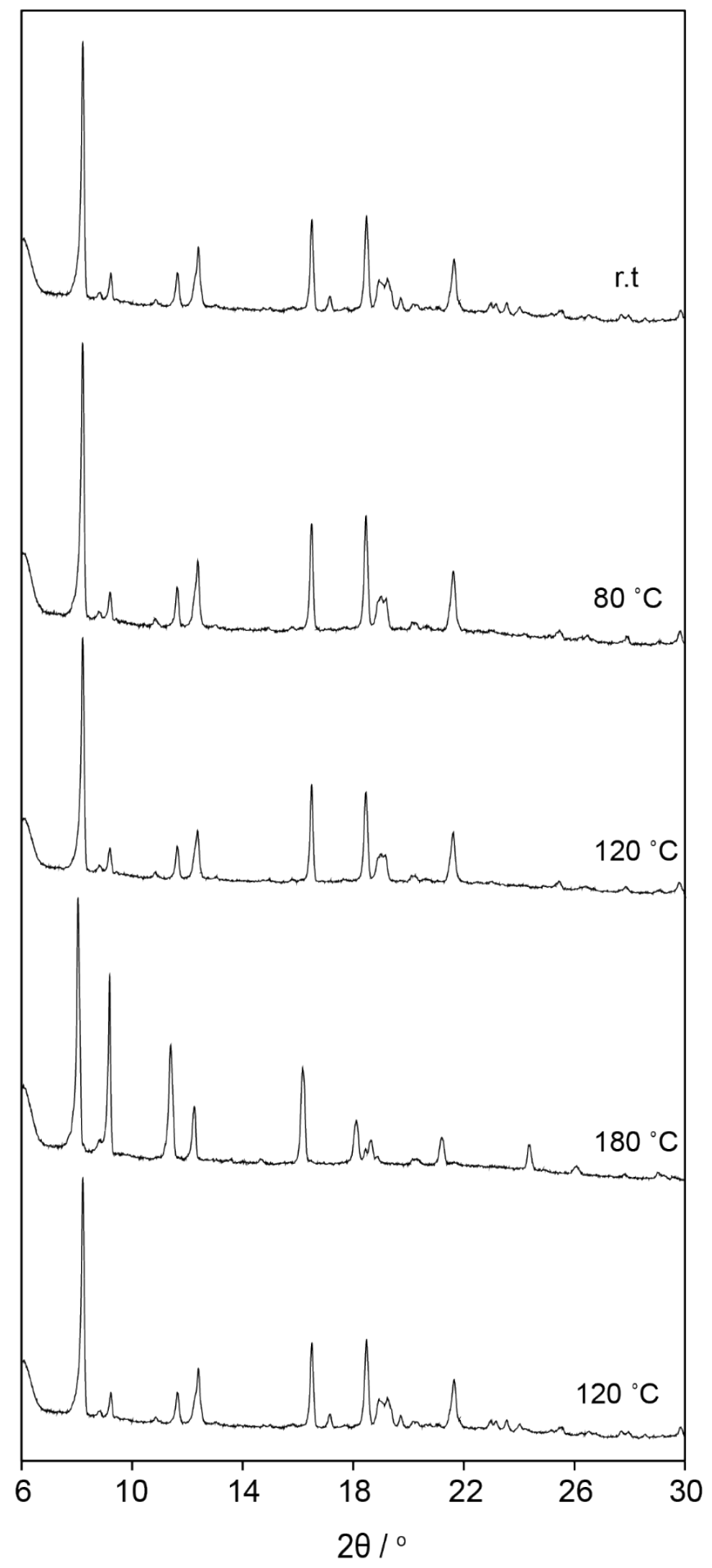

Figure S6. VT-XRPD studies of Co-1 دAB $\mathrm{AB}^{\mathrm{vac}-0 \mathrm{~h}}$ between ambient temperature to $180{ }^{\circ} \mathrm{C}$ to show the reversibility of the $n p$ phase to the $o p$ phase. Small reflections of crystalline trans-AB are visible below $80^{\circ} \mathrm{C}$. 


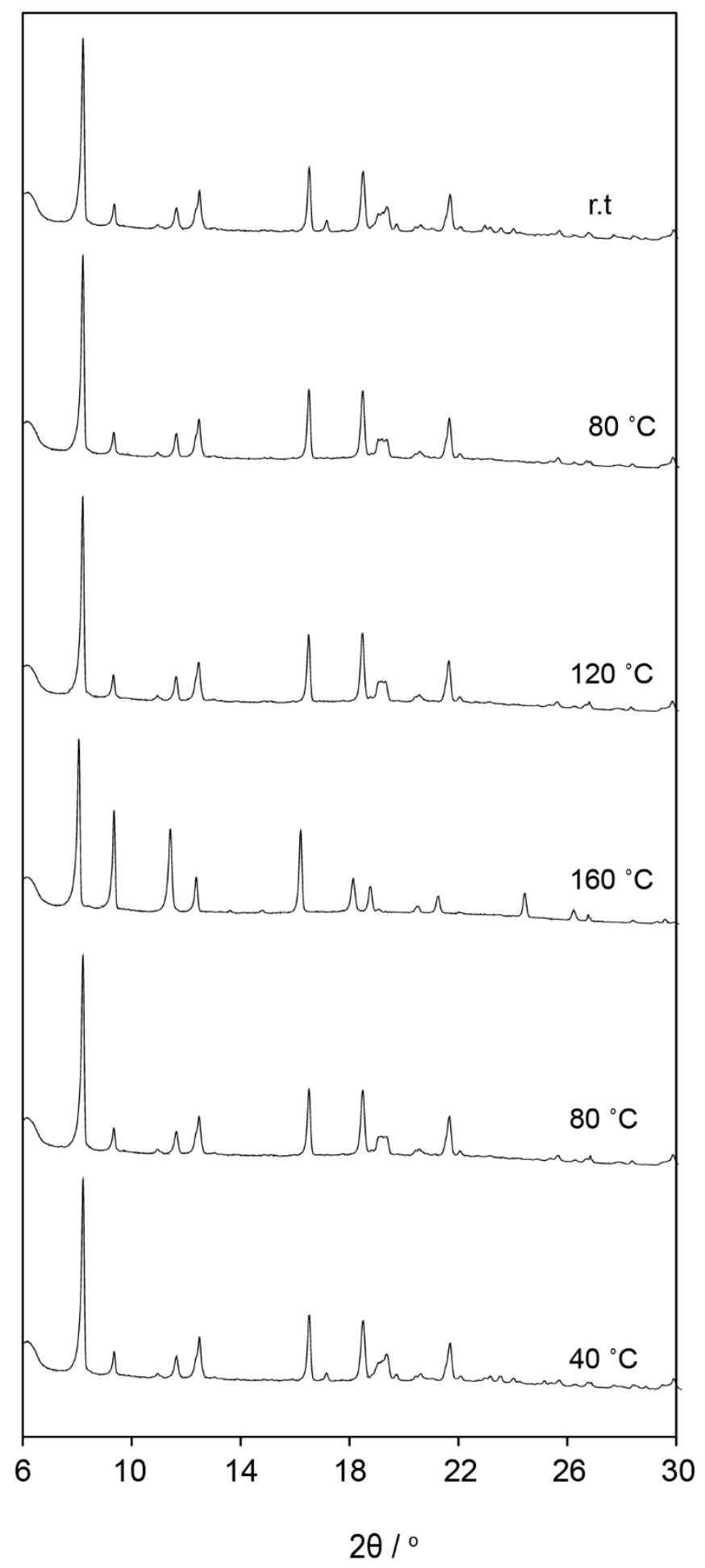

Figure S7. VT-XRPD studies of Ni-1 دAB ${ }^{\text {vac-0h }}$ between ambient temperature to $160{ }^{\circ} \mathrm{C}$ to show the reversibility of the $n p$ phase to the $o p$ phase. Small reflections of crystalline trans-AB are visible below $80^{\circ} \mathrm{C}$. 


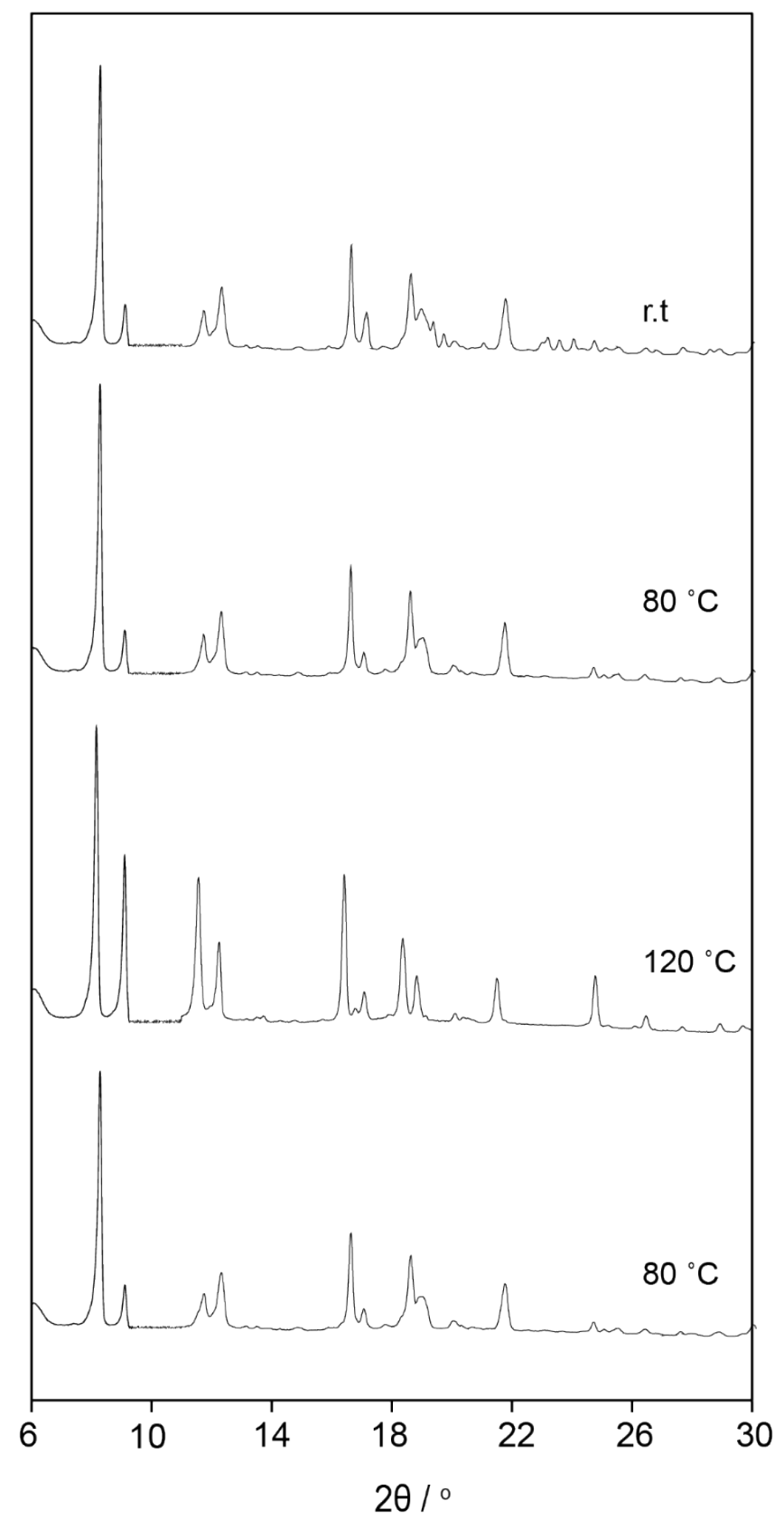

Figure S8. VT-XRPD studies of $\mathbf{C u}-1 \supset \mathrm{AB}^{\text {vac-0h }}$ between ambient temperature to $120^{\circ} \mathrm{C}$ to show the reversibility of the $n p$ phase to the $o p$ phase. Small reflections of crystalline trans-AB are visible in each pattern. 
a)

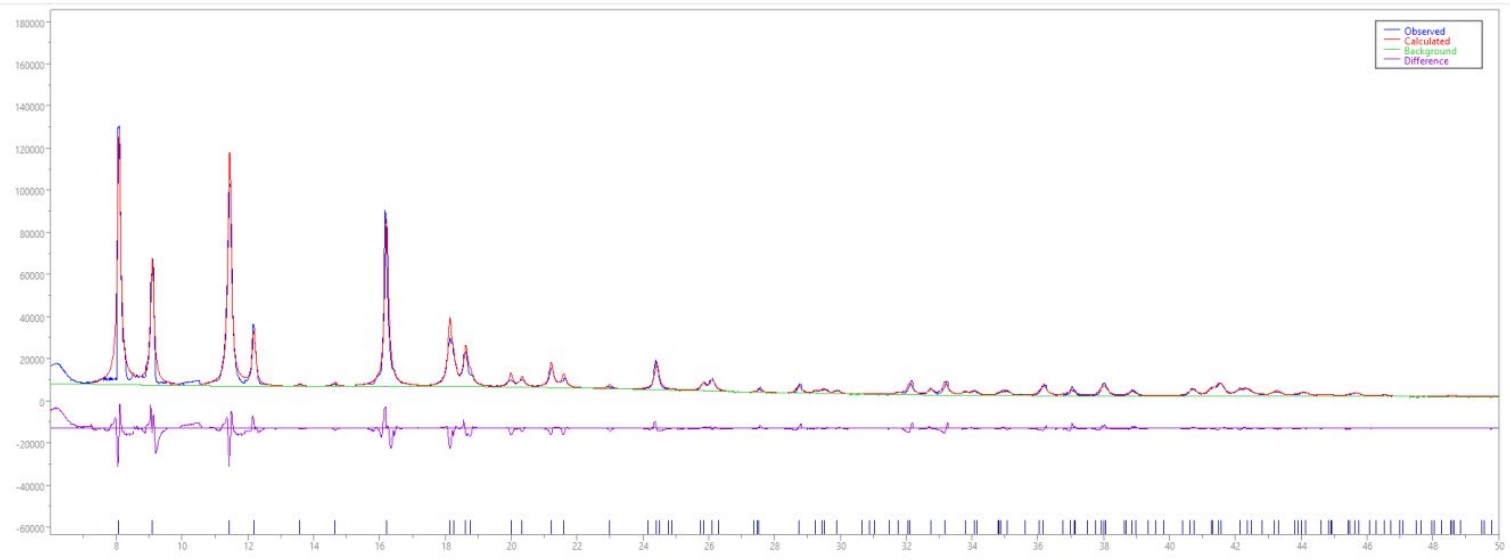

b)

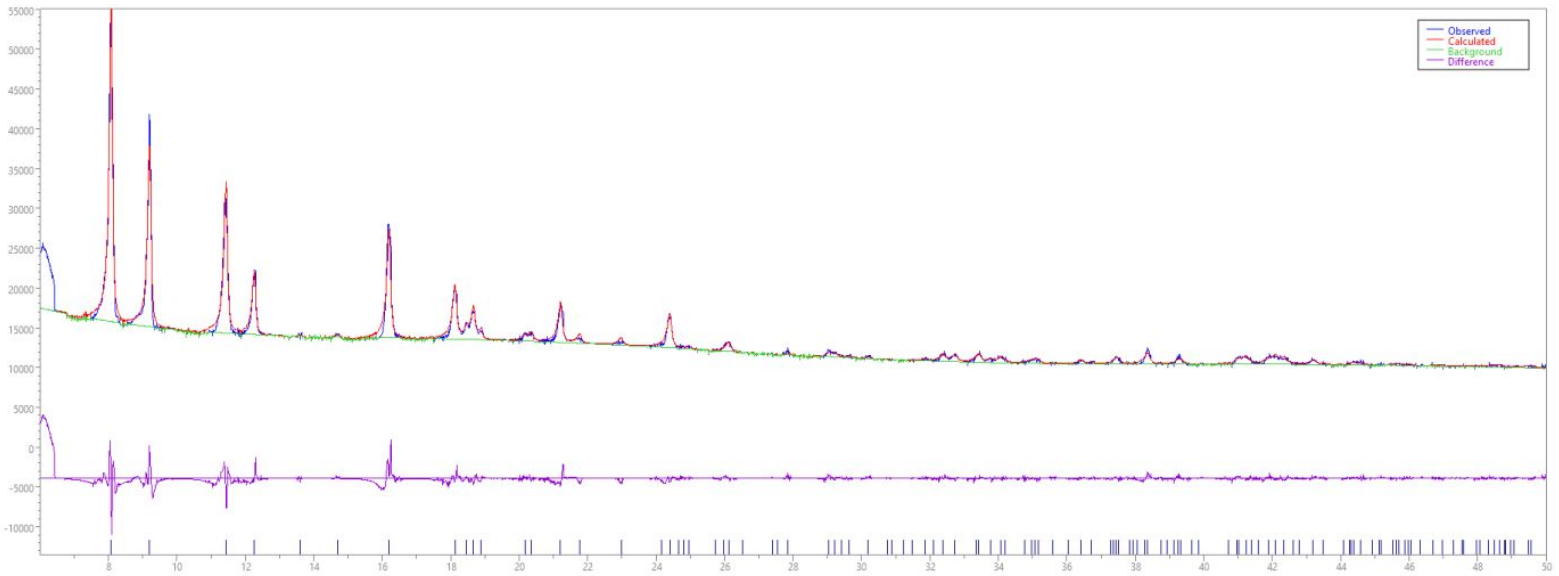

c)

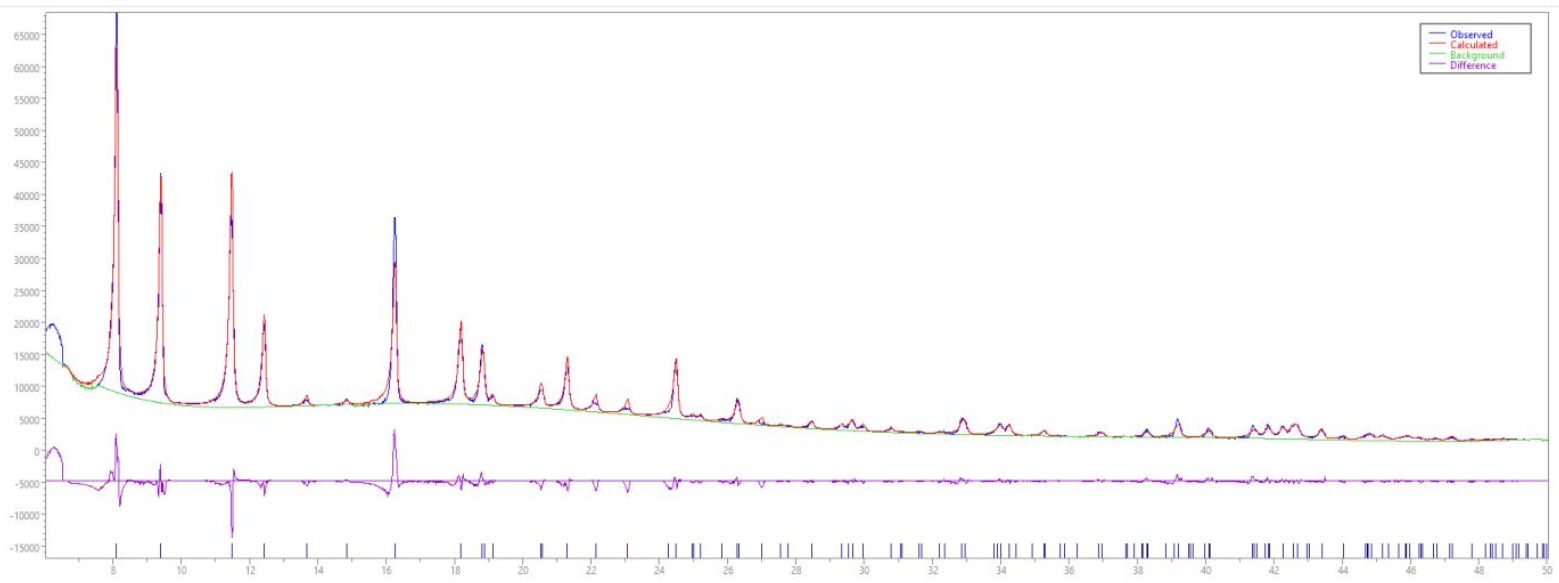


d)

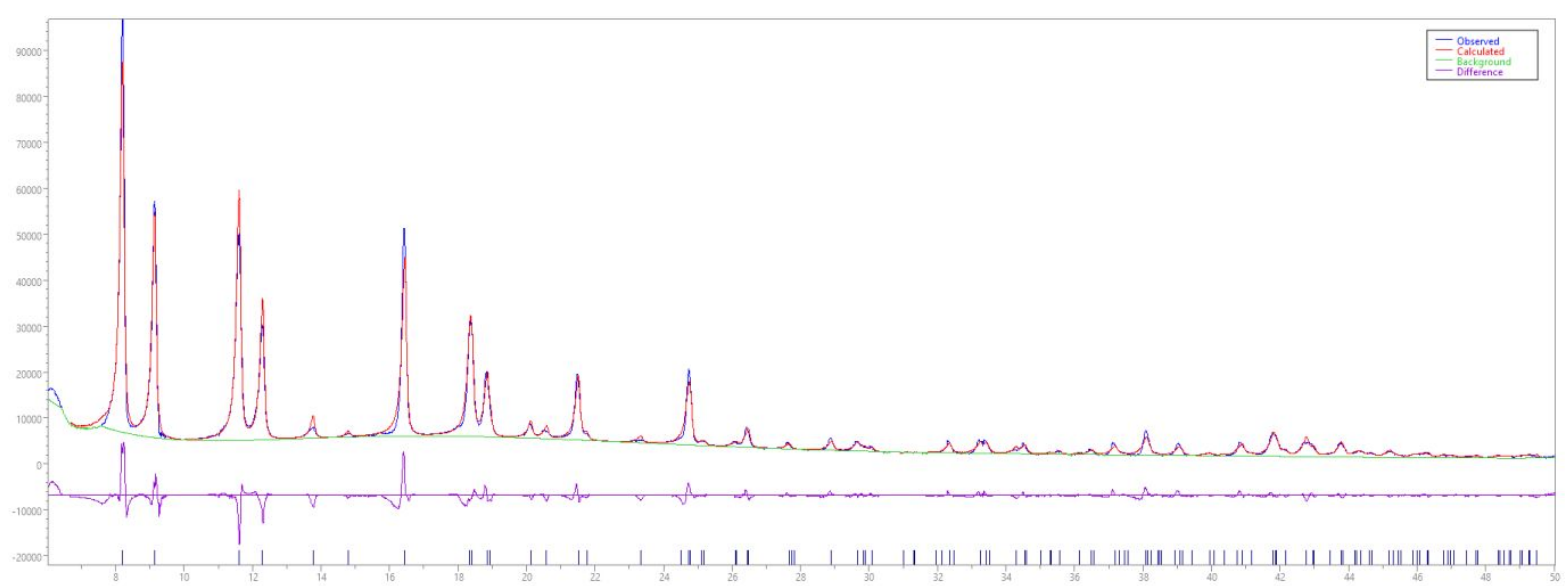

Figure S9. Le Bail fits of (a) Zn-1つAB $\mathbf{B}^{\mathrm{vac}-0 \mathrm{~h}}$, (b) Co-1つAB ${ }^{\mathrm{vac}-0 \mathrm{~h}}$, (c) Ni-1つAB $\mathbf{B}^{\mathrm{vac}-0 \mathrm{~h}}$ and (d) $\mathbf{C u -}$ $1 \supset \mathbf{A B}^{\text {vac-0h }}$ at $180{ }^{\circ} \mathrm{C}$. The crystal system for each phase was found to be tetragonal in the $I 4 / \mathrm{mcm}$ spacegroup. The lattice parameters were refined to be (a) $a=b=15.442(9) \AA, c=19.387(9) \AA$, $\alpha=\beta=\gamma=90^{\circ}, \mathrm{V}=4623.1(3) \AA^{3}$; (b) $a=b=15.484$ (9) $\AA, c=19.208$ (3) $\AA, \alpha=\beta=\gamma=90^{\circ}, \mathrm{V}=$ 4605.8(1) $\AA^{3}$; (c) $a=b=15.414(3) \AA, c=18.812(2) \AA, \alpha=\beta=\gamma=90^{\circ}, \mathrm{V}=4470.0$ (2) $\AA^{3}$, (d) $a=b$ $=15.363(4) \AA, c=19.329(2) \AA, \alpha=\beta=\gamma=90^{\circ}, \mathrm{V}=4562.4(6) \AA^{3}$. The reliability (R) factors based on the powder profiles $R p$ were (a) $9.41 \%$, (b) $5.22 \%$, (c) $6.23 \%$ and (d) $7.64 \%$.

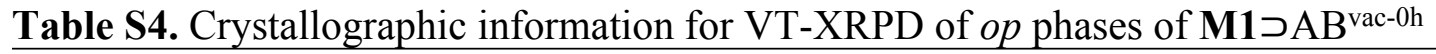

\begin{tabular}{ccccccc}
\hline Compound & $\begin{array}{c}\text { Temperature } \\
/{ }^{\circ} \mathrm{C}\end{array}$ & Space group & $a=b$ & $c$ & $\begin{array}{c}\alpha=\beta=\gamma / \\
\mathrm{o}\end{array}$ & $\mathrm{V} / \mathrm{A}^{3}$ \\
\hline Zn-1 $\supset \mathrm{AB}^{\text {vac-0h }}$ & 180 & $I 4 / m c m$ & 15.442 & 19.388 & 90 & 4623.1 \\
Co-1 $\supset \mathrm{AB}^{\text {vac-0h }}$ & 180 & $I 4 / m c m$ & 15.485 & 19.208 & 90 & 4605.8 \\
$\mathbf{N i - 1} \supset \mathrm{AB}^{\text {vac-0h }}$ & 160 & $I 4 / m c m$ & 15.415 & 18.812 & 90 & 4470.0 \\
$\mathbf{C u}-1 \supset \mathrm{AB}^{\text {vac-0h }}$ & 120 & $I 4 / m c m$ & 15.363 & 19.329 & 90 & 4562.4 \\
\hline
\end{tabular}

Table S5. Percentage expansion of reduced unit cell parameters of $\mathbf{M}-\mathbf{1} \supset \mathbf{A B} \mathbf{B}_{\text {vac- }-0 \mathrm{~h}}$ from the $n p$ to $o p$ form

\begin{tabular}{cccc}
\hline $\begin{array}{c}\text { M-1 } \supset \mathrm{AB}_{\text {vac-0h }}(n p) \text { expansion to } \mathbf{M}- \\
\mathbf{1}_{\mathrm{AB}} \text { vac-0h }(o p)(\mathrm{M}=)\end{array}$ & $\begin{array}{c}\text { Expansion of } \\
\text { reduced } a=b \\
\text { cell length } / \%\end{array}$ & $\begin{array}{c}\text { Expansion of } \\
\text { reduced } c \text { cell } \\
\text { length } / \%\end{array}$ & $\begin{array}{c}\text { Expansion of } \\
\text { reduced unit cell } \\
\text { volume } / \%\end{array}$ \\
\hline $\begin{array}{l}\mathbf{Z n}-1 \supset \mathrm{AB}^{\text {vac-0h }} \\
\mathbf{C o - 1} \supset \mathrm{AB}^{\text {vac-0h }}\end{array}$ & 2.53 & 0.19 & 5.32 \\
$\mathbf{N i - 1} \supset \mathrm{AB}^{\text {vac-0h }}$ & 2.41 & -0.13 & 4.73 \\
$\mathbf{C u}-1 \supset \mathrm{AB}^{\text {vac-0h }}$ & 1.56 & 0.11 & 3.24 \\
\hline
\end{tabular}




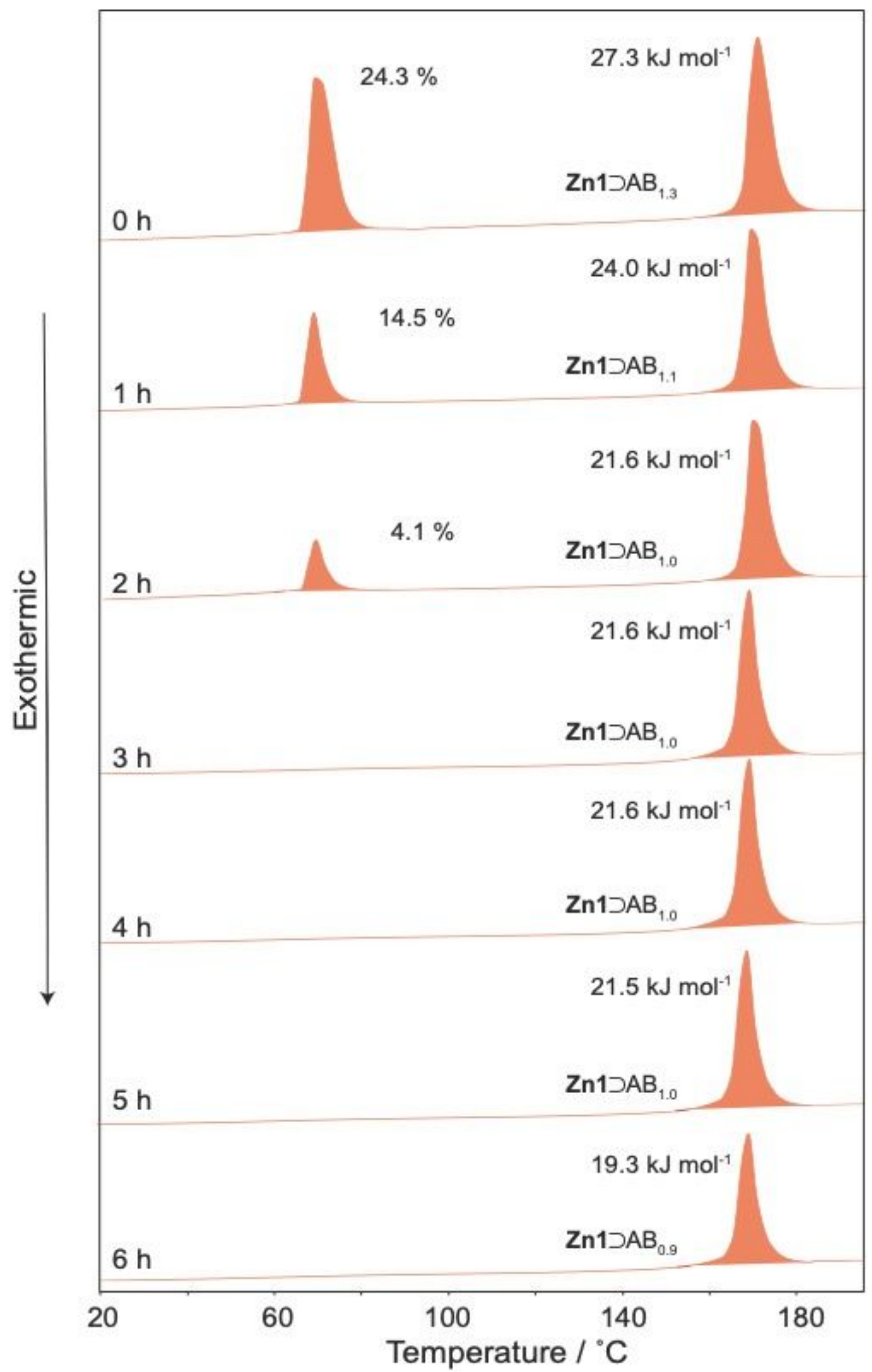

Figure S10. DSC traces of the $\mathbf{Z n - 1} \supset \mathrm{AB}^{\text {vac-xh }}$ with different durations of vacuum treatment at 120 ${ }^{\circ} \mathrm{C}$. Between $0-2$ hours crystalline trans-AB can be observed on the first heating branch and is fully removed after $3 \mathrm{~h}$. The endothermic transition (1) energy stabilises after $2 \mathrm{~h}$ before decreasing after $6 \mathrm{~h}$. 
Table S6. The effect of vacuum treatment length on the ratio of occluded trans-AB within $\mathbf{Z n - 1}$ and $n p \rightarrow o p$ phase transition enthalpy.

\begin{tabular}{|c|c|c|c|c|}
\hline Sample & $\begin{array}{c}\text { Vacuum } \\
\text { treatment } \\
\text { time / } \\
\text { hours }^{(a)}\end{array}$ & $\begin{array}{c}\text { Excess AB } \\
/ \%\end{array}$ & $\begin{array}{c}\mathrm{Zn}-1: \\
\text { trans-AB }\end{array}$ & $\begin{array}{c}n p \rightarrow o p \text { phase transition } \\
\text { enthalpy } / \mathrm{kJ} \mathrm{mol}^{-1}\end{array}$ \\
\hline $\mathrm{Zn}-1 \supset \mathrm{AB}^{\mathrm{vac}-0 \mathrm{~h}}$ & 0 & 24 & $1: 1.3$ & 27.3 \\
\hline $\mathrm{Zn}-1 \supset \mathrm{AB}^{\mathrm{vac}-1 \mathrm{~h}}$ & 1 & 15 & $1: 1$ & 24.0 \\
\hline $\mathrm{Zn}-1 \supset \mathrm{AB}^{\mathrm{vac}-2 \mathrm{~h}}$ & 2 & 4 & $1: 1$ & 21.6 \\
\hline $\mathrm{Zn}-1 \supset \mathrm{AB}^{\mathrm{vac}-3 \mathrm{~h}}$ & 3 & 0 & $1: 1$ & 21.6 \\
\hline $\mathrm{Zn}-1 \supset \mathrm{AB}^{\mathrm{vac}-4 \mathrm{~h}}$ & 4 & 0 & $1: 1$ & 21.6 \\
\hline $\mathrm{Zn}-1 \supset \mathrm{AB}^{\mathrm{vac}-5 \mathrm{~h}}$ & 5 & 0 & $1: 1$ & 21.5 \\
\hline $\mathrm{Zn}-1 \supset \mathrm{AB}^{\mathrm{vac}-6 \mathrm{~h}}$ & 6 & 0 & $1: 0.9$ & 19.3 \\
\hline
\end{tabular}

(a) Vacuum treatment was performed at $120{ }^{\circ} \mathrm{C}$ at $1 \mathrm{mB}$

To determine how the length of vacuum treatment affects the structural properties of $\mathbf{M}-1 \supset \mathrm{AB}$ composites, a sample of $\mathbf{Z n - 1} \supset \mathrm{AB}^{\text {vac-0h }}$ was subjected to vacuum treatment at $120{ }^{\circ} \mathrm{C}$, with $\mathrm{XRPD}$ patterns and ${ }^{13} \mathrm{C}$ CPMAS NMR spectra recorded at hourly intervals. Between $0-5 \mathrm{~h}$ of vacuum treatment, the XRPD patterns (S22 and S23) show the loss of reflections attributed to excess trans$\mathrm{AB}$, but no shifting or emergence of new reflections, and the pattern remains consistent with the I4/ mcm space group. The ${ }^{13} \mathrm{C}$ CPMAS NMR spectra (S24) only show the characteristic resonances of the tetragonal $n p$ structure. ${ }^{1}$ The intensities of the trans-AB resonances relative to the framework resonances do not change - although we note that the CPMAS experiment is not fully quantitative. 
This indicates that despite the difference in loading level, $\mathbf{Z n - 1} \supset \mathrm{AB}^{\mathrm{vac}-0 \mathrm{~h}}$ and $\mathbf{Z n}-1 \supset \mathrm{AB}^{\mathrm{vac}-5 \mathrm{~h}}$ have the same long-range framework structure at room temperature, and there is no evidence of a significant change in the ordering of trans-AB molecules within the pores. After $6 \mathrm{~h}$ of vacuum treatment XRPD and ${ }^{13} \mathrm{C}$ CPMAS NMR show the emergence of a phase consistent with the orthorhombic $n p$ structure reported by Yanai et al., ${ }^{2}$ which was also found in multi-phased unsaturated samples (S22, Zn$1 \supset \mathrm{AB}_{0.3}, \mathbf{Z n}-1 \supset \mathrm{AB}_{0.5}$ and $\left.\mathbf{Z n}-1 \supset \mathrm{AB}_{0.9}\right){ }^{1}$

Table S7. Calculation of the ratio of $\mathbf{Z n - 1} \supset \mathrm{AB}^{\mathrm{vac}-\mathrm{xh}}$ at different vacuum treatment times.

\begin{tabular}{ccccccc}
\hline & & $\begin{array}{c}\text { Endotherm } \\
\text { energy/ } \\
\mathrm{AB} / \mathrm{mol}\end{array}$ & $\begin{array}{c}\text { mole } \\
\text { fraction } \\
\mathbf{Z n - 1} / \mathrm{mol}\end{array}$ & $\begin{array}{c}\text { mole } \\
\text { fraction } \\
\text { Jn-1 }\end{array}$ & $\begin{array}{c}\text { No. moles } \\
\text { in 1 g of } \\
\text { composite }\end{array}$ & $\begin{array}{c}\text { Enthalpy / } \\
\mathrm{kJ} \mathrm{mol}^{-1}\end{array}$ \\
\hline 1.00 & 1.01 & 28.4 & 0.50 & 0.50 & 0.00131311 & 21.6 \\
0.88 & 1.02 & 25 & 0.47 & 0.53 & 0.00135195 & 18.5 \\
0.52 & 1.04 & 12.9 & 0.34 & 0.66 & 0.00148358 & 8.7 \\
0.33 & 1.01 & 5.1 & 0.25 & 0.75 & 0.00156394 & 3.3 \\
1.27 & 1.02 & 34.2 & 0.56 & 0.44 & 0.00125297 & 27.3 \\
1.09 & 1.04 & 30.8 & 0.52 & 0.48 & 0.00128542 & 24.0 \\
\hline
\end{tabular}

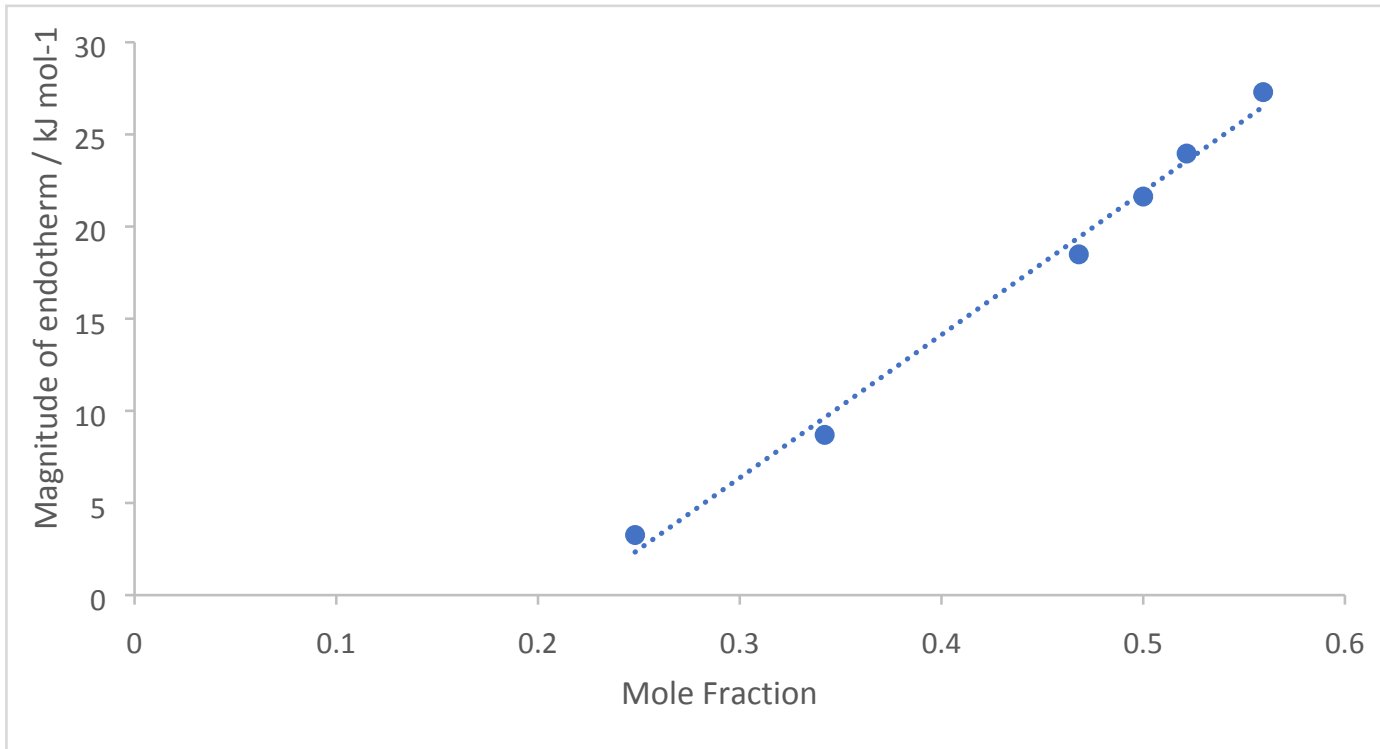


Figure S11. Relationship between moles of $A B$ in $\mathbf{Z n - 1} \supset A B_{x}$ to enthalpy of the reversible phase change.

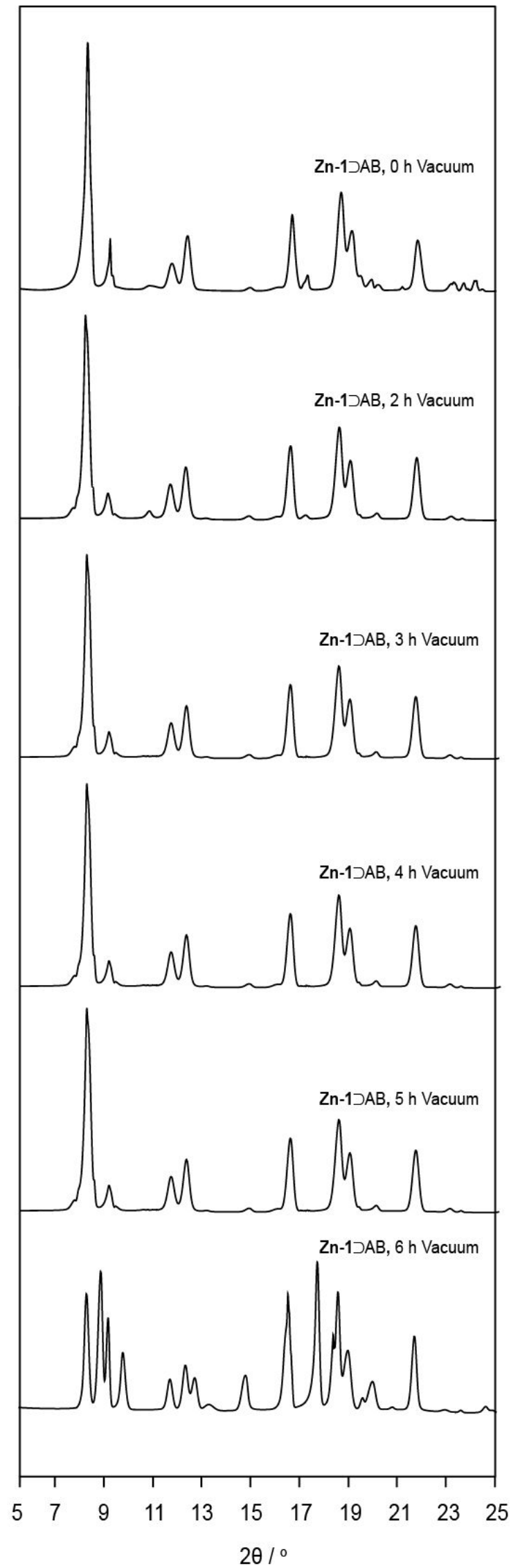


Figure S12. XRPD patterns of vacuum treated $\mathbf{Z n - 1} \supset \mathrm{AB}$ between $0-6 \mathrm{~h}$.

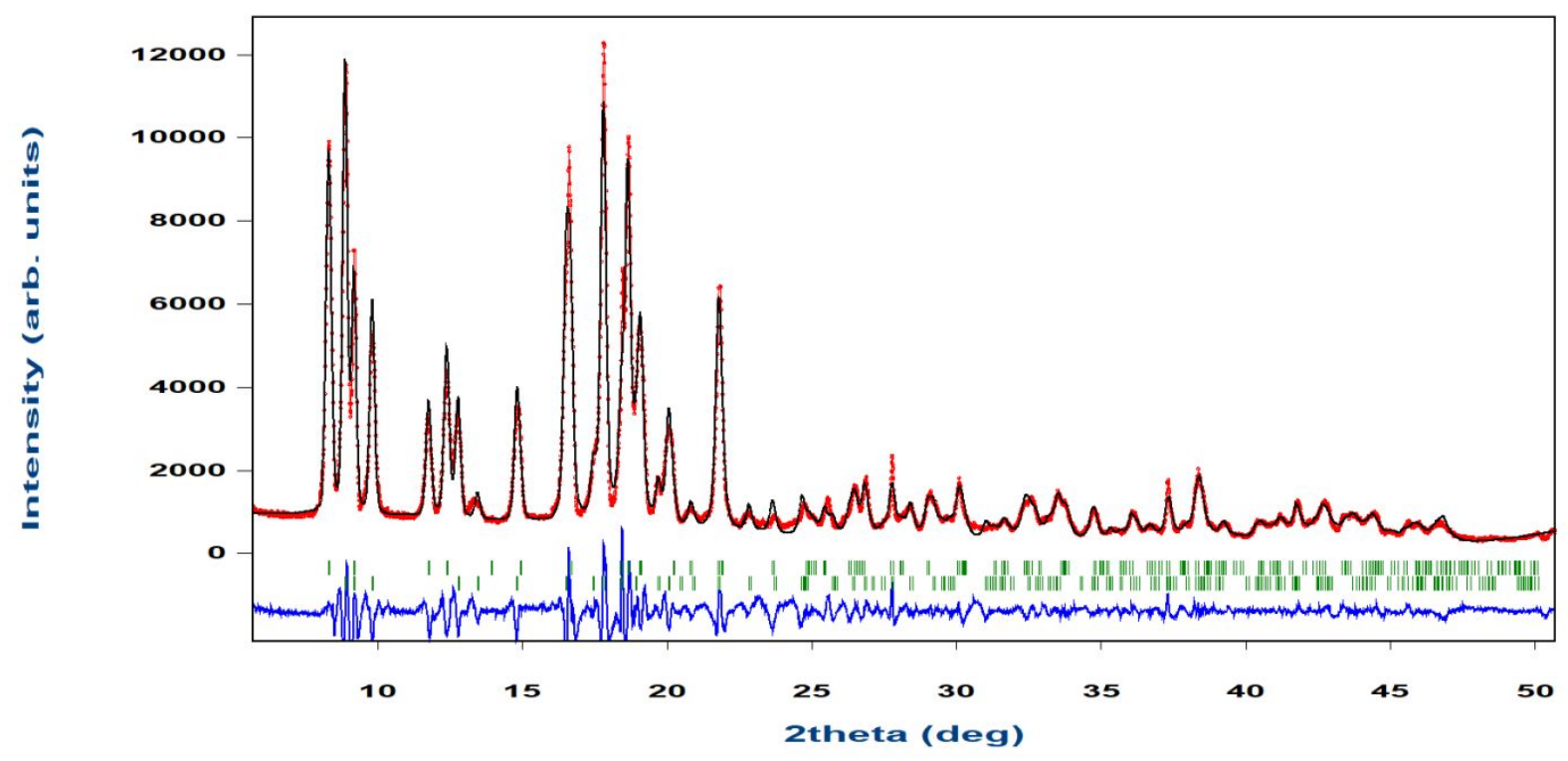

Figure S13. Le Bail fit of $\mathbf{Z n - 1} \supset \mathrm{AB}, 6 \mathrm{~h}$ vacuum. The profile was fit with two phases. The first phase was found to be orthorhombic $(\mathrm{Cmmm})$ with lattice parameters refined to be $a=11.950 \AA, b$ $=18.021 \AA, c=9.633 \AA, \alpha=\beta=\gamma=90^{\circ}$. The second phase was tetragonal $(I 4 / \mathrm{mcm})$ with lattice parameters refined to $a=b=15.037$ and $\mathrm{c}=19.280, \alpha=\beta=\gamma=90^{\circ}$. The reliability $(R)$ factor based on the powder profile $R p$ is $12.43 \%$. 

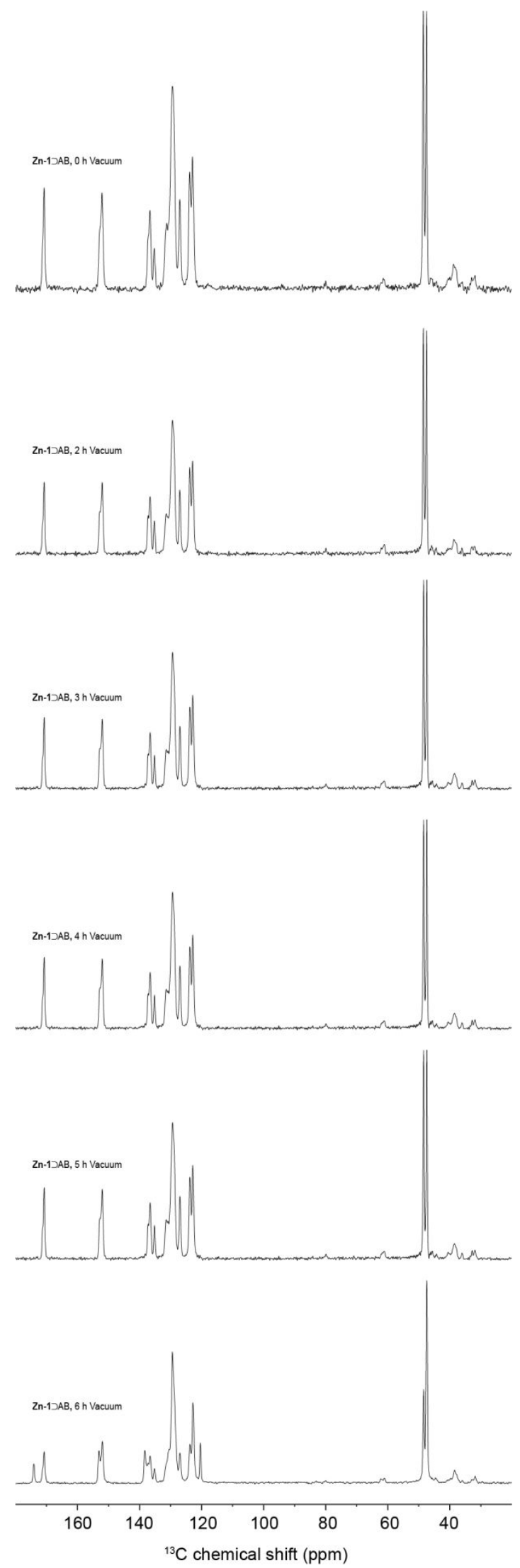

Figure S14. ${ }^{13} \mathrm{C}$ CPMAS NMR spectra of $\mathbf{Z n - 1} \supset \mathrm{AB}$ with different durations of vacuum treatment at $120{ }^{\circ} \mathrm{C}$. 
Table S8. Calculation for estimated pore-filling efficiency.

\begin{tabular}{ccc}
\hline MOF & AB molecules per pore & Pore filling efficiency $/ \%$ \\
\hline Zn-1 & 1.0 & 60 \\
Zn-1 & 1.3 & 78 \\
\hline
\end{tabular}

A Platon analysis of CCDC reference WAFKEU gives a pore size of $373 \AA^{3}$ (using a $1.2 \AA$ probe from Van der Waal surfaces). The molecular volume of trans-AB was estimated as $224 \AA^{3}$ based on a Gaussian DFT calculation for an isolated molecule. This gives a pore filling efficiency of $60 \%$ for 1 molecule per pore, and 78\% for 1.3 molecules per pore in $\mathbf{Z n - 1}$. However, we note that the framework contracts to the $n p$ form upon guest absorption, and so the efficiency is likely higher than these estimates.

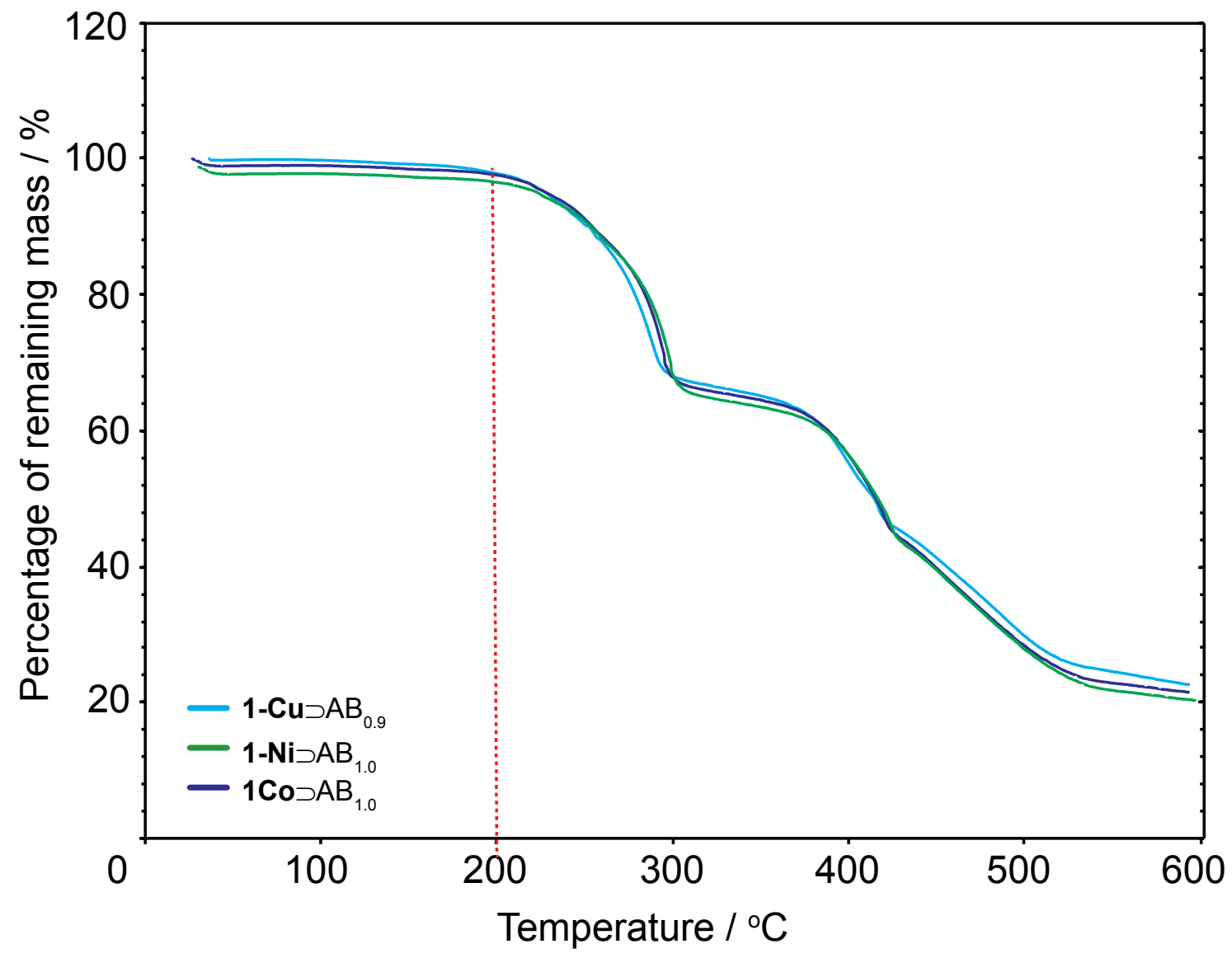

Figure S15. TGA of M-1 $\supset A_{1.0}$. The final masses are consistent with the percentage loading of trans-AB in each composite and expected degradation product. The percentage of remaining mass is stable between $25-225^{\circ} \mathrm{C}$ between $100-98.5 \%$ for each of the composite. 


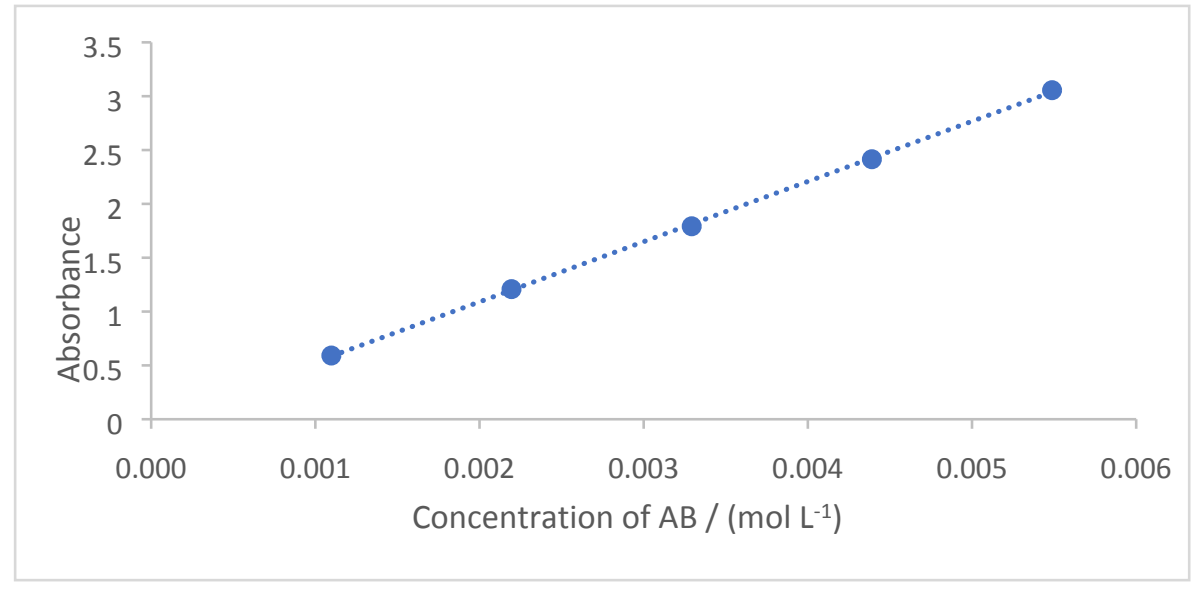

Figure S16. UV/Vis calibration curve for known concentrations of trans-AB in $\mathrm{MeOH}$.

UV-Vis data was collected on a Cary 60 UV/VIS spectrophotometer with a quartz cell $(3 \mathrm{~mL})$ within a 200-600 nm range. The peak absorbance at $441 \mathrm{~nm}$ was recorded for the calibration curve. 
Table S9. Calculated masses of trans-AB for $\mathbf{M}-1 \supset \mathrm{AB}_{1.0}$.

\begin{tabular}{|c|c|c|c|c|c|c|c|c|}
\hline Sample & $\begin{array}{l}\text { mass of 1- } \\
\mathbf{M} \supset \mathrm{AB} / \mathrm{g}\end{array}$ & $\begin{array}{l}\text { Absorbance } \\
\text { peak / nm }\end{array}$ & Absorbance & $\begin{array}{c}\text { mass of } A B / \\
g\end{array}$ & $\begin{array}{c}\text { mass of M-1 } \\
/ \mathrm{g}\end{array}$ & $\begin{array}{c}\text { moles of M-1 } \\
\qquad / \mathrm{mol}\end{array}$ & moles of $\mathrm{AB} / \mathrm{mol}$ & $\begin{array}{c}\text { Ratio (M- } \\
\text { 1:AB) }\end{array}$ \\
\hline $\mathbf{1 - C u} \supset \mathrm{AB}_{0.9}$ & 0.0569 & 440.9932 & 0.7986 & 0.0131 & 0.0438 & 0.00007569 & 0.00007165 & $1: 0.947$ \\
\hline $\mathbf{1 - N i \supset \mathrm { AB } _ { 1 . 0 }}$ & 0.0545 & 440.9892 & 0.8013 & 0.0131 & 0.0413 & 0.00007147 & 0.00007189 & $1: 0.994$ \\
\hline
\end{tabular}


a)

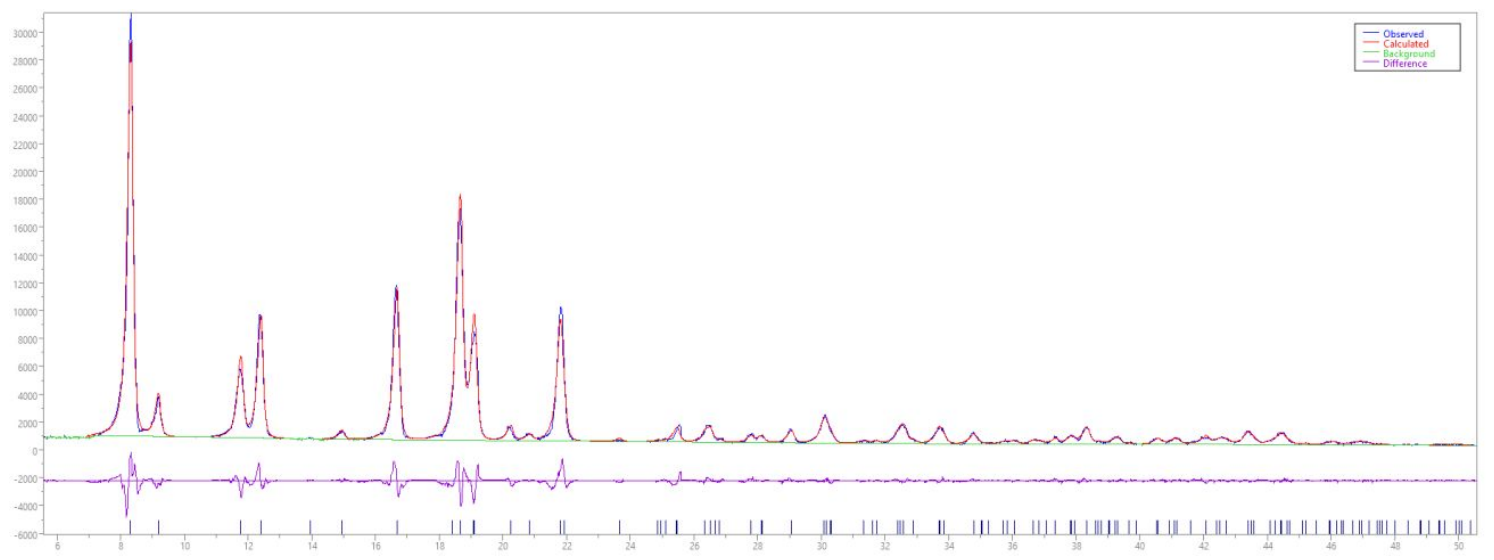

b)

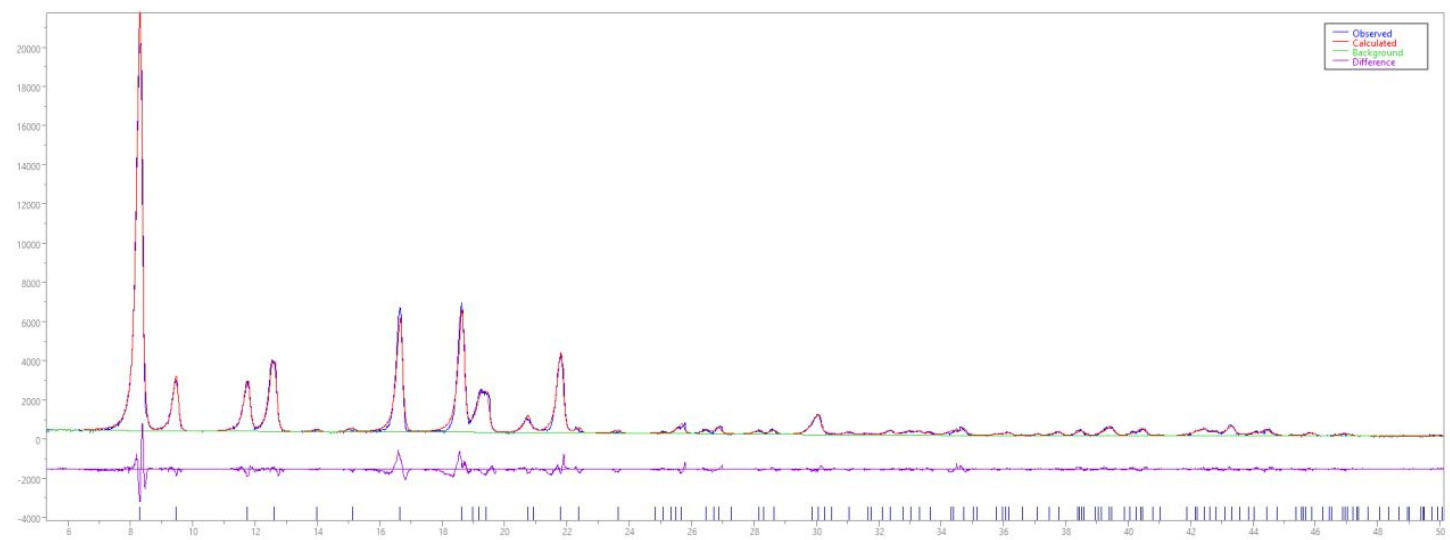

c)

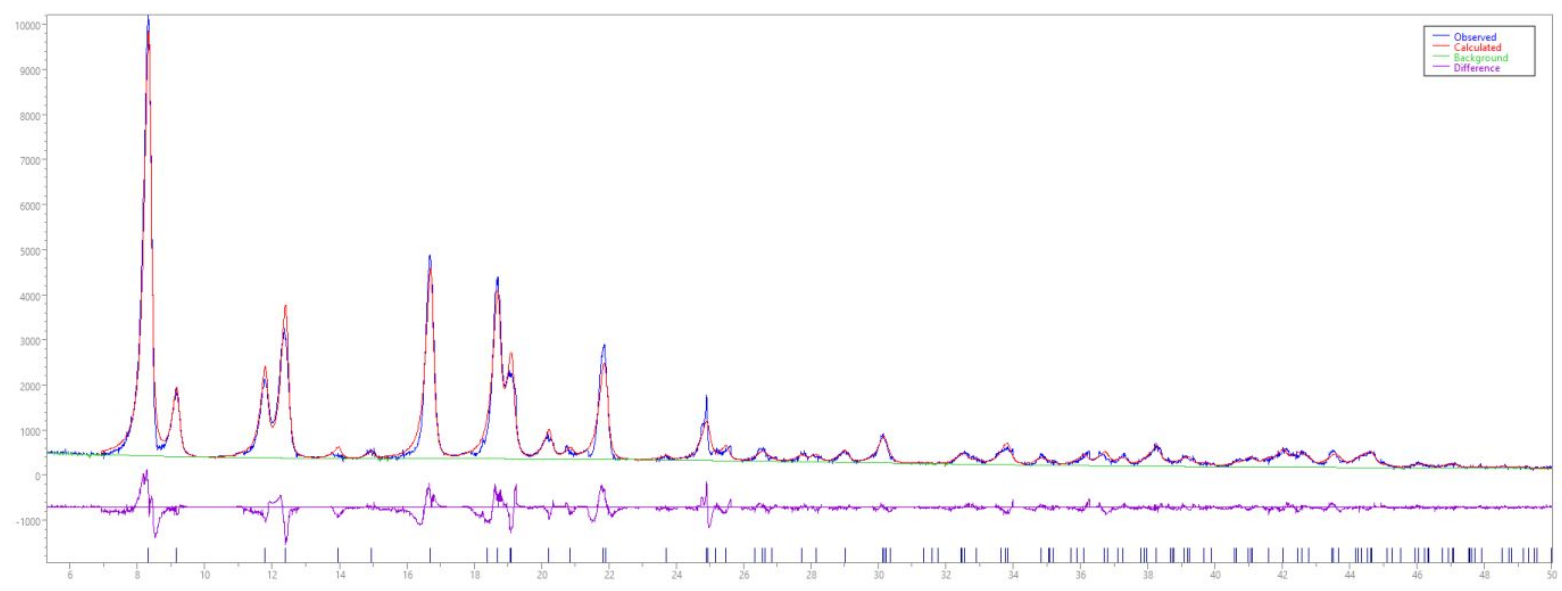

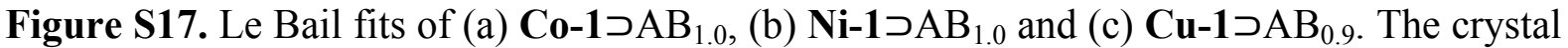
system for each phase was found to be tetragonal with space group $I 4 / \mathrm{mcm}$. The lattice parameters were refined to be: (a) $a=b=15.051$ (3) $\AA, c=19.284(6) \AA, \alpha=\beta=\gamma=90^{\circ}, \mathrm{V}=$ 4366.1(9) $\AA^{3}$; (b) $a=b=15.231$ (2) $\AA, c=18.902(4) \AA, \alpha=\beta=\gamma=90^{\circ}, \mathrm{V}=4386.5(6) \AA^{3}$; (c) $a=b=15.311(4) \AA, c=19.32(4) \AA, \alpha=\beta=\gamma=90^{\circ}, \mathrm{V}=4535.2(4) \AA^{3}$. The reliability (R) factors based on the powder profile $R p$ were (a) $5.55 \%$, (b) $6.55 \%$ and (c) $8.81 \%$. 
a)

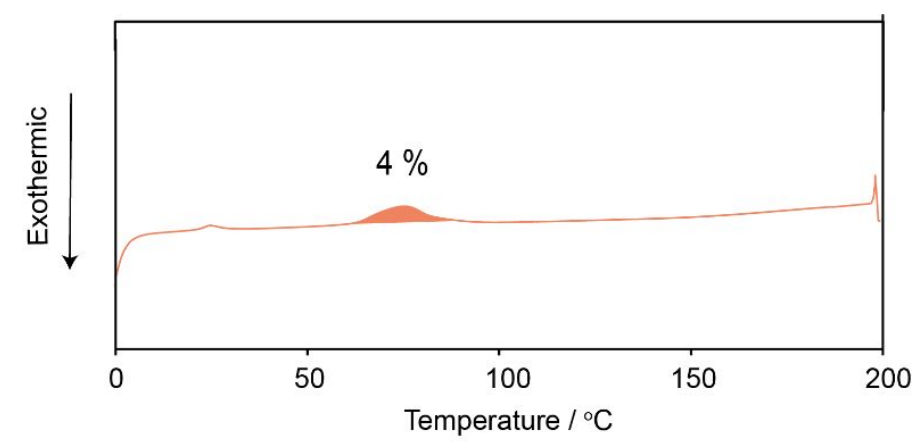

b)

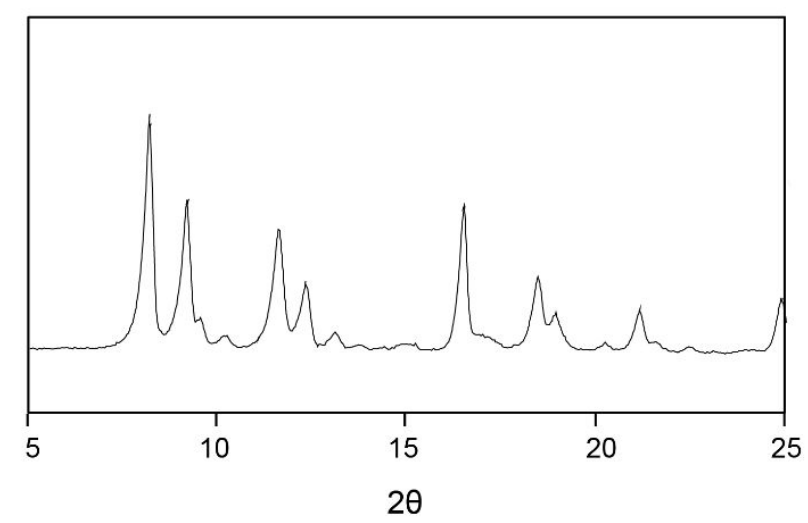

c)

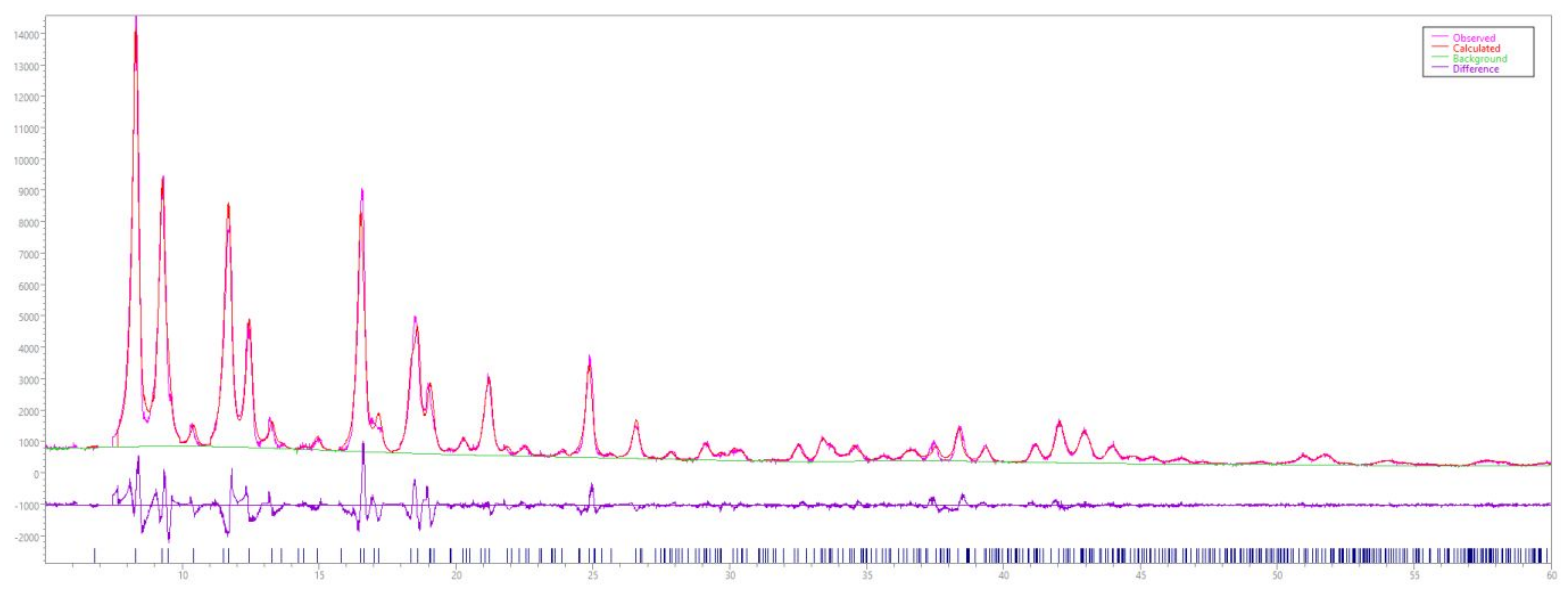

Figure S18. (a) DSC trace of the first heating branch, and (b) XRPD pattern and (c) Le Bail fit of $\mathbf{C u}-1 \supset \mathrm{AB}^{\text {vac-Oh }}$ after 3 hours of vacuum treated at $120^{\circ} \mathrm{C}$. The crystal system was found to be orthorhombic. The lattice parameters were refined to be $a=12.895(4) \AA, b=18.591(8), c$ $=9.674$ (5) $\AA, \alpha=\beta=\gamma=90^{\circ}, \mathrm{V}=2288.5(4) \AA^{3}$. The space group was found to be Pmmm. General formula $\mathrm{Cu}_{2} \mathrm{C}_{22} \mathrm{H}_{28} \mathrm{~N}_{2} \mathrm{O}_{8}$. The reliability (R) factor based on the powder profile $R p$ was $7.72 \%$. A phase change endotherm is not observed and the XRPD pattern is not consistent with any of the known phases. 
a)

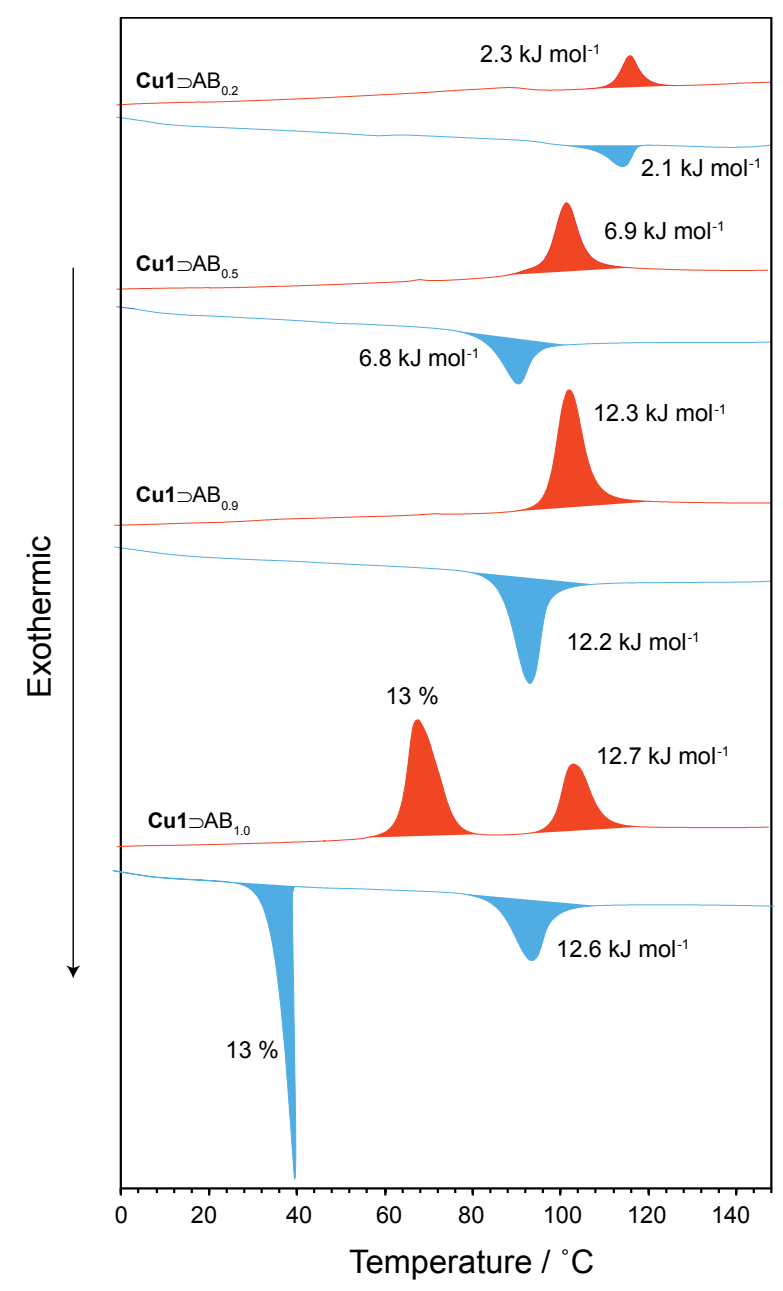

b)

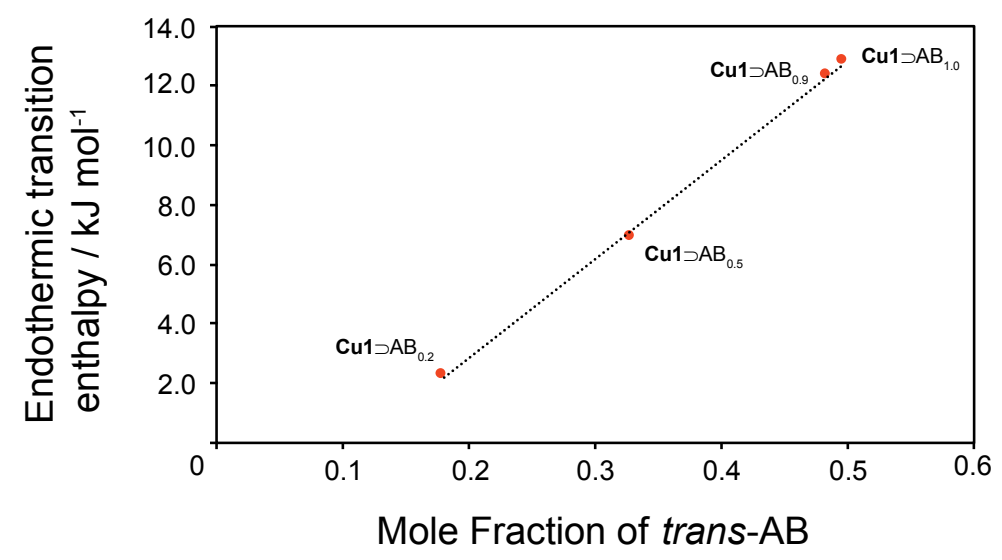

Figure S19. (a) DSC data for $\mathbf{C u}-1 \supset \mathrm{AB}_{\mathrm{x}}$ between $0-150{ }^{\circ} \mathrm{C}$ at a scan rate of $20 \mathrm{~K} \mathrm{~min}^{-1}$. (b) Plot of the endothermic transition enthalpy for $\mathbf{C u}-1 \supset \mathrm{AB}_{\mathrm{x}}$ as a function of mole fraction of trans-AB in the structure. 

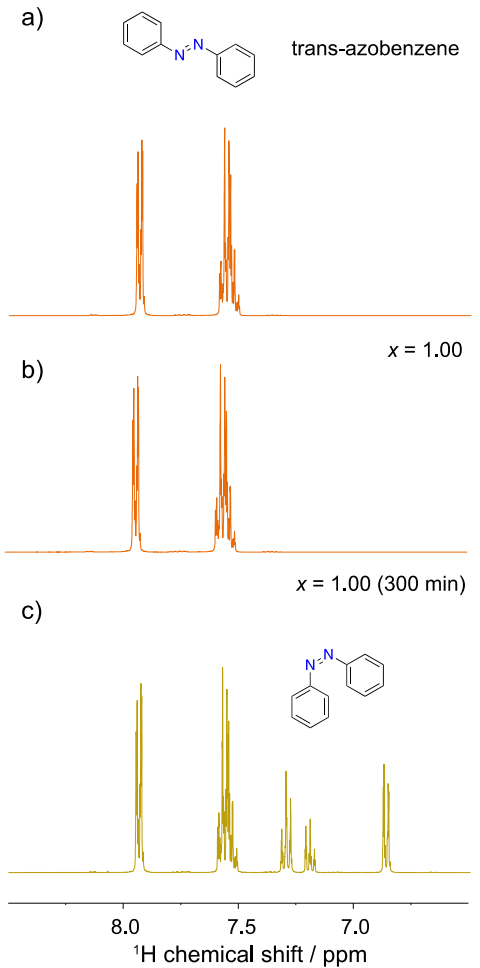

Figure S20. ${ }^{1} \mathrm{H}$ NMR spectra of a) trans-AB, b) extract from $\mathbf{Z n - 1} \supset \mathrm{AB}_{1.0}$ showing characteristic trans- $\mathrm{AB}$ resonances, c) extract from irradiated $\mathbf{Z n - 1} \supset \mathrm{AB}_{1.0}$ showing both trans- $\mathrm{AB}$ and $c i s-\mathrm{AB}$ resonances. Measured in $\mathrm{MeOH}-d_{4}$.

Table S10. Relationship between unit cell contraction from M-1 to M-1つAB $\mathrm{AB}_{1.0}$ and the PSS.

\begin{tabular}{ccccc}
\hline M & $\begin{array}{c}\text { M-1 unit cell } \\
\text { volume / A }\end{array}$ & $\begin{array}{c}\text { M-1 } \text { PAB unit } \\
\text { cell volume/ }\end{array}$ & $\begin{array}{c}\text { Contraction of } \\
\text { unit cell \% }\end{array}$ & PSS \\
\hline $\mathrm{Zn}$ & 1164.1 & 4355.6 & 6.5 & 40 \\
$\mathrm{Co}$ & 1164.1 & 4366.1 & 6.2 & 39 \\
$\mathrm{Ni}$ & 1143.9 & 4386.5 & 4.1 & 33 \\
$\mathrm{Cu}$ & 1152.9 & 4535.6 & 1.6 & 15 \\
\hline
\end{tabular}




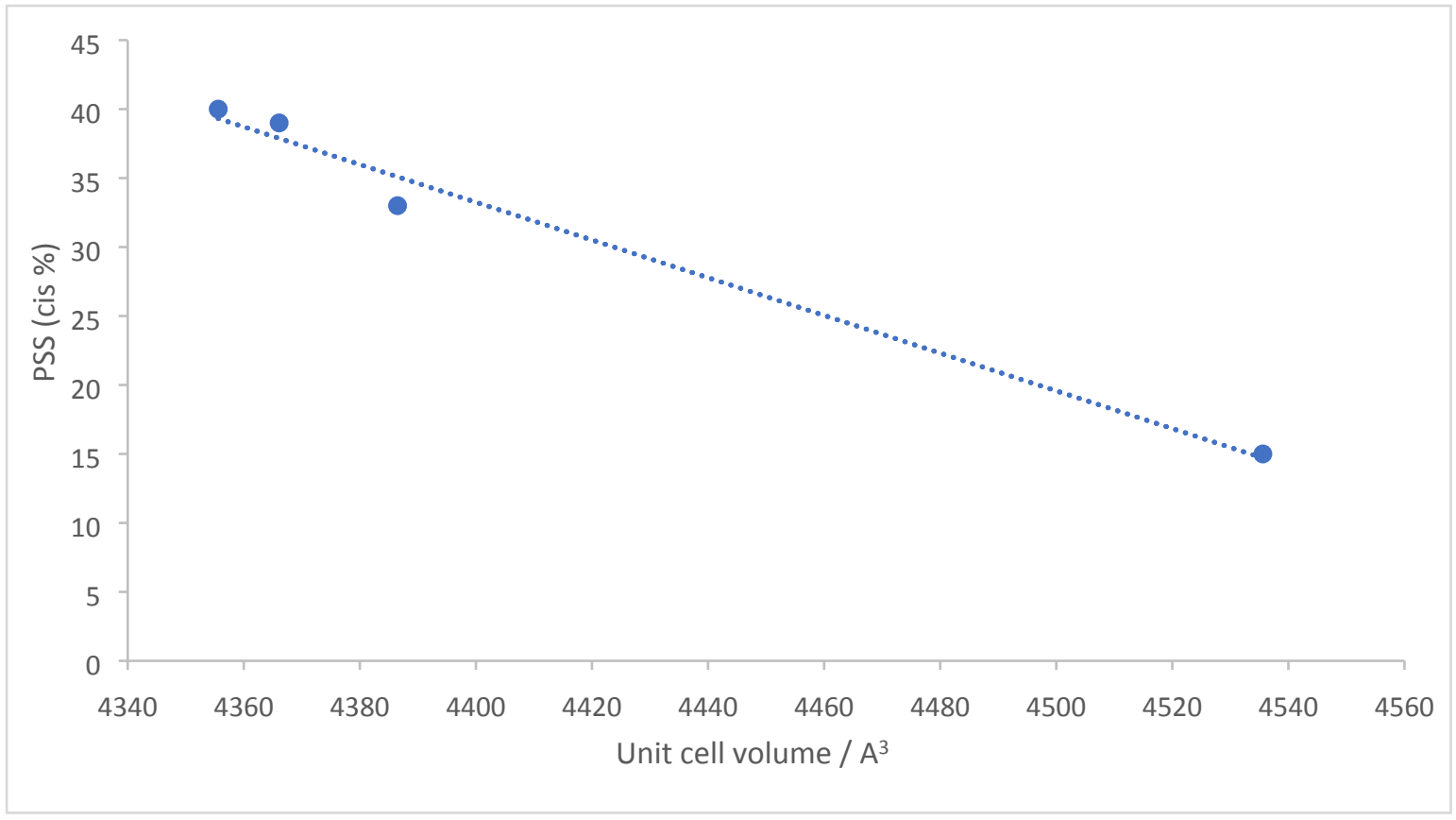

Figure S21. Relationship between unit cell volume of $\mathbf{M}-1 \supset \mathrm{AB}_{1.0}$ and the photostationary state (PSS) of AB when irradiated with $365 \mathrm{~nm}$ light.

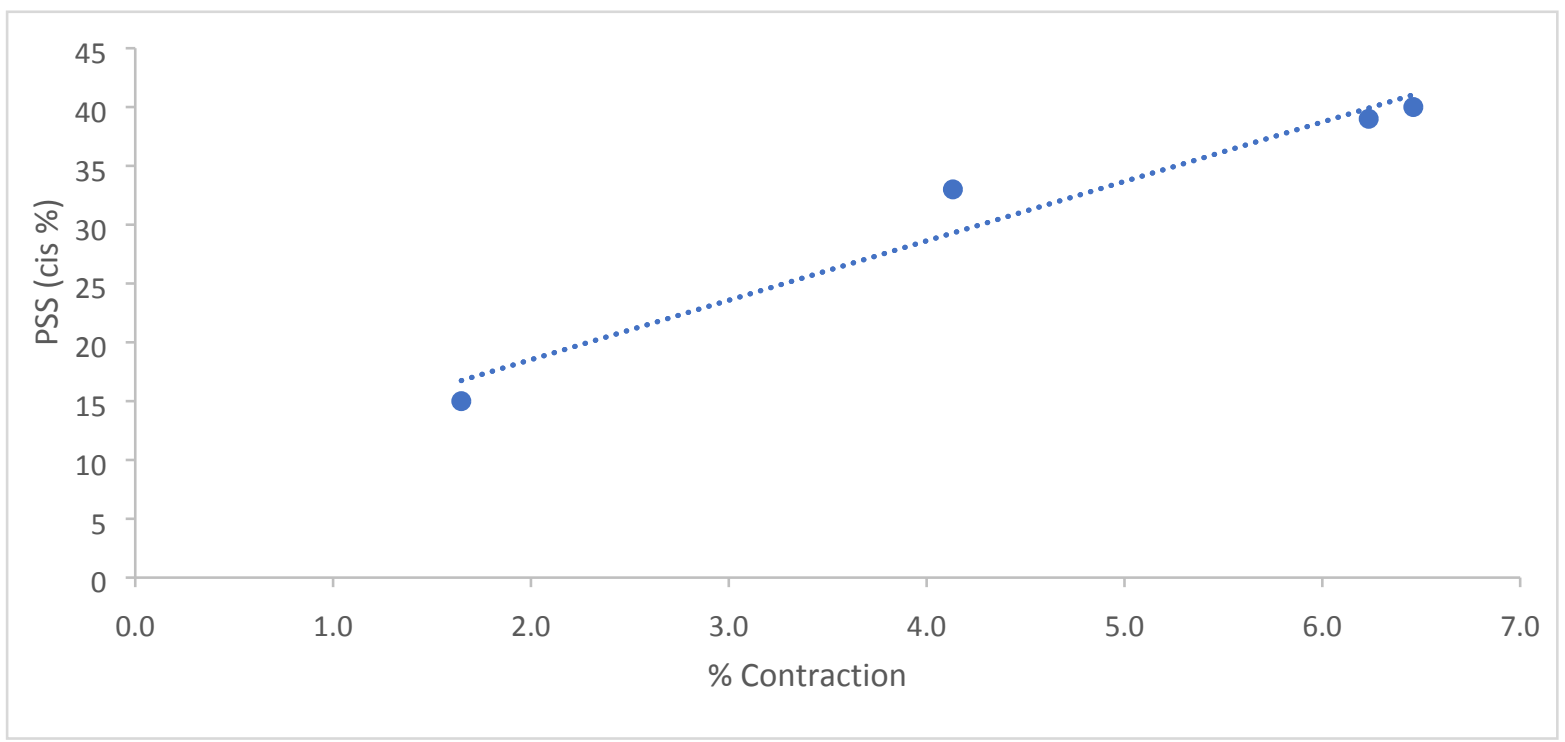

Figure S22. Relationship between percentage contraction of $\mathbf{M}-1 \supset \mathrm{AB}_{1.0}$ from $\mathbf{M}-\mathbf{1}$ and the photostationary state (PSS) of AB when irradiated with $365 \mathrm{~nm}$ light. 
a)

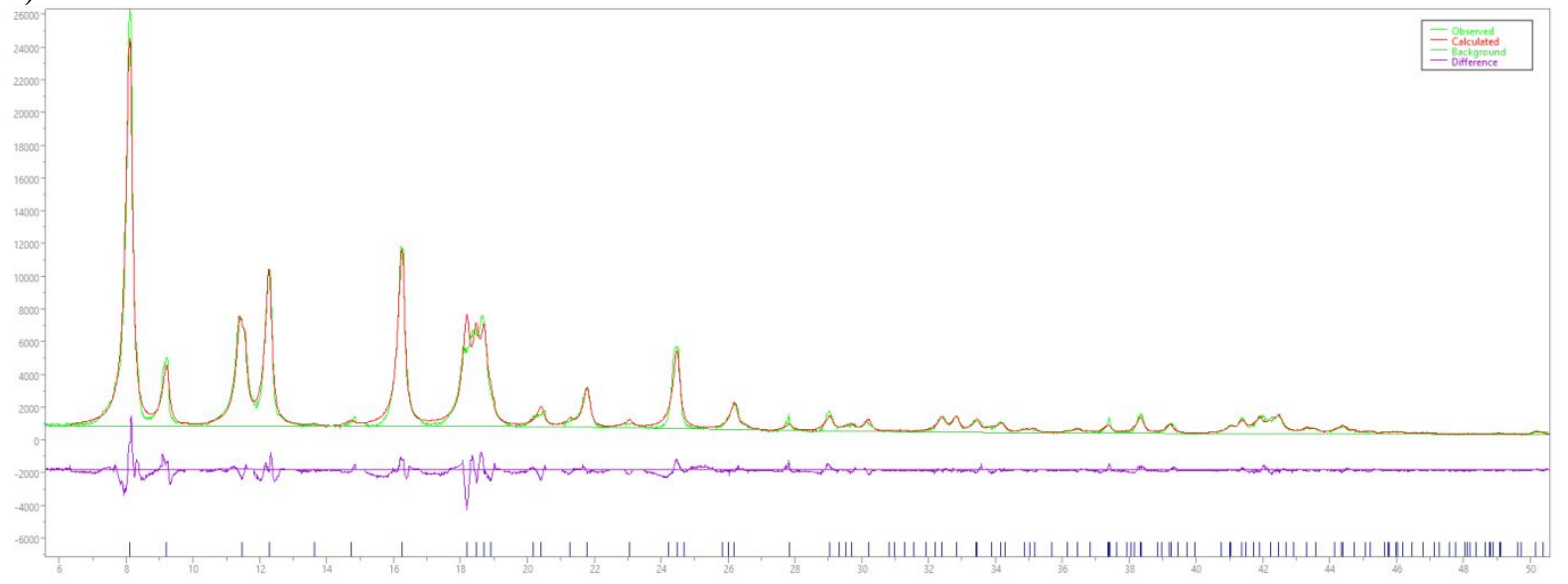

b)

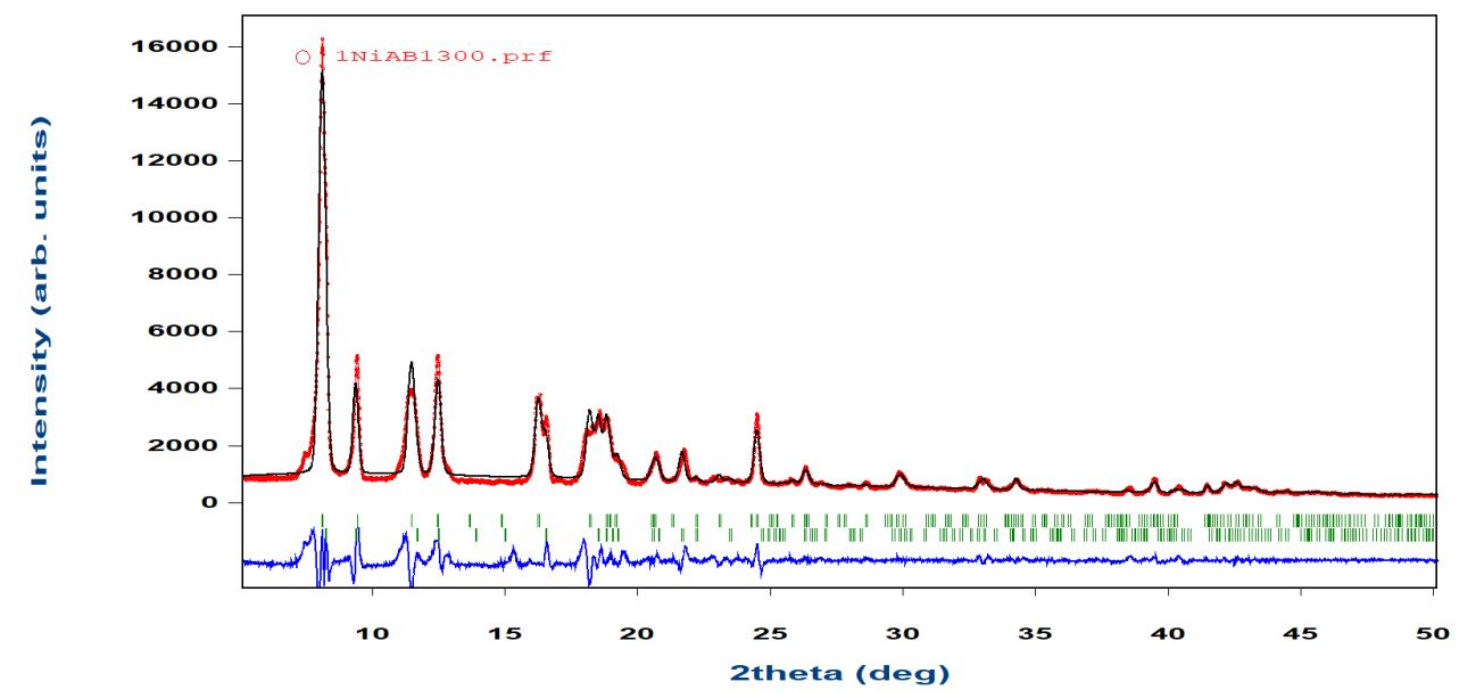

c)

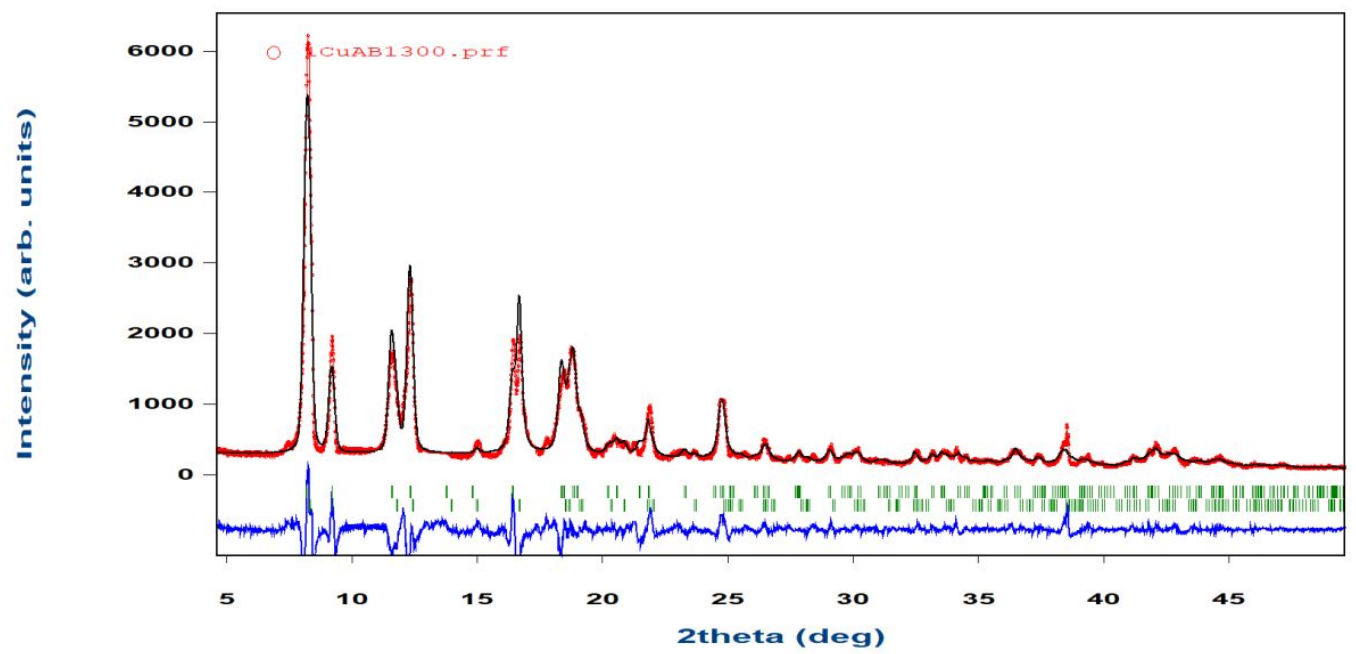

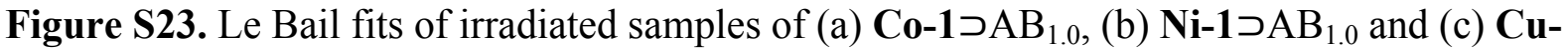
$1 \supset \mathrm{AB}_{0.9}$. For (a), the crystal system was found to be tetragonal. For (b) and (c) two phases 
were observed: the phase first was the irradiated phase with a tetragonal crystal system in the spacegroup $I 4 / \mathrm{mcm}$, and the second phase was the same as observed in the unirradiated sample. The lattice parameters for the irradiated phases were refined to be (a) $a=b=15.411$ (2) $\AA, c=$ 19.281(4) $\AA, \alpha=\beta=\gamma=90^{\circ}, \mathrm{V}=4572.4(6) \AA^{3}$; (b) $a=b=15.472(4) \AA, c=18.920(2) \AA$, $\alpha=\beta=\gamma=90^{\circ}, \mathrm{V}=4528.8(8) \AA^{3}$; (c) $a=b=15.401(3) \AA, c=19.360$ (3) $\AA, \alpha=\beta=\gamma=90^{\circ}$, $\mathrm{V}=4590.5(9) \AA^{3}$. The reliability (R) factors based on the powder profile $R p$ were (a) $7.14 \%$, (b) $9.74 \%$ and (c) $10.22 \%$.

Table S11. Crystallographic information for irradiated $\mathbf{M}-1 \supset \mathrm{AB}_{1.0}$.

\begin{tabular}{lcccc}
\hline & Space group & $a=b$ & $c$ & $\mathrm{~V}$ \\
& & $/ \AA$ & $/ \AA$ & $/ \AA^{3}$ \\
\hline $\mathbf{Z n - 1} \supset \mathrm{AB}_{1.0}$ & $I 4 / \mathrm{mcm}$ & 15.412 & 19.31 & 4587.4 \\
$\mathbf{C o - 1} \supset \mathrm{AB}_{1.0}$ & $I 4 / \mathrm{mcm}$ & 15.411 & 19.35 & 4572.5 \\
$\mathbf{N i - 1} \supset \mathrm{AB}_{1.0}$ & $I 4 / \mathrm{mcm}$ & 15.472 & 18.92 & 4528.8 \\
$\mathbf{C u}-1 \supset \mathrm{AB}_{0.9}$ & $I 4 / \mathrm{mcm}$ & 15.401 & 19.36 & 4590.5 \\
\hline
\end{tabular}

Table S12. Percentage expansion of reduced unit cell parameters of $M-1 \supset A_{1.0}$ to the irradiated form.

\begin{tabular}{cccc}
\hline $\begin{array}{c}\text { M-1 } \supset \mathrm{AB}_{1.0}(n p) \text { expansion to } \\
\text { irradiated M-1 } \supset \mathrm{AB}_{1.0}(\mathrm{M}=)\end{array}$ & $\begin{array}{c}\text { Expansion of } \\
\text { reduced } a=b \\
\text { cell length } / \%\end{array}$ & $\begin{array}{c}\text { Expansion of } \\
\text { reduced } c \text { cell } \\
\text { length } / \%\end{array}$ & $\begin{array}{c}\text { Expansion of } \\
\text { reduced unit cell } \\
\text { volume } / \%\end{array}$ \\
\hline $\mathbf{Z n - 1} \supset \mathrm{AB}_{1.0}$ & 2.52 & 0.19 & 5.32 \\
$\mathbf{C o - 1} \supset \mathrm{AB}_{1.0}$ & 2.40 & -0.13 & 4.72 \\
$\mathbf{N i - 1} \supset \mathrm{AB}_{1.0}$ & 1.56 & 0.11 & 3.24 \\
$\mathbf{C u}-1 \supset \mathrm{AB}_{1.0}$ & 0.59 & 0.03 & 1.22 \\
\hline
\end{tabular}




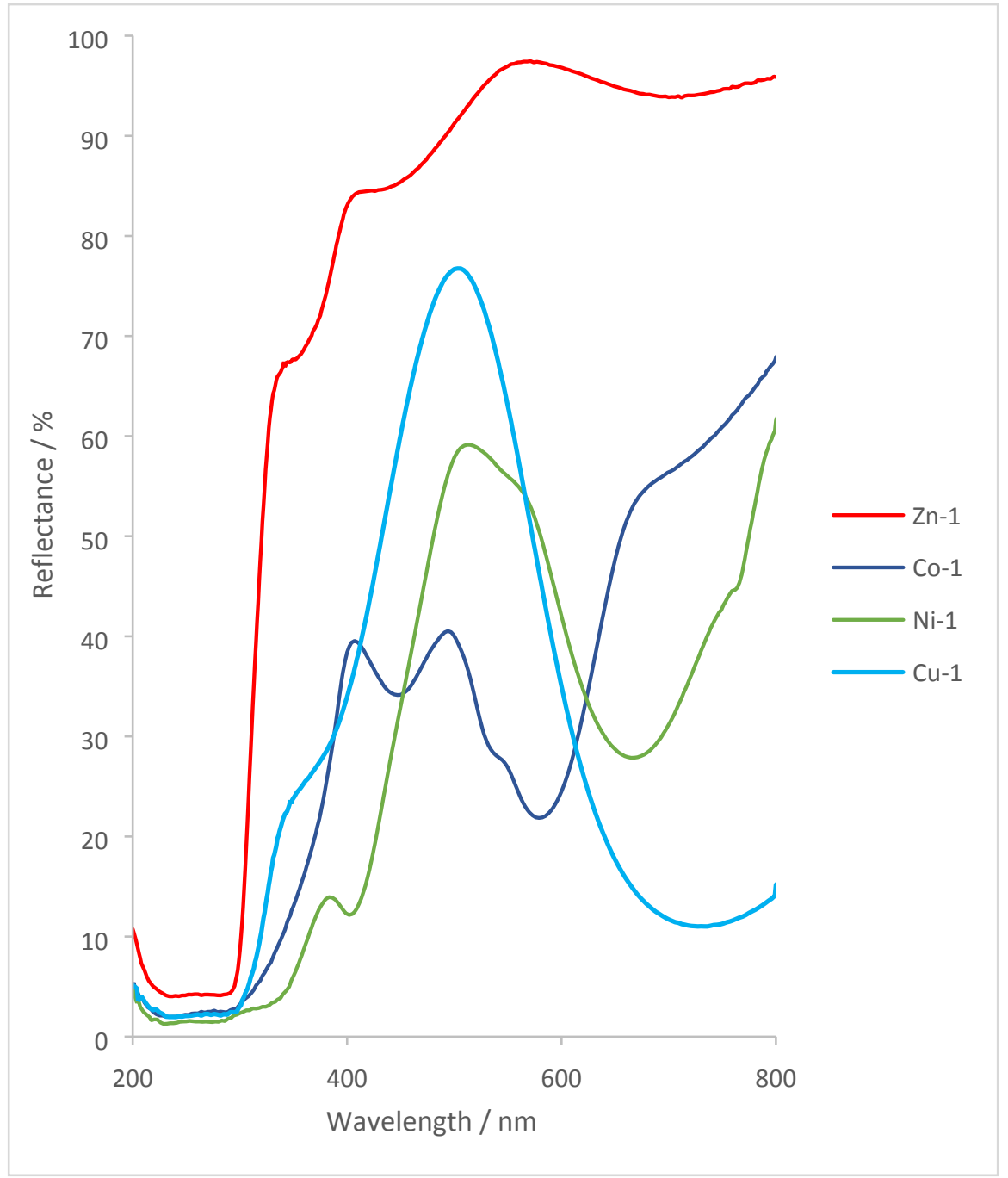

Figure S24. UV-vis percentage reflectance spectra for M-1. 


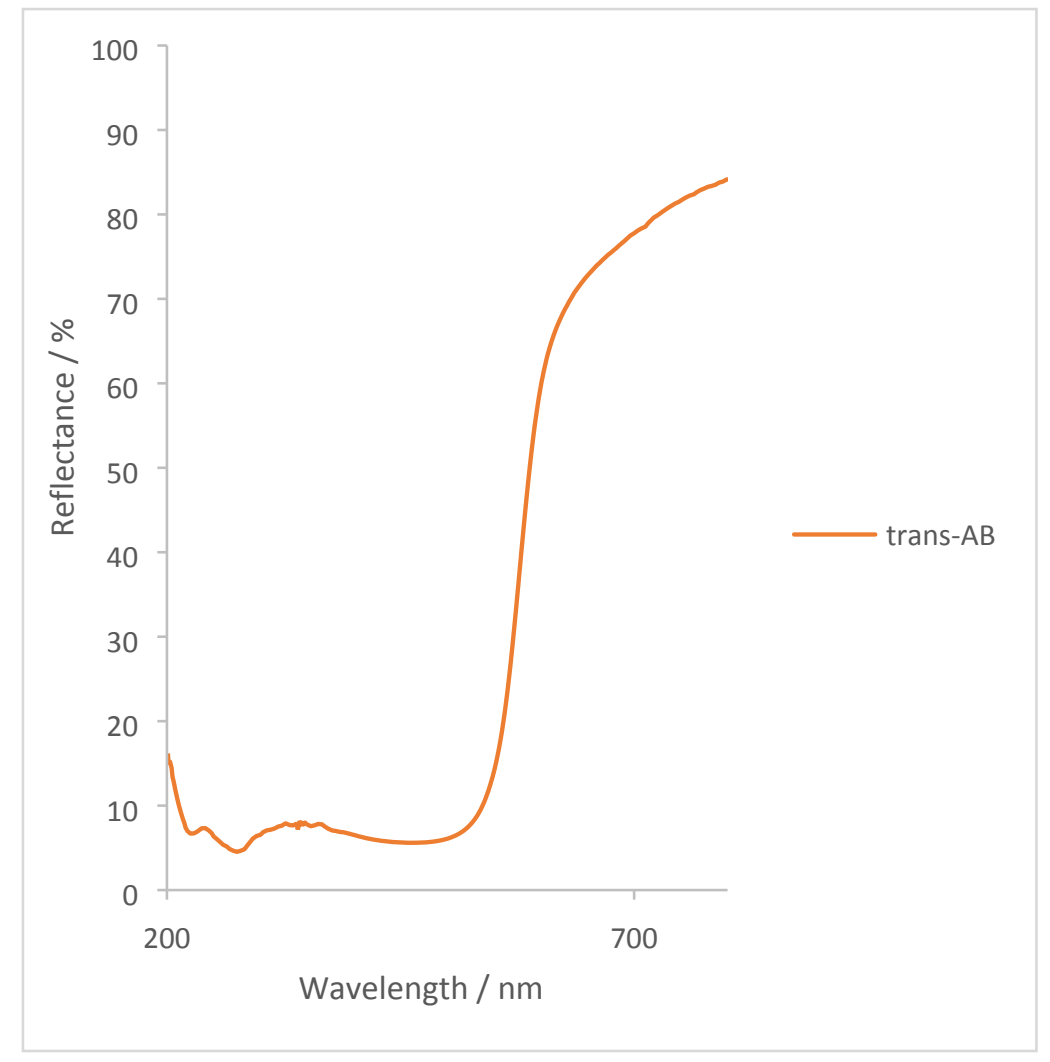

Figure S25. UV-vis percentage reflectance spectrum for trans-AB.

Table S13. Data for the first heating branch for irradiated Co-1 $\supset \mathrm{AB}_{1.0} .0-200{ }^{\circ} \mathrm{C}$ at $20{ }^{\circ} \mathrm{C}$ $\mathrm{min}^{-1}$.

\begin{tabular}{ccccccc}
\hline $\begin{array}{c}\text { Time/ } \\
\text { minutes }\end{array}$ & $\begin{array}{c}\text { Endotherm } \\
\text { onset }(1) \\
/{ }^{\circ} \mathrm{C}\end{array}$ & $\begin{array}{c}\text { Endotherm } \\
\text { peak(1) } \\
/{ }^{\circ} \mathrm{C}\end{array}$ & $\begin{array}{c}\text { Endotherm } \\
\text { energy }(1) \\
/ \mathrm{Jg}-1\end{array}$ & $\begin{array}{c}\text { Exotherm } \\
\text { onset }(2) \\
/{ }^{\circ} \mathrm{C}\end{array}$ & $\begin{array}{c}\text { Exotherm } \\
\text { peak (2) / } \\
{ }^{\circ} \mathrm{C}\end{array}$ & $\begin{array}{c}\text { Exotherm } \\
\text { energy (2) } \\
/ \mathrm{J} \mathrm{g}^{-1}\end{array}$ \\
\hline 0 & 152.5 & 159.4 & 28.9 & 0.0 & 0.0 & 0.0 \\
30 & 152.3 & 159.9 & 20.0 & 0.0 & 0.0 & 0.0 \\
60 & 150.3 & 158.7 & 14.1 & 166.6 & 174.2 & -2.9 \\
90 & 149.5 & 157.9 & 10.9 & 168.3 & 176.8 & -3.5 \\
120 & 149.8 & 157.4 & 9.1 & 172.4 & 178.9 & -3.9 \\
180 & 150.1 & 156.5 & 5.7 & 175.9 & 180.9 & -3.6 \\
240 & 149.8 & 155.8 & 3.8 & 177.6 & 182.8 & -3.5 \\
300 & 149.9 & 155.4 & 3.6 & 178.0 & 182.3 & -3.5 \\
360 & 149.9 & 155.3 & 3.6 & 178.0 & 182.3 & -3.5 \\
\hline
\end{tabular}


Table S14. Data for the first cooling branch for irradiated Co-1 $\supset \mathrm{AB}_{1.0} .0-200{ }^{\circ} \mathrm{C}$ at $20{ }^{\circ} \mathrm{C}$ $\min ^{-1}$.

\begin{tabular}{ccccccc}
\hline $\begin{array}{c}\text { Time / } \\
\text { minutes }\end{array}$ & $\begin{array}{c}\text { Exotherm } \\
\text { onset (1)/ }\end{array}$ & $\begin{array}{c}\text { Exotherm } \\
\text { peak (1)/ } \\
{ }^{\circ} \mathrm{C}\end{array}$ & $\begin{array}{c}\text { Exotherm } \\
\text { energy (1) } \\
{ }^{\circ} \mathrm{C}\end{array}$ & $\begin{array}{c}\text { Exotherm } \\
\text { onset }(2) / \\
\mathrm{Jg}^{-1}\end{array}$ & $\begin{array}{c}\text { Exotherm } \\
\text { peak (2) } / \\
{ }^{\circ} \mathrm{C}\end{array}$ & $\begin{array}{c}\text { Exotherm } \\
\text { energy (2) } \\
/ \mathrm{J} \mathrm{g}^{-1}\end{array}$ \\
\hline 0 & 153.5 & 147.7 & -24.3 & 121.9 & 115.9 & -5.0 \\
30 & 154.3 & 147.7 & -24.6 & 123.5 & 117.9 & -4.7 \\
60 & 153.4 & 146.4 & -24.2 & 122.1 & 114.6 & -4.7 \\
90 & 153.4 & 146.1 & -24.2 & 121.5 & 112.6 & -4.8 \\
120 & 153.3 & 146.4 & -24.3 & 121.4 & 113.2 & -4.8 \\
180 & 154.3 & 147.7 & -24.5 & 123.4 & 117.6 & -4.5 \\
240 & 152.8 & 146.1 & -24.1 & 121.9 & 111.9 & -4.7 \\
300 & 152.6 & 146.0 & -24.3 & 121.8 & 111.7 & -4.7 \\
\hline
\end{tabular}

Table S15. Data for the first heating branch for irradiated Ni-1 د $\mathrm{AB}_{1.0 .} .0-200{ }^{\circ} \mathrm{C}$ at $20{ }^{\circ} \mathrm{C}$ $\min ^{-1}$.

\begin{tabular}{ccccccc} 
min $^{-1}$. & $\begin{array}{c}\text { Endotherm } \\
\text { onset (1) } \\
\text { minutes }\end{array}$ & $\begin{array}{c}\text { Endotherm } \\
\text { Peak (1) }\end{array}$ & $\begin{array}{c}\text { Endotherm } \\
\text { energy (1) } \\
/{ }^{\circ} \mathrm{Cg}\end{array}$ & $\begin{array}{c}\text { Exotherm } \\
\text { onset (2) } \\
/{ }^{\circ} \mathrm{C}\end{array}$ & $\begin{array}{c}\text { Exotherm } \\
\text { peak (2) / } \\
{ }^{\circ} \mathrm{C}\end{array}$ & $\begin{array}{c}\text { Exotherm } \\
\text { energy (2) } \\
/ \mathrm{Jg}^{-1}\end{array}$ \\
\hline 0 & 133.1 & 138.5 & 28.5 & 0.0 & 0.0 & 0.0 \\
60 & 132.8 & 136.9 & 18.5 & 149.3 & 145.2 & -1.2 \\
120 & 132.4 & 137.2 & 16.5 & 152.7 & 147.8 & -1.3 \\
180 & 132.4 & 137.0 & 13.2 & 155.5 & 149.8 & -1.8 \\
240 & 131.4 & 135.9 & 10.9 & 157.1 & 151.1 & -1.9 \\
300 & 131.7 & 136.0 & 8.8 & 158.4 & 151.8 & -2.0 \\
360 & 131.7 & 136.1 & 8.7 & 158.5 & 152.0 & -2.0 \\
\hline
\end{tabular}


Table S16. Data for the first cooling branch for irradiated Ni-1つAB $\mathrm{AB}_{1.0} .0-200{ }^{\circ} \mathrm{C}$ at $20{ }^{\circ} \mathrm{C}$ $\min ^{-1}$.

\begin{tabular}{cccc}
\hline Time / minutes & $\begin{array}{c}\text { Exotherm onset (1) } \\
/{ }^{\circ} \mathrm{C}\end{array}$ & $\begin{array}{c}\text { Exotherm peak (1) } \\
/{ }^{\circ} \mathrm{C}\end{array}$ & $\begin{array}{c}\text { Exotherm energy (1)/ } \\
\mathrm{Jg}^{-1}\end{array}$ \\
\hline 0 & 133.8 & 129.5 & -28.2 \\
60 & 134.0 & 130.6 & -29.7 \\
120 & 133.8 & 130.6 & -29.1 \\
180 & 134.0 & 130.6 & -29.4 \\
240 & 133.0 & 129.6 & -29.7 \\
300 & 133.4 & 129.9 & -29.5 \\
360 & 133.3 & 129.8 & -29.5 \\
\hline
\end{tabular}

Table S17. Data for the first heating branch for irradiated $\mathbf{C u}-1 \supset \mathrm{AB}_{0.9} .0-200{ }^{\circ} \mathrm{C}$ at $20{ }^{\circ} \mathrm{C}$ $\min ^{-1}$

\begin{tabular}{|c|c|c|c|c|c|c|}
\hline Time/ minutes & $\begin{array}{c}\text { Endotherm } \\
\text { onset (1) } \\
\quad /{ }^{\circ} \mathrm{C}\end{array}$ & $\begin{array}{c}\text { Endotherm } \\
\text { Peak (1) } \\
\quad /{ }^{\circ} \mathrm{C}\end{array}$ & $\begin{array}{c}\text { Endotherm } \\
\text { energy (1) / } \\
\mathrm{Jg}^{-1}\end{array}$ & $\begin{array}{c}\text { cis-trans } \\
\text { exotherm } \\
\text { onset (2) } \\
/{ }^{\circ} \mathrm{C}\end{array}$ & $\begin{array}{l}\text { cis-trans } \\
\text { exotherm } \\
\operatorname{peak}(2) / \\
{ }^{\circ} \mathrm{C}\end{array}$ & $\begin{array}{c}\text { cis-trans } \\
\text { exotherm } \\
\text { energy (2) } \\
\mathrm{Jg}^{-1}\end{array}$ \\
\hline 0 & 98.6 & 103.7 & 16.5 & 0 & 0 & 0 \\
\hline 60 & 98.9 & 102.7 & 16.4 & 149.6 & 158.8 & 3.4 \\
\hline 120 & 98.7 & 102.4 & 16.1 & 153.1 & 162.2 & 5.6 \\
\hline 180 & 98.2 & 101.7 & 16.0 & 156.3 & 164.2 & 6.5 \\
\hline 240 & 97.5 & 101.6 & 15.9 & 157.9 & 164.8 & 7.2 \\
\hline 300 & 97.3 & 101.7 & 15.7 & 160.1 & 166.1 & 8.9 \\
\hline 360 & 97.2 & 101.6 & 15.5 & 161.6 & 167.4 & 9.9 \\
\hline 420 & 97.2 & 101.6 & 15.5 & 162.0 & 167.7 & 10.4 \\
\hline 480 & 97.2 & 101.6 & 15.4 & 162.1 & 167.8 & 10.1 \\
\hline 540 & 97.1 & 101.6 & 15.4 & 162.2 & 168.0 & 10.4 \\
\hline
\end{tabular}




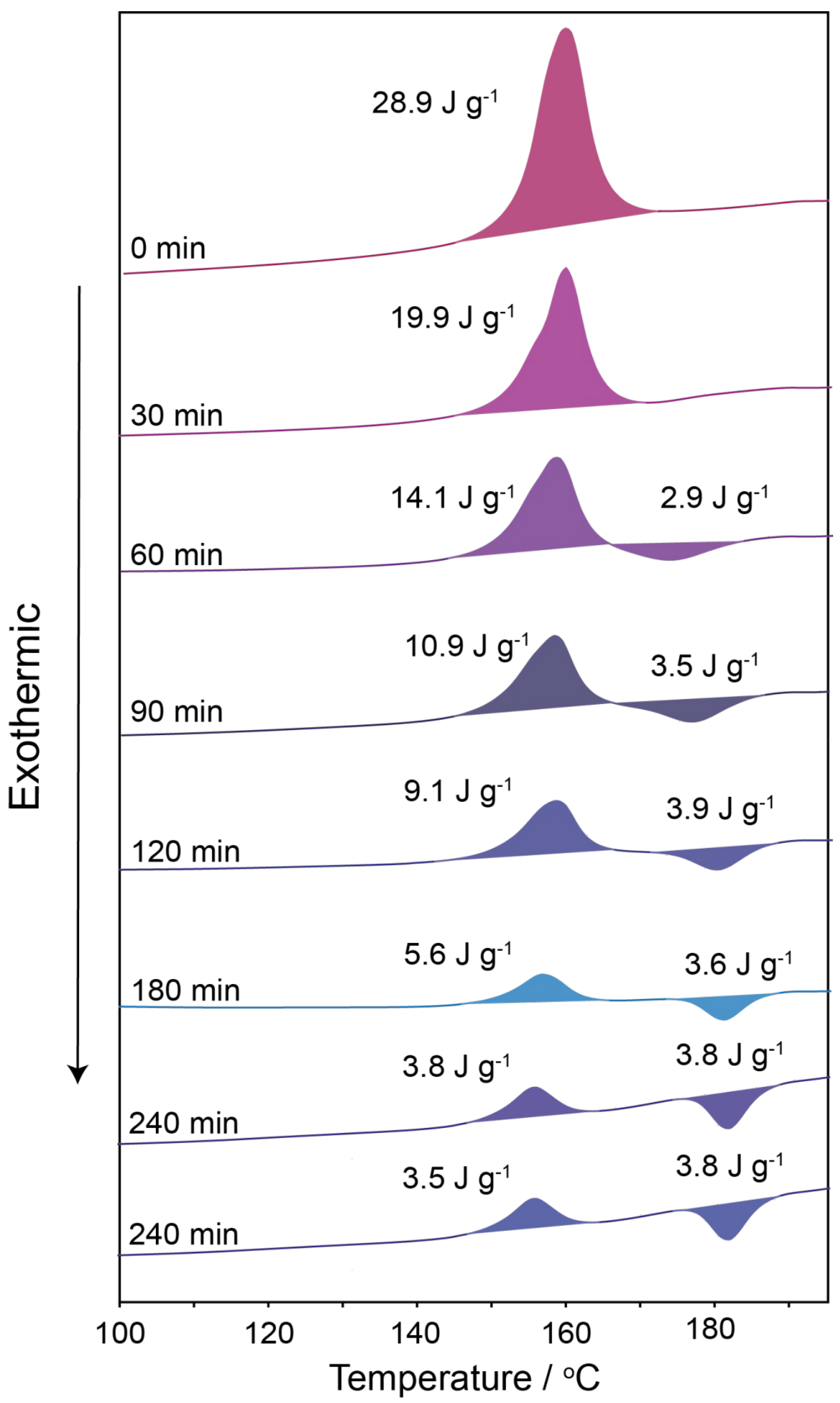

Figure S26. DSC cycles of Co-1 $\supset \mathrm{AB}_{1.0}$ at different irradiation times between $100-200{ }^{\circ} \mathrm{C}$ at a rate of $20{ }^{\circ} \mathrm{C} \mathrm{min}-1$. 


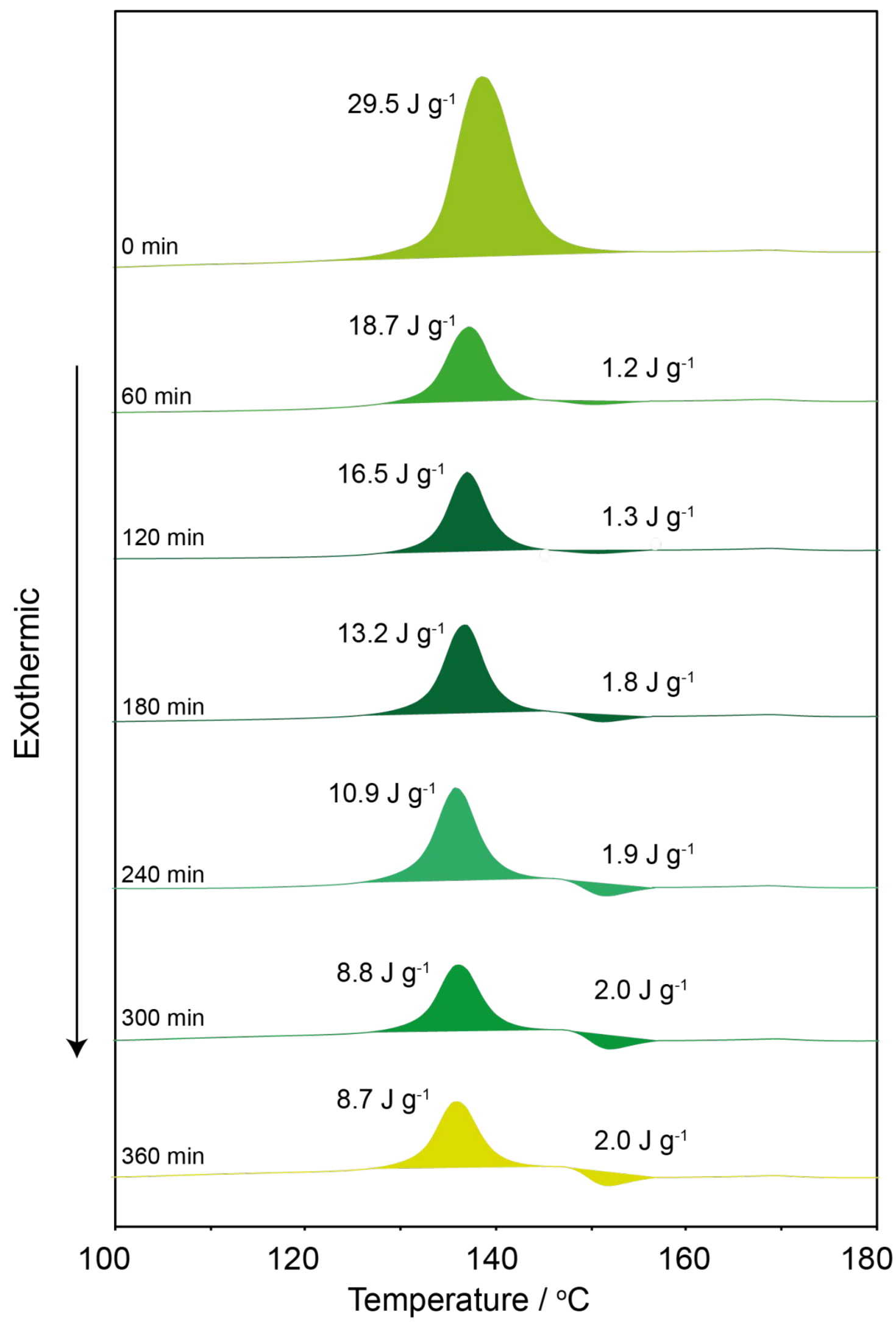

Figure S27. DSC cycles of Ni-1 $\supset \mathrm{AB}_{1.0}$ at different irradiation times between $100-200{ }^{\circ} \mathrm{C}$ at a rate of $20{ }^{\circ} \mathrm{C} \mathrm{min}-1$. 
a)

b)

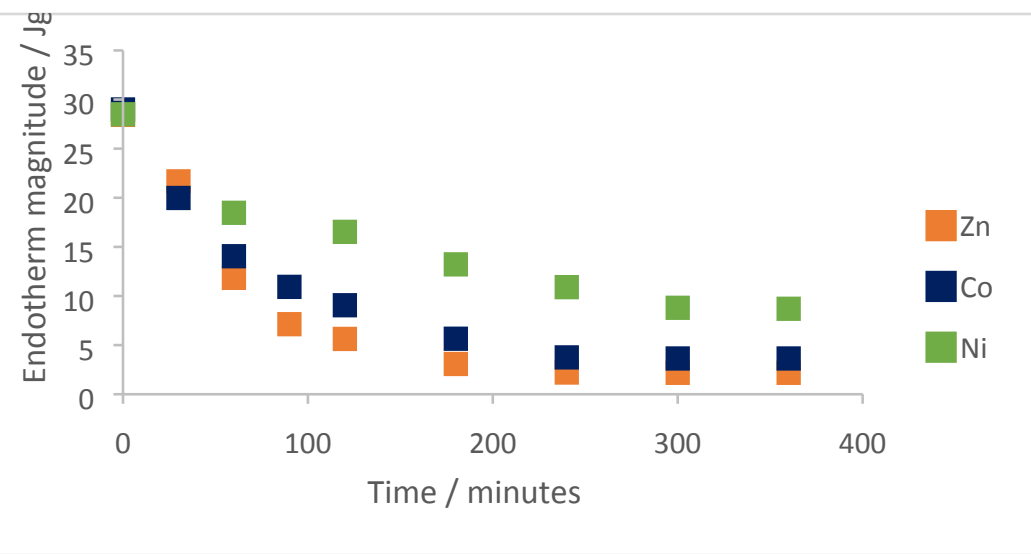

c)
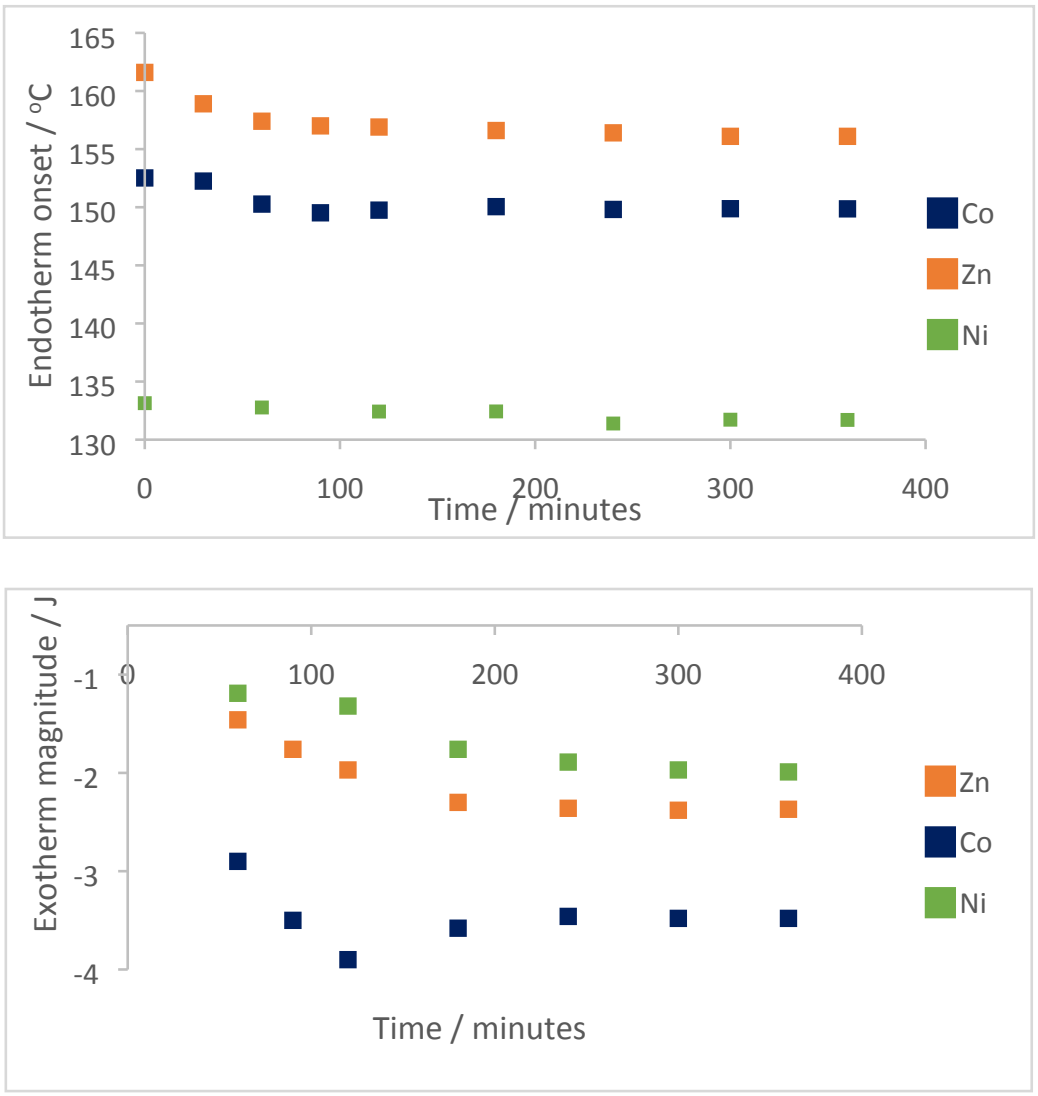

d)

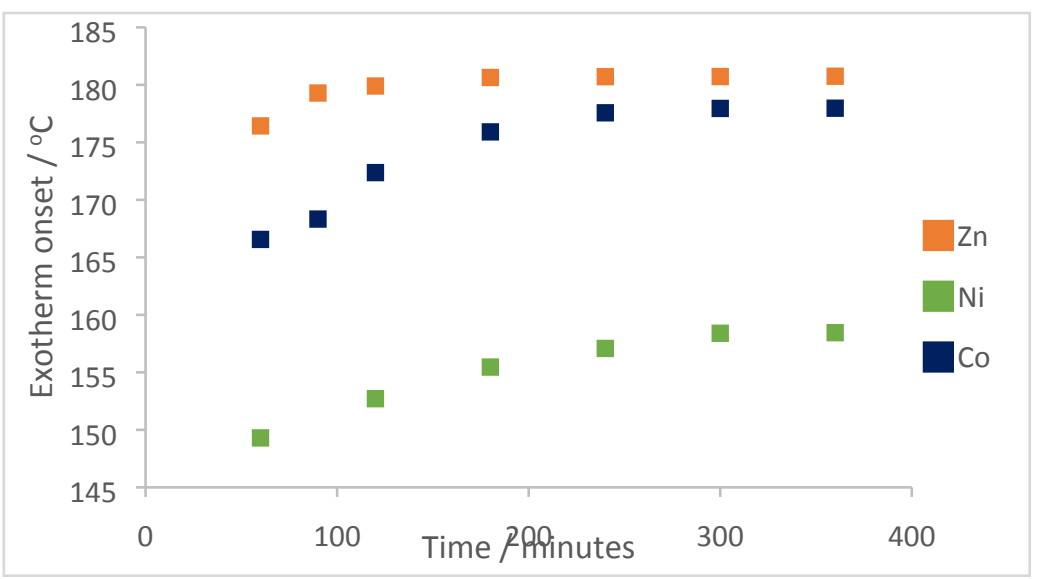


Figure S28 (previous page). Plotted data to compare the first heating branches for irradiation of $\mathbf{M}-1 \supset \mathrm{AB}_{1.0}(\mathrm{M}=\mathrm{Ni}, \mathrm{Co}$ and $\mathrm{Zn})$ for different lengths. a) endotherm magnitude, $\left.b\right)$ endotherm onset temperature, c) cis-trans exotherm energy, and d) cis-trans exotherm onset temperature. 
a)

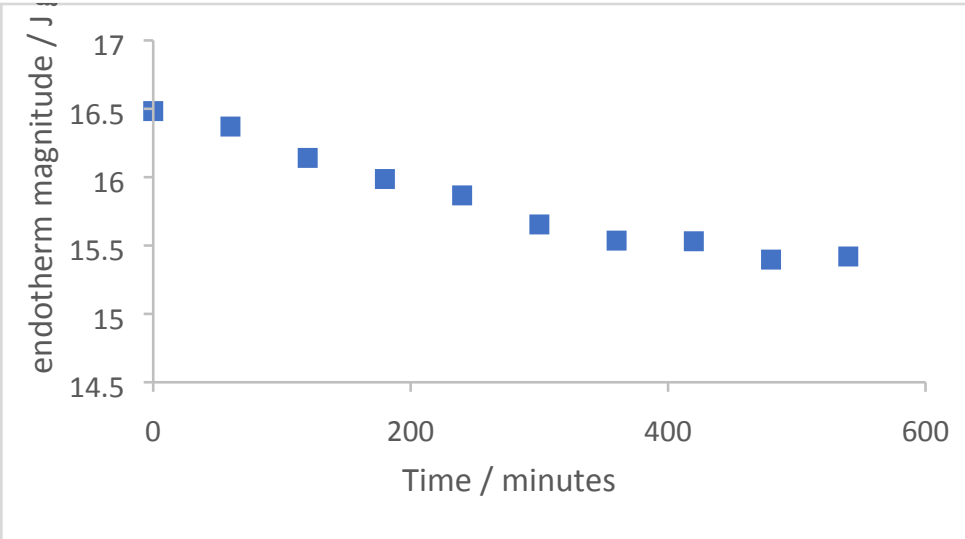

b)

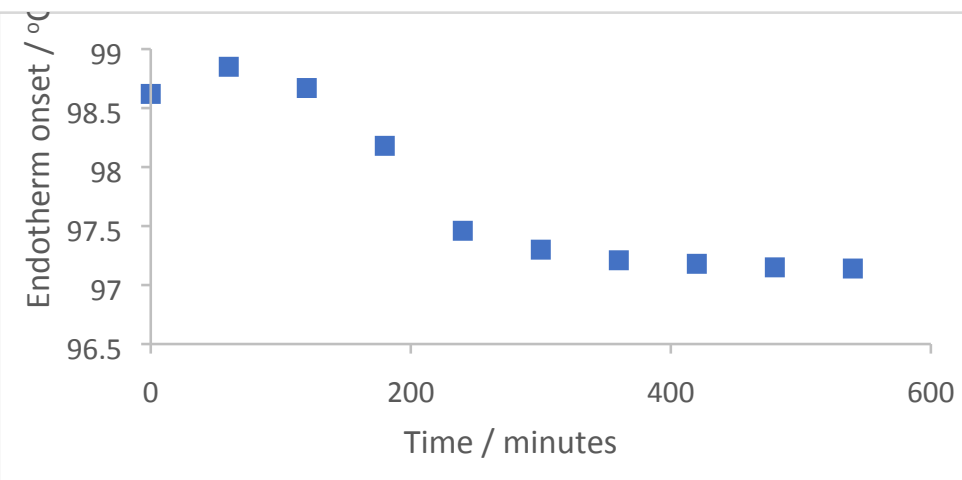

c)

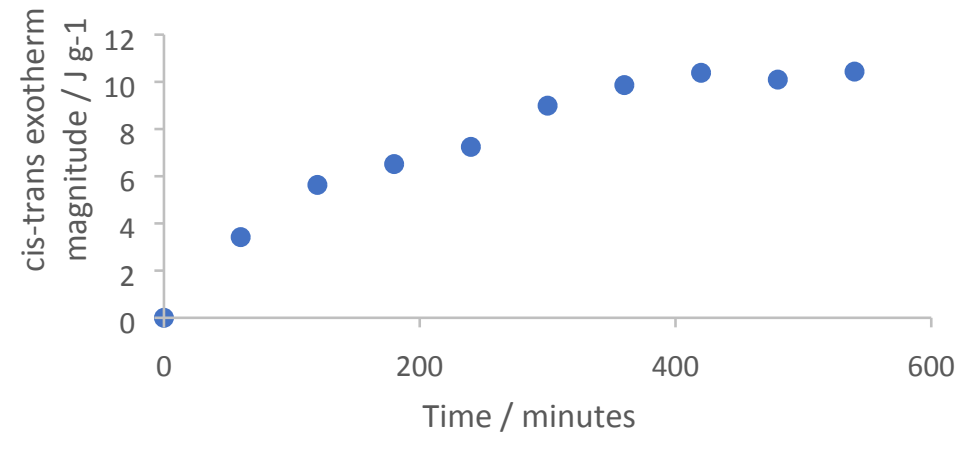

d)

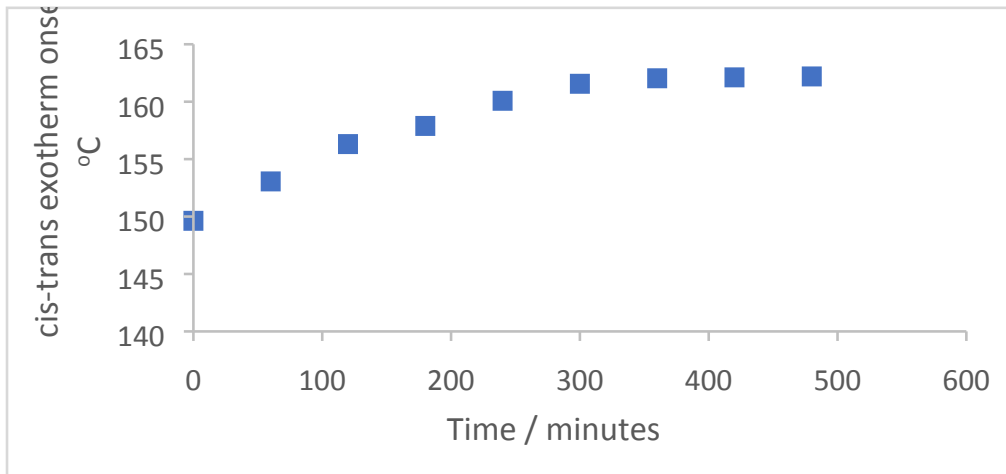


Figure S29 (previous page). Plotted data to compare the first heating branches for irradiation of $\mathbf{C u}-1 \supset \mathrm{AB}_{0.9}$ for different lengths. a) endotherm energy, b) endotherm onset temperature, c) cis-trans exotherm energy, and d) cis-trans exotherm onset temperature.

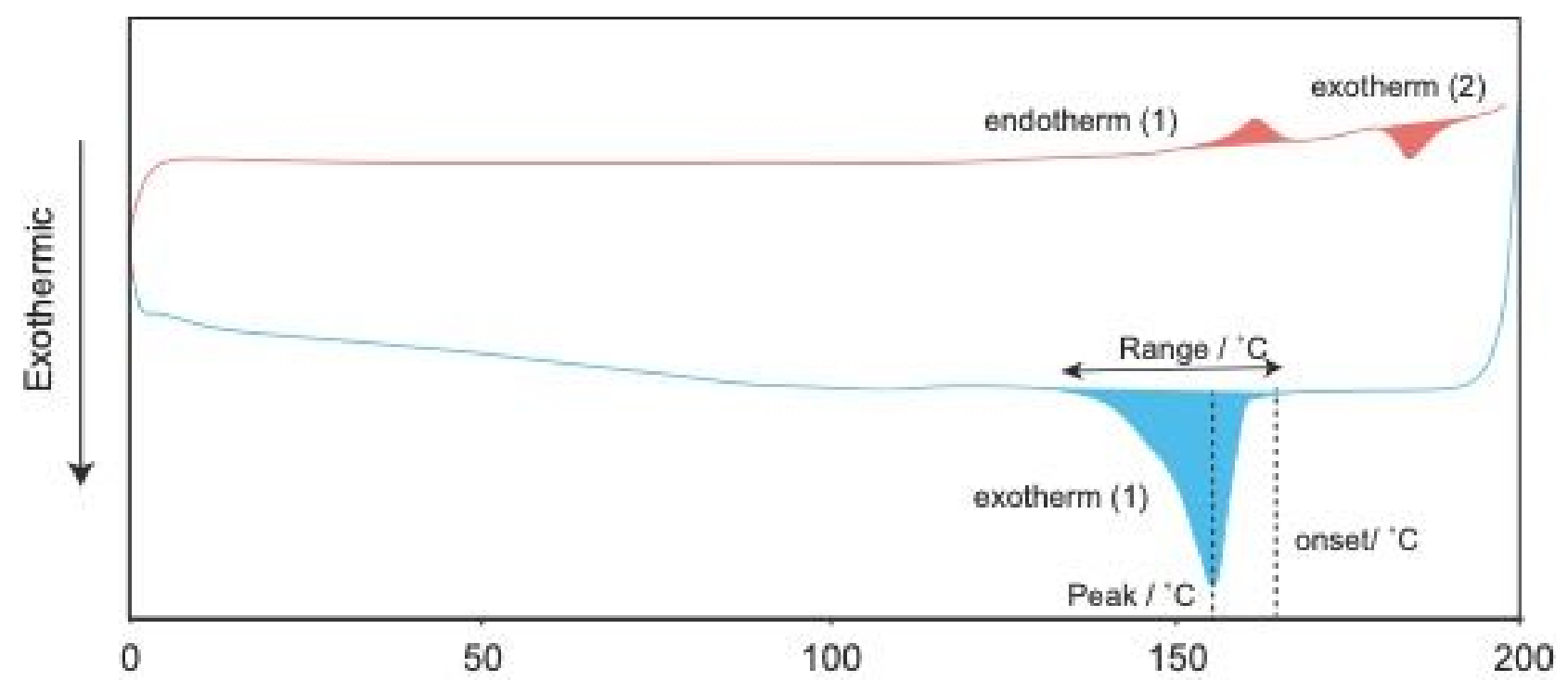

Key - DSC cycle. First heating branch (orange). First cooling branch (blue). On the heating branch, a small $n p$-op phase change endotherm is observed, followed by a small cis-trans reconversion exotherm. On the cooling branch, the full op-np phase change exotherm is observed. 
Table S18. Calculated energy difference between trans-AB and cis-AB.

\begin{tabular}{|c|c|c|c|c|}
\hline & (energy/molecule) / (eV/molecule) & (energy/mole) $/ \mathrm{eV} \mathrm{mol}^{-1}$ & (energy/mole) / J mol-1 & (energy/g) / J g ${ }^{-1}$ \\
\hline trans-AB & -2603.707821 & $-1.5679895255 \times 10^{27}$ & $-2.512201458 \times 10^{8}$ & $-1.3786185605 \times 10^{6}$ \\
\hline cis-AB & -2603.164885 & $-1.5676625620 \times 10^{27}$ & $-2.5116776036 \times 10^{8}$ & $-1.3783310854 \times 10^{6}$ \\
\hline Energy difference & -0.542935646 & $-3.2696349381 \times 10^{23}$ & $-5.2385437052 \times 10^{4}$ & $-2.8747509714 \times 10^{2}$ \\
\hline
\end{tabular}

- The energy difference between isolated cis and trans-AB per gram is $-288.48 \mathrm{~J} \mathrm{~g}^{-1}$.

- The photo-stationary state between cis and trans- $\mathrm{AB}$ cis:trans within $1 \supset \mathrm{AB}_{1.0}$ is 0.40 .

- $\quad-288.48 \mathrm{~J} \mathrm{~g}^{-1}$ x $0.40=-114.9 \mathrm{~J} \mathrm{~g}^{-1}$

The mass of 1 must be accounted for as well as the proportion of trans-azobenzene within $1 \supset \mathrm{AB}_{1.0}$.

- $1 \supset \mathrm{AB}_{1.0}=\left[\mathrm{Zn}_{2}(\mathrm{BDC})_{2}(\mathrm{DABCO})(\mathrm{AB})\right]$

\begin{tabular}{ccc}
\hline & $\mathrm{RMM}(\mathrm{g} / \mathrm{mol})$ & Fractional mass of AB \\
\hline $\mathbf{1}$ & 579.3 & 0.00 \\
$\mathbf{Z n - 1} \supset \mathrm{AB}_{1.0}$ & 761.4 & 0.24 \\
$\mathbf{C o}-\mathbf{1} \supset \mathrm{AB}_{1.0}$ & 747.4 & 0.24 \\
$\mathbf{N i}-\mathbf{1} \supset \mathrm{AB}_{1.0}$ & 750.1 & 0.24 \\
$\mathbf{C u}-1 \supset \mathrm{AB}_{0.9}$ & 758.3 & 0.24 \\
\hline
\end{tabular}


Table S19. Difference between observed energy difference on the first heating branch for UV irradiated Co-1 $\supset \mathrm{AB}_{1.0}$ and calculated cis-trans $\mathrm{AB}$ thermal relaxation energies.

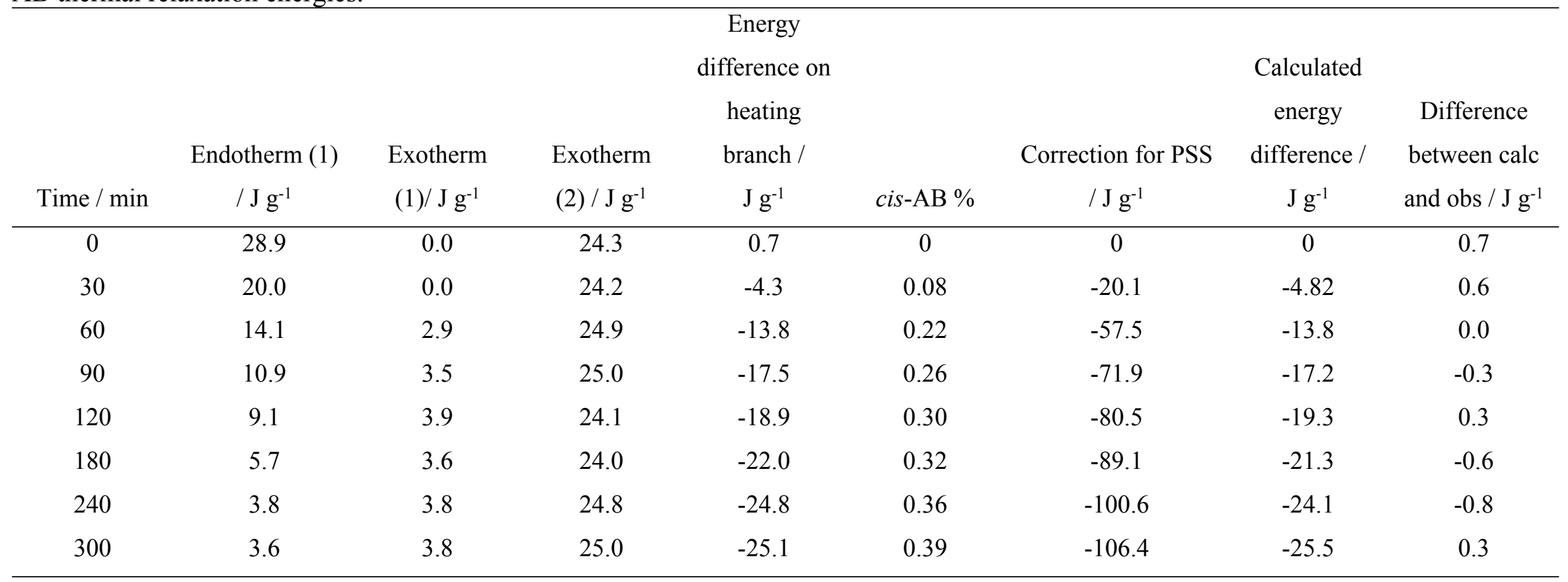


Table S20. Difference between observed energy difference on the first heating branch for UV irradiated Ni-1 $\supset \mathrm{AB}_{1.0}$ and calculated cis-trans AB thermal relaxation energies.

\begin{tabular}{|c|c|c|c|c|c|c|c|c|}
\hline Time / min & $\begin{array}{c}\text { Endotherm (1) } \\
\qquad / \mathrm{J} \mathrm{g}^{-1}\end{array}$ & $\begin{array}{l}\text { Exotherm (1)/ } \\
\qquad \mathrm{J} \mathrm{g}^{-1}\end{array}$ & $\begin{array}{l}\text { Exotherm } \\
\text { (2) / J g-1 }\end{array}$ & $\begin{array}{c}\text { Energy } \\
\text { difference on } \\
\text { heating } \\
\text { branch / } \\
\mathrm{J} \mathrm{g}^{-1}\end{array}$ & cis-AB \% & $\begin{array}{l}\text { Correction for } \\
\text { PSS / } \mathbf{J ~ g}^{-1}\end{array}$ & $\begin{array}{c}\text { Calculated } \\
\text { energy } \\
\text { difference / } \\
\mathrm{J} \mathrm{g}^{-1}\end{array}$ & $\begin{array}{c}\text { Difference } \\
\text { between calc } \\
\text { and obs / } \\
\mathrm{J} \mathrm{g} \mathrm{g}^{-1}\end{array}$ \\
\hline 0 & 29.5 & 0 & 29.2 & 0.3 & 0 & 0 & 0 & \\
\hline 60 & 18.7 & 1.2 & 29.7 & -12.2 & 0.17 & -48.9 & -11.7 & -0.5 \\
\hline 120 & 16.5 & 1.3 & 29.1 & -13.9 & 0.2 & -57.5 & -13.8 & -0.1 \\
\hline 180 & 13.2 & 1.8 & 29.4 & -18.0 & 0.26 & -74.7 & -17.9 & -0.1 \\
\hline 240 & 10.9 & 1.9 & 29.7 & -20.7 & 0.3 & -86.2 & -20.6 & -0.1 \\
\hline 300 & 8.8 & 2.0 & 29.5 & -22.7 & 0.32 & -92.0 & -22.0 & -0.7 \\
\hline 360 & 8.7 & 2.0 & 29.5 & -22.8 & 0.33 & -94.9 & -22.7 & -0.1 \\
\hline
\end{tabular}


Table S21. Difference between observed cis-AB exotherm for UV irradiated $\mathbf{C u}-\mathbf{1} \supset \mathrm{AB}_{0.9}$ and calculated cis-trans $\mathrm{AB}$ thermal relaxation energies.

\begin{tabular}{|c|c|c|c|c|c|}
\hline & cis-trans exotherm & cis-AB/ \% & & Calculated energy difference & $\begin{array}{c}\text { Energy } \\
\text { Difference / }\end{array}$ \\
\hline Time / Minutes & $/ \mathrm{J} \mathrm{g}^{-1}$ & & Correction for PSS & $/ \mathrm{J} \mathrm{g}^{-1}$ & $\mathrm{~J} \mathrm{~g}^{-1}$ \\
\hline 0 & 0.0 & 0 & 0.00 & 0.00 & 0.0 \\
\hline 60 & 3.4 & 0.05 & -14.37 & -3.39 & 0.0 \\
\hline 120 & 5.6 & 0.08 & -23.00 & -5.42 & 0.2 \\
\hline 180 & 6.5 & 0.1 & -28.75 & -6.77 & -0.3 \\
\hline 240 & 7.2 & 0.11 & -31.62 & -7.45 & -0.2 \\
\hline 300 & 8.9 & 0.13 & -37.37 & -8.81 & 0.2 \\
\hline 360 & 99 & 0.14 & -40.25 & -9.48 & 0.4 \\
\hline 420 & 10.4 & 0.15 & -43.12 & -10.16 & 0.2 \\
\hline 480 & 10.1 & 0.15 & -43.12 & -10.16 & -0.1 \\
\hline 540 & 10.4 & 0.15 & -43.12 & -10.16 & 0.3 \\
\hline
\end{tabular}




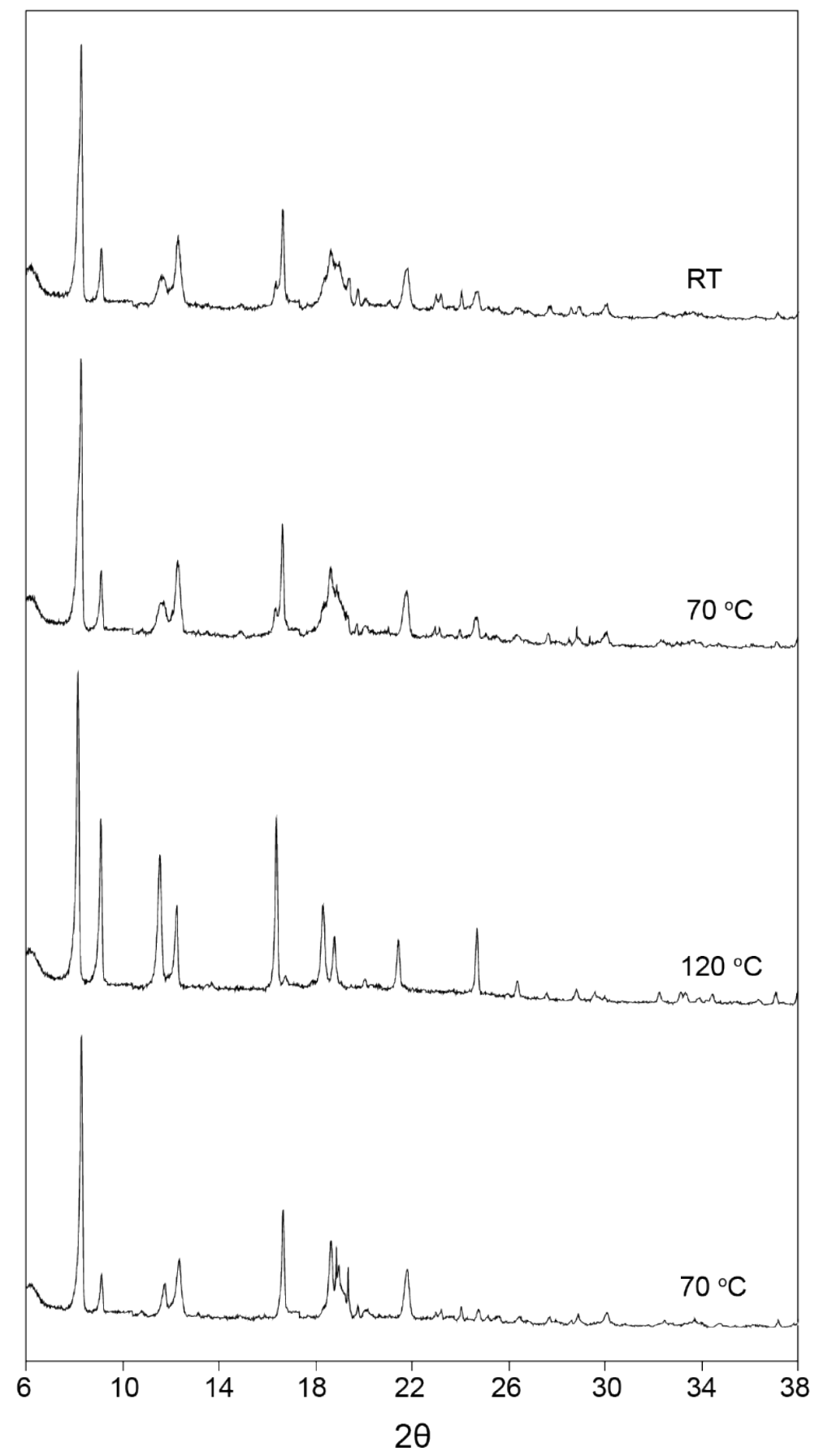

Figure S30. VT-XRPD studies of irradiated $\mathrm{Cu}-1 \supset \mathrm{AB}_{1.0}$ between r.t to $120{ }^{\circ} \mathrm{C}$ to show the reversibility of the $n p$ irradiated phase to the $l p$ irradiated phase. 


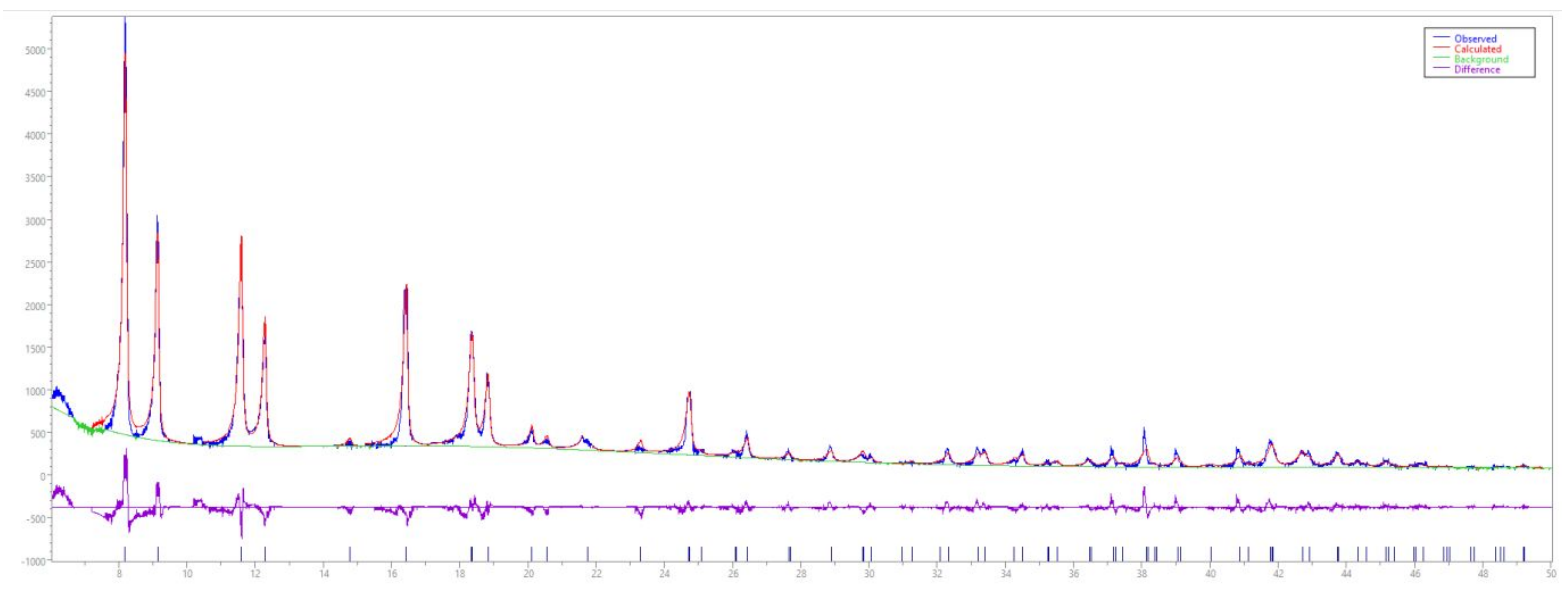

Figure S31. Le Bail fit of irradiated $\mathbf{C u}-1 \supset \mathrm{AB}_{1.0}$ at $120^{\circ} \mathrm{C}$. The crystal system was found to be tetragonal. The lattice parameters were refined to be $a=b=10.910(3) \AA, c=9.674(5) \AA$, $\alpha=\beta=\gamma=90^{\circ}, \mathrm{V}=1151.5(8) \AA^{3}$. The space group was found to be $P 4 / \mathrm{mmm}$. General formula $\mathrm{Cu}_{2} \mathrm{C}_{32} \mathrm{H}_{30} \mathrm{~N}_{4} \mathrm{O}_{8}$. The reliability (R) factor based on the powder profile $R p$ was $8.32 \%$.

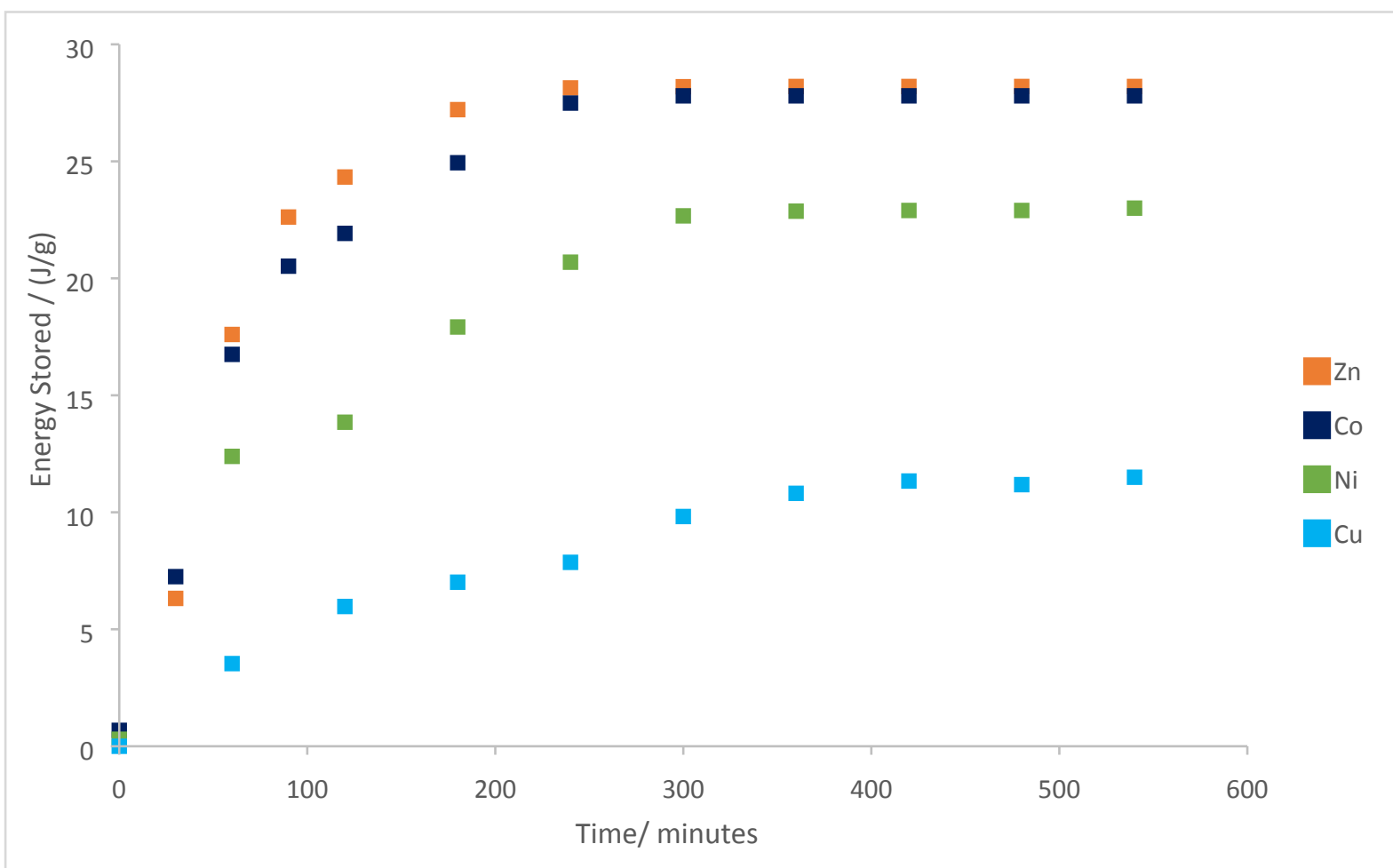

Figure S32. The relationship between energy density and irradiation time for $\mathbf{M}-1 \supset \mathrm{AB}_{1.0}$

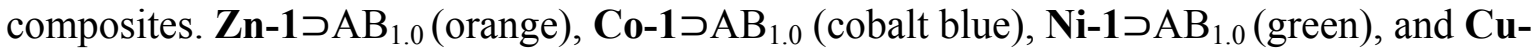
$1 \supset \mathrm{AB}_{1.0}$ (light blue). 
Table S22. Half-life calculations

a) $\mathbf{Z n - 1} \supset \mathrm{AB}_{1.0}$

\begin{tabular}{cccc}
\hline Time / months & Proportion of cis-AB & $\mathrm{N}_{(\mathrm{t})} / \mathrm{N}_{(0)}$ & $\operatorname{Ln}\left(\mathrm{N}_{(\mathrm{t})} / \mathrm{N}_{(0)}\right)$ \\
\hline 0 & 0.4 & 1 & 0 \\
1 & 0.39 & 0.975 & -0.0253178 \\
2 & 0.39 & 0.975 & -0.0253178 \\
3 & 0.38 & 0.950 & -0.0512933 \\
4 & 0.38 & 0.950 & -0.0512933 \\
\hline
\end{tabular}

b) Co-1 $\supset \mathrm{AB}_{1.0}$

\begin{tabular}{cccc}
\hline Time / Months & Proportion of cis-AB & $\mathrm{N}_{(\mathrm{t})} / \mathrm{N}_{(0)}$ & $\operatorname{Ln}\left(\mathrm{N}_{(\mathrm{t})} / \mathrm{N}_{(0)}\right)$ \\
\hline 0 & 0.37 & 1 & 0 \\
1 & 0.36 & 0.97297297 & -0.027399 \\
2 & 0.36 & 0.97297297 & -0.027399 \\
3 & 0.35 & 0.94594595 & -0.0555699 \\
4 & 0.34 & 0.91891892 & -0.0845574 \\
\hline
\end{tabular}

c) Ni-1 $\supset \mathrm{AB}_{1.0}$

\begin{tabular}{cccc}
\hline Time / Months & Proportion of cis-AB & $\mathrm{N}_{(\mathrm{t})} / \mathrm{N}_{(0)}$ & $\operatorname{Ln}\left(\mathrm{N}_{(\mathrm{t})} / \mathrm{N}_{(0)}\right)$ \\
\hline 0 & 0.33 & 1 & 0 \\
1 & 0.30 & 0.90909091 & -0.0953102 \\
2 & 0.28 & 0.84848485 & -0.1643031 \\
3 & 0.26 & 0.78787879 & -0.238411 \\
4 & 0.24 & 0.72727273 & -0.3184537 \\
\hline
\end{tabular}

d) $\mathbf{C u}-1 \supset \mathrm{AB}_{0.9}$

\begin{tabular}{cccc}
\hline Time / Months & Proportion of cis-AB & $\mathrm{N}_{(\mathrm{t})} / \mathrm{N}_{(0)}$ & $\mathrm{Ln}\left(\mathrm{N}_{(\mathrm{t})} / \mathrm{N}_{(0)}\right)$ \\
\hline 0 & 0.15 & 1 & 0 \\
1 & 0.10 & 0.66666667 & -0.4054651 \\
2 & 0.06 & 0.40000000 & -0.9162907 \\
3 & 0.04 & 0.26666667 & -1.3217558 \\
\hline
\end{tabular}

Assuming the metastable cis isomer undergoes thermal reconversion to the ground-state transisomer according to the first-order kinetics, the number of guest molecules in the cis isomeric state as a function of time $\left(\mathrm{N}_{c i s}(\mathrm{t})\right)$ can be expressed by:

$$
N_{c i s}(t)=N_{c i s}(0) e^{-\lambda t}
$$

(Equation S1)

where $N_{\text {cis }}(0)$ is the number of guest molecules in the cis isomeric state at the beginning of the measurement and $\lambda$ is a decay constant. This rearranges to the following form whereby plotting $\ln \left(N_{\text {cis }}(t) / N_{\text {cis }}(0)\right)$ vs $t$ allows determination of $\lambda$ from the gradient of the straight line of best fit.

$$
\ln \left(\frac{N_{c i s}(t)}{N_{c i s}(0)}\right)=-\lambda t
$$


The half-life, $t_{1 / 2}$, then given by

$$
t_{\overline{1}}=\frac{\ln 2}{\lambda}
$$

Table S23. Decay constants and half-lives for $\mathbf{M}-1 \supset \mathrm{AB}_{1.0}$ composites.

\begin{tabular}{cccc}
\hline Sample & $\begin{array}{c}\text { Decay constant / } \\
\text { months }^{-1}\end{array}$ & Half-life / Months & Half life / Years \\
\hline $\mathbf{Z n - 1} \supset \mathrm{AB}_{1.0}$ & 0.0129 & 53.732 & 4.5 \\
$\mathbf{C o - 1} \supset \mathrm{AB}_{1.0}$ & 0.0197 & 35.185 & 2.9 \\
$\mathbf{N i}-1 \supset \mathrm{AB}_{1.0}$ & 0.0780 & 8.886 & 0.7 \\
$\mathbf{C u}-1 \supset \mathrm{AB}_{0.9}$ & 0.4476 & 1.548 & 0.1 \\
\hline
\end{tabular}

\section{Bibliography}

(1) Griffiths, K.; Halcovitch, N. R.; Griffin, J. M. Long-Term Solar Energy Storage under Ambient Conditions in a MOF-Based Solid-Solid Phase-Change Material. Chem. Mater. 2020. https://doi.org/10.1021/acs.chemmater.0c02708.

(2) Yanai, N.; Uemura, T.; Inoue, M.; Matsuda, R.; Fukushima, T.; Tsujimoto, M.; Isoda, S.; Kitagawa, S. Guest-to-Host Transmission of Structural Changes for StimuliResponsive Adsorption Property. J. Am. Chem. Soc. 2012, 134 (10), 4501-4504. https://doi.org/10.1021/ja2115713. 